IFN Working Paper No. 799, 2009

\title{
Creative Destruction and Productive Preemption
}

Pehr-Johan Norbäck, Lars Persson and Roger Svensson 


\title{
Creative Destruction and Productive Preemption*
}

\author{
Pehr-Johan Norbäck \\ Research Institute of Industrial Economics (IFN) \\ Lars Persson \\ Research Institute of Industrial Economics (IFN) and CEPR \\ Roger Svensson \\ Research Institute of Industrial Economics (IFN)
}

September 19, 2014

\begin{abstract}
We develop a theory of innovation for entry and sale into oligopoly, and show that inventions of higher quality are more likely to be sold (or licensed) to an incumbent due to strategic product market effects on the sales price. Such preemptive acquisitions by incumbents are shown to stimulate the process of creative destruction by increasing the entrepreneurial effort allocated to high-quality invention projects. Using data on patents granted to small firms and individuals, we find evidence that high-quality inventions are sold under preemptive bidding competition. Asymmetric information problems are shown to be solved by verification through entry for sale.

Keywords: Acquisitions, Entrepreneurship, Innovation, Start-ups, Patent, Ownership, Quality

JEL classification: G24, L1, L2, M13, O3
\end{abstract}

\footnotetext{
${ }^{*}$ We have greatly benefitted from comments from Marcus Asplund, Magnus Henrekson, Jim Levinsohn, Hodaka Morita, Sören-Bo Nielsen and Marie Thursby, and participants in seminars at IIOC Conference, IFN Stockholm Conference, Copenhagen Bussines School, Tilburg University, University of Mannheim and Royal Institute of Technology (Stockholm). Financial support from Jan Wallander's and Tom Hedelius' Research Foundation and Vinnova are gratefully acknowledged. Email: lars.persson@ifn.se, pehr.johan.norback@ifn.se.
} 


\section{Introduction}

Schumpeter (1942) argued that the ongoing process where new inventions create "monopoly rents" for entrepreneurs while reducing rents for incumbent firms is central for sustained growth in a market economy. This process of "creative destruction" and its welfare implications has been extensively studied in the case where an entrepreneur commercializes the invention by entering the product market. ${ }^{1}$ However, if the incumbents' profits are diminished by entrepreneurial entry, incumbents have an incentive to acquire these entrepreneurial firms (or their inventions) to block entry (entry-deterring acquisitions), or preempt rivals from obtaining superior assets (preemptive acquisitions). ${ }^{2}$

The purpose of this paper is to examine how the innovation process and its welfare effects are affected by the hitherto ignored fact that entrepreneurial entry might be blocked by incumbents - either by entry-deterring or by preemptive acquisitions.

To this end, we develop a theoretical model where initially, an entrepreneur decides how much to invest in research to discover an invention. If successful, the entrepreneur could either enter the product market with the invention, or sell it to one of many incumbent firms competing to acquire the invention in an auction framework. Finally, firms compete in oligopoly fashion, thereby generating profits.

We first examine what type of inventions - in terms of quality - will be sold? At first sight, it seems reasonable that the level of quality should not matter in a context of perfect information, since the entrepreneur's reservation price and incumbents' willingness to pay should be equally affected by a change in quality. However, we show that the incentive for commercialization by sale relative to commercialization by entry increases with a higher quality of the invention. To see this note that an incumbent's valuation of the invention consists of the incumbent's product market profits when owning the invention relative to the profits it generates when a rival possesses the invention. Then note that a higher invention quality increases entrants' and acquirers' product market profits in a similar fashion, but also reduces the profits of the incumbent as a non-acquirer. This implies that the incumbents' willingness to pay for the invention increases more than the entrant's profit in quality.

Next, we examine how the acquisition price (reward from selling) depends on the quality of the invention. We show that for medium quality, the entrepreneur is paid her reservation price which is simply the entrepreneur's net profit from entry. Such entry-deterring acquisitions are then replaced by preemptive acquisitions at even higher quality. The reason is that as non-acquiring incumbents' profits in the product market deteriorates when the quality of the

\footnotetext{
${ }^{1}$ See, for instance, Arrow (1962), Aghion and Howitt (1992), Gilbert and Newberry (1982) and Grossman and Helpman (1991).

${ }^{2}$ Bloningen and Taylor (2000), Granstrand and Sjölander (1990), Hall (1990), and Lerner and Merges (1998) present evidence of firms acquiring innovative targets to gain access to their technologies.

According to The Economist (Feb 18th, 1999), innovators know that incumbent firms that risk tough competition from not buying are willing to pay a great deal for inventions, as indicated by the following quote: "Companies like Cisco, Intel and Microsoft recognize the threat posed by nimble young firms getting technologies to market at unimaginable speeds," says Red Herring's Brian Taptich. "And they're willing to pay extremely high premiums to protect their franchises."
}

An example is Cerent which was acquired by Cisco at $\$ 6.9$ billion. 
invention becomes higher, a bidding war among incumbents' over the invention will eventually occur. The acquisition price then is increased to an incumbent's preemptive valuation.

We then direct our attention to welfare implications. Entrepreneurship has emerged as a key issue in the policy arena in Europe and US, where policy makers believe small entrepreneurial firms to be the firms that are better at capturing opportunities and coping with challenges created by the ongoing globalization process. In the European Union, for instance, the Commission has taken action, launching the "Small Business Act for Europe" in June 2008, proposing that member states should create an environment that rewards entrepreneurship and small firm growth. ${ }^{3}$ According to this view, acquisitions of small entrepreneurial firms is detrimental to the efficiency of the innovation process.

In contrast, we show that the expected consumer welfare can be higher under commercialization by sale despite the risk of increased market power. The reason is that when the quality of the invention is sufficiently high, preemptive acquisitions emerge where the bidding competition drives the acquisition price above the entry value. Entrepreneurs who sell will then have a stronger incentive to develop high-quality inventions than entrepreneurs who enters.

The welfare analysis suggests that incumbent acquisitions of entrepreneurial inventions are beneficial for society if they are preemptive in nature (i.e. not entry deterring). To examine the empirical relevance of preemptive acquisitions we estimate commercialization decision of the entrepreneur on detailed data on patents granted to Swedish small firms and individual inventors. We use forward patent citations as a proxy for the quality of the invention. Our estimates do identify preemptive bidding competition between incumbent firms: we find that the estimated coefficients of core variables from the model are jointly significantly different from zero, and that higher patent quality is conducive to commercialization by sale. Additional predictions such as higher entry costs being conducive to sale are also supported by the data. To our knowledge, we are the first to provide evidence of preemptive bidding competition in a structural model approach.

We also examine how asymmetric information problems may affect our findings. In the extended theoretical model, we show that entrepreneurs can mitigate information problems by first entering the product market and revealing high profits, low costs or high sales. ${ }^{4}$ Indeed, in the data, we find that 30 out of the 91 patents sold were first commercialized by entry and subsequently sold. The entrepreneur then faces the choice of selling early under asymmetric information, entering to stay, or entering to sell late under perfect information. We show that a higher quality of the invention is conducive to a late sale (after an initial commercialization by entry), whereas higher quality is not conducive to a direct sale. These predictions of the model are found to be supported by the empirical estimations.

A potential concern in identifying the effect of higher quality on the mode of commercial-

\footnotetext{
${ }^{3}$ Baumol (2002) documents that small entrepreneurial firms create a large share of breakthrough inventions in the United States. Scherer and Ross (1990) list a large number of breakthrough inventions made by independent innovators and state that "new entrants without a commitment to accepted technologies have been responsible for a substantial share of the really revolutionary new industrial products and processes".

${ }^{4}$ There is a small literature on costly disclosure and debt financing (see Townsend (1979) and Gale and Hellwig (1985)).
} 
ization is reverse causality, since many forward citations occur after the patents have been commercialized. However, the way in which patent institutions are set up suggests that we do not face a problem of reverse causality here. The reason is that the final decision regarding which patents are cited is made by the examiner at the patent office, who seldom has any information of the commercialization mode. In fact, if the commercialization mode affects forward citation, we should observe the time pattern of forward citations to differ across commercialization modes, but we find no such pattern in the data.

This paper contributes to the literature on entrepreneurship, innovation and welfare (for overviews, see Achs and Audreatch (2005), Bianchi and Henrekson (2005) and Carlsson et al., 2013). Previous literature has shown that entrepreneurs play an important role in challenging existing oligopolistic markets through de-novo entry into the product market. Yet, we identify another important role of the entrepreneur as a challenger of existing oligopolies through the aggressive development of inventions for sale. The role as an aggressive invention supplier may be even more important than the role as de-novo entrant. Indeed, we show that the possibility of preemptive incumbent acquisition gives entrepreneurs an incentive to increase their efforts in high-quality research projects so that the expected welfare can increase despite the risk of increased market power. The entrepreneurship literature has shown that the entrepreneur has returned as a prominent player in the economy's innovation system in the last few decades (Baumol 2002, 2004). One of the most frequently cited reasons for the increased importance of entrepreneurship is globalization (e.g. Gilbert, Audretsch and McDougall, 2004). An implication of our work is then that the emergence of an international market for corporate control is likely to enhance the role of the entrepreneur as invention supplier. ${ }^{5}$

This paper also contributes to the literature studying when assets will be sold on the market. To date, it has been found that commercialization by sale is more likely when entry costs are high, when the entrepreneurial firm lacks complementary assets, when brokers facilitating trade are available, and when the expropriation problem associated with asset transfers is low (see, for instance, Anton and Yao (1994), Gans and Stern (2000) and Gans, Hsu and Stern (2002)). Moreover, in his seminal paper, Akerlof (1970) showed that informational asymmetries can give rise to adverse selection on markets, resulting in only low-quality assets being sold. ${ }^{6}$ In contrast, we show theoretically that when inventions are sold into oligopolistic markets, absent the information problem, product market externalities imply that only high-quality assets will be sold on the market. In the presence of information problems, we show that the entrepreneur has an incentive to verify high-quality inventions by entering the product market and then selling the invention. We also find empirical evidence that high-quality inventions are sold on the market. However, these data also show that the strongest effect is found for the case

\footnotetext{
${ }^{5}$ This paper is also related to the literature on patent licensing (for an overview, see Kamien (1992)), and to the literature on the persistence of monopoly (see, for instance, Chen (2000) and Gilbert and Newbery (1982)). However, this corpus of research never examines how the trade-off between entry and sales (licence) for the potential entrant depends on the quality of the invention, which is the focus of our analysis.

${ }^{6}$ The empirical literature on the "lemons" effect gives mixed evidence. For instance, Bond (1982) found no evidence, Genesove (1993) weak evidence, and Gilligan (2004) strong evidence of adverse selection.
} 
where the entrepreneur first enters the product market and then sells the invention; thus, the asymmetric information problem could materialize in the cost of entry for verification of the quality of the invention. Serrano (2010) explores data on the transfer of U.S. patents and finds that as the importance of the patent increases, as measured by patent citations received, the proportion of transferred patents (the sales rate) increases substantially. While our data set is much smaller, an advantage of this data is that we do not only have information if an entrepreneur has sold her patent, the entrepreneur is also asked if she has commercialized the patent on her own. Indeed, it is through the latter information that we can identify patents that are sold under bidding competition. ${ }^{7}$

This paper can finally be seen as a contribution to the literature on endogenous ownership and efficiency dating back to Coase (1960). Coase argued that in a zero-transaction world, laissez-faire always leads to the optimal outcome irrespective of the initial assignment of property rights. Departing from the zero transaction cost world, authors such as Grossman and Hart (1986) and Hart and Moore (1990), have shown that the ownership structure has implications for efficiency when contracts are incomplete. We follow the approach taken by Jehiel, Moldovanu and Stacchetti (1996, 1999) determining the ownership of assets in an auction with externalities set-up. ${ }^{8}$ Jehiel and Moldovanu (1999) have shown that equilibrium ownership allocation is not efficient when auctions have externalities and contracts are incomplete. Taking the starting point that competition laws forbid cooperation between incumbents and that innovations (entrepreneurial firms) are sold in a competitive environment, we use a first price auction to determine the ownership of the innovation. This enables us to show that inventors innovating for sale will have a greater incentive to invest as compared to the acquirer of the invention, as well as the inventors innovating for market entry. This result occurs due to the externalities of the acquisition auction and shows that not only the ownership allocation can be distorted from the point of view of firms participating in the market for control of the innovation, but also the R\&D investment itself. Noteworthy, however, in our setting where innovators overinvest in R\&D under innovation for sale, such overinvestment is likely to benefit consumers. Moreover, to our knowledge, we provide the first model with empirical support for an auction with externality model. ${ }^{9}$ We also expect similar mechanisms for how quality affects the entry sale pattern and incentive to innovate to be in play in multi-firm bargaining oligopoly models, as long as the threat points of the firms vary with the quality of the invention. ${ }^{10}$

\footnotetext{
${ }^{7}$ Serrano (2010) shows that his finding is consistent with a set-up where the synergies over time associated with a patent sale are linear in the current value of the patent and the transaction costs are constant. Our formalized theoretical explanation differs in that they do not rely on the synergies associated with the sale of a patent increasing in the initial quality of the patent. In our model, the surplus captured by the buyer of the patent may not even increase in the initial quality of the patent, or the synergies arising from an acquisition.

${ }^{8}$ Most papers in this literature treat the size of the asset for sale as exogenous. To our knowledge, the only exceptions are Katz and Shapiro (1986) who determine the optimal licensing fee of a research lab which can affect the size of the innovation and Norbäck and Persson (2009) who determine the optimal development investment for a venture-backed firm that will exit by a trade sale to an incumbent.

${ }^{9}$ For an overview, see Jehiel and Moldovanu (2006).

10 Extending the models provided by Gans, Hsu and Stern (2002) and Jehiel and Moldovanu (1995) by allowing for quality differences seems a fruitful way of proceeding in this respect.
} 


\section{An example}

We will here show that when an entrepreneur chooses between to enter the market with an innovation or to sell it to an incumbent, the entrepreneur will sell it only if the innovation has a sufficiently high quality. The reason for this is that a bidding competition will occur only over high quality innovations and bidding competition will ensure that the entrepreneur captures a sufficiently high share of the oligopolistic rents in the market when selling. We will also show that the possibility to sell innovations substantially increases the incentive for entrepreneurs to develop high quality innovations since the bidding competition over such innovations creates supra normal rents for entrepreneurs.

To see this consider a three-stage game where a product market is initially served by two symmetric incumbents, $i_{1}$ and $i_{2}$. There is also an entrepreneur, denoted $e$, who undertakes an effort which increases the probability of discovering a new invention with a given size or quality $k$. The innovation reduces marginal cost.

Stage 3 is a Cournot model (described more detail in Example 1 below) with homogenous products. Two incumbents (or the two incumbents and the entrepreneur) face the inverse demand $P(Q)=a-Q$, where $Q=\sum_{j} q_{j}$. Let $\pi_{j}=\left[P_{j}-c_{j}\right] q_{j}$ be the direct profit function where $c_{j}=c$ when firm $j$ does not possess the invention and $c_{j}=c-k$ is the marginal cost when firm $j$ does possess the innovation. From the Nash-quantities in the product market interaction $Q^{*}(l)=q_{j}^{*}(l)+q_{-j}^{*}(l)$, let $\pi_{j}(l)=\left[P\left(Q^{*}(l)\right)-c_{j}\right] q_{j}^{*}(l)$ be the reduced-form profit of firm $j$, where $l$ indicates which firm owns the innovation $k$. Since the innovation reduces the marginal cost of the possessor, it is easy to show that $\frac{d \pi_{j}(l)}{d k}>0$ if $j=l$ and $\frac{d \pi_{j}(l)}{d k}<0$ if $j \neq l$ : due to her low marginal cost the possessor can commit to a higher level of output, which induces a non-possessor to reduce her output in order to mitigate the fall in output price. Since the consumer surplus is $C S(l)=\left[Q^{*}(l)\right]^{2} / 2$, it is easily checked that consumers gain from a higher innovation quality due to a lower consumer price and increased consumption.

In stage 2, there is an entry-acquisition auction where incumbents simultaneously post bids and the entrepreneur then either accepts or rejects these bids. If she rejects the bids, the entrepreneur will enter the market if and only if the product market profit covers the entry cost $F$. Thus, the market structure in stage 3 becomes a Triopoly $(\mathrm{T})$ when the entrepreneur keeps the innovation $(l=e)$, and a duopoly (D) if she sells to an incumbent $(l=i)$.

In stage 2 , there are three different valuations to consider:

- $v_{e}$ is the entry value (or reservation price), i.e. the profit for the entrepreneur when competing with both incumbents $\left(\pi_{E}^{T}(e)-F\right)$ :

$$
v_{e}=\pi_{E}^{T}(e)-G
$$

- $v_{i e}$ is the entry-deterring valuation, i.e. an incumbent's profit of possessing the invention, $\pi_{A}^{D}(i)$, minus its profit if the entrepreneur would otherwise enter, $\pi_{N}^{T}(e)$ :

$$
v_{i e}=\pi_{A}^{D}(i)-\pi_{N}^{T}(e)
$$


- $v_{i i}$ is the preemptive valuation, i.e. an incumbent's profit of possessing the invention $\pi_{A}^{D}(i)$ minus its profit if the rival would otherwise obtain the invention, $\pi_{N}^{D}(i)$ :

$$
v_{i i}=\pi_{A}^{D}(i)-\pi_{N}^{D}(i)
$$

Figure 2.1 (i) shows the different valuations of the invention for the different owners, and how these valuations depend on the quality of the innovation $k$. Figure 2.1 (ii) summarizes the Equilibrium Ownership Structure (EOS). Figure 2.1 (iii) summarizes the reward for a successful innovation to the entrepreneur $R_{E}$ as a function of the quality of the innovation $k$.

From Salant, Switzer and Reynolds (1983), it follows that $v_{e}>v_{i e}$ holds at $k=0$ if $F=0$. Assuming that the entry cost $F$ is limited in size this condition holds at some $F>0$. Note that $v_{i e}-v_{i i}=\pi_{N}^{D}(i)-\pi_{N}^{T}(e)>0$. Thus, at a low quality of the innovation, the entrepreneur will commercialize through entry $\left(l^{*}=e\right)$ since $v_{e}>v_{i e}>v_{i i}$. What happens if the quality of the innovation increases? As illustrated in Figure 2.1 (i), a higher innovation quality increases the entry value, $v_{e, k}^{\prime}=\frac{d \pi_{E}^{T}(e)}{d k}>0$. Now turn to incumbents' valuations. Differentiating $v_{i l}-v_{e}$ and using (2.1) and (2.3), we show in Appendix 9.2 that unless the quality is so high that the possessor is close to obtaining a monopoly, the following holds

$$
v_{i l, k}^{\prime}-v_{e, k}^{\prime}=\underbrace{\frac{d \pi_{A}^{D}(i)}{d k}-\frac{d \pi_{E}^{T}(e)}{d k}}_{\text {Small in absolute value }}-\frac{d \pi_{N}^{T}(l)}{d k}>0 .
$$

As illustrated in Figure 2.1 (i), incumbents' valuations $v_{i l}$ increase more than the entrepreneur's value of entry $v_{e}$ when the innovation quality increases. The reason for this is that a higher quality increases the entrant's and acquirer's profits in a similar fashion $\left(\frac{d \pi_{A}^{D}(i)}{d k}-\frac{d \pi_{E}^{T}(e)}{d k}\right.$ is small in absolute value). However, since the profit of a non-acquirer $\pi_{N}^{T}(l)$ decreases in $k$, this creates an additional increase in the incumbent valuation, thereby implying that $\frac{d v_{i l}}{d k}>\frac{d v_{e}}{d k}$.

At $k=k^{E D}, v_{i e}=v_{e}$ holds and further increases in quality $k$ will make an entry deterring acquisition strictly profitable as $v_{i e}>v_{e}$. This is illustrated at point ED in Figure 2.1(i). As shown in Figure 2.1(ii), an acquisition of the invention then takes place $\left(l^{*}=i\right)$ where one incumbent bids $v_{e}$ and the entrepreneur accepts this bid. The main value of acquiring the innovation here is to deter entry: the quality of the innovation is not sufficiently high to provoke competing bids from rival incumbents, $v_{i i}<v_{e}$. However, at $k=k^{P E}, v_{i i}=v_{e}$ holds. This induces a bidding war among incumbents which drives the equilibrium sales price above the entry value for the entrepreneur, i.e. $S^{*}=v_{i i}$. For $k>k^{P E}$ the bidding among incumbents under such a preemptive acquisition will make the reward to commercialization under sale $v_{i i}$ higher than if the entrepreneur would have commercialized by entry, $S^{*}=v_{i i}>v_{e}$.

We can then state the following results which are proved formally in the Appendix 9.2 for the case with $n>1$ incumbents:

Result 1 Entrepreneurs will sell their high quality innovations to incumbent firms. The reason for this is that a higher innovation quality increases not only the value of possessing the innovation, but it also makes it less favorable to become a non-acquiring incumbent. Therefore incumbents value high quality innovations more than entrepreneurs do. 


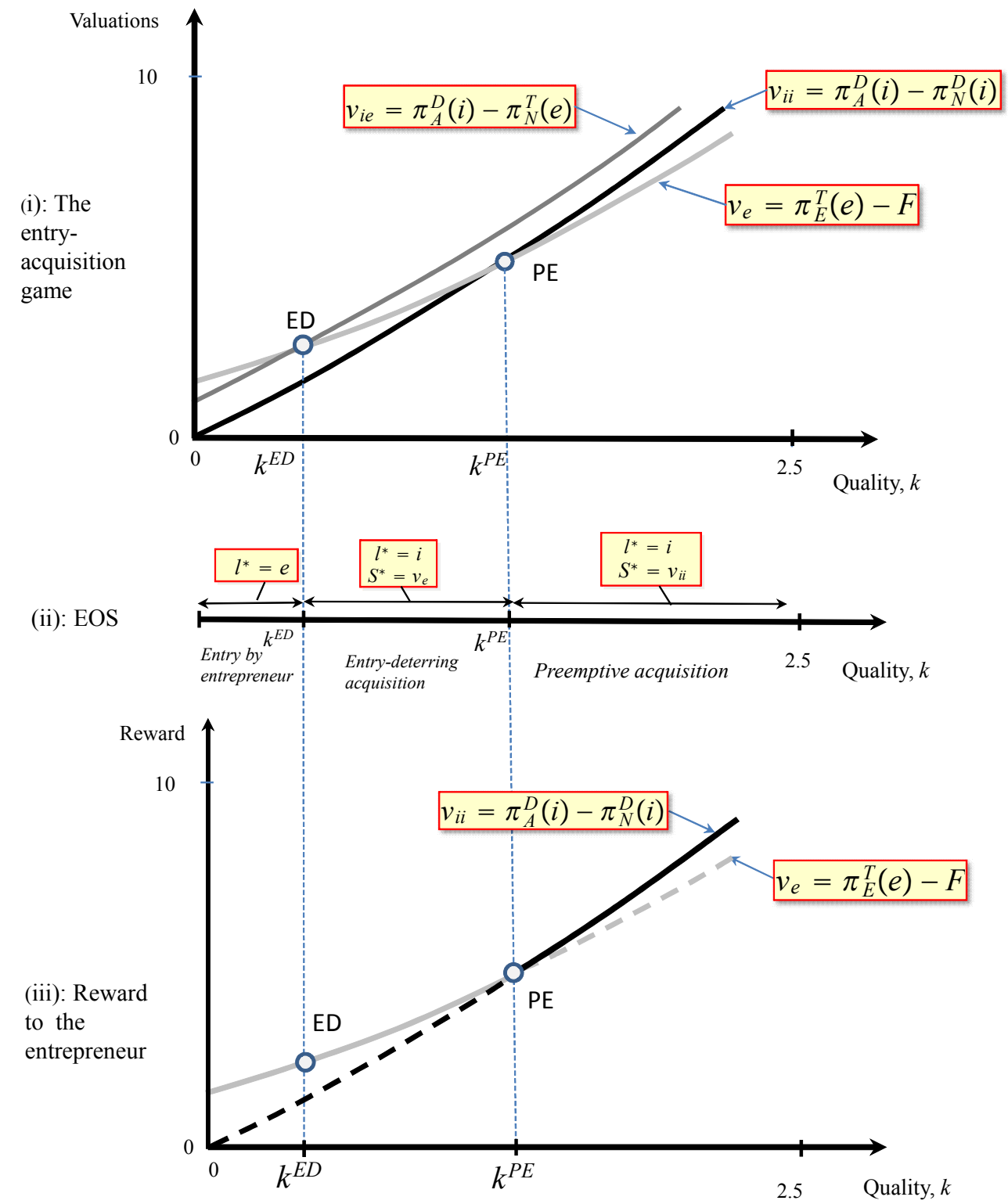

Figure 2.1: Illustrating the Equilibrium Ownership structure (EOS) in the linear Cournot model in Example 1, assuming $\Lambda=a-c=5, \gamma=1$ and $G=0.05$ and $n=2$. 
Result 2: The reward for entrepreneurs to sell high quality innovations will be substantially greater than the reward for using them to enter the product market. The reason is that bidding competition will occur over high quality innovations, implying that the entrepreneurs captures a large share of the rents in the oligopoly market when selling.

In stage 1, the entrepreneur decides how much effort to undertake in order to increase the probability of being successful in creating an innovation. This decision will crucially depend on the reward for taking a successful innovation to the market. In stage 1, the entrepreneur decides how much to invest in research, depending on the reward for taking an invention to the market. Inspecting Figure 2.1(ii), we see that the reward to the entrepreneur becomes:

$$
R_{E}(l)=\left\{\begin{array}{c}
v_{e}, \quad k \in\left[0, k^{E D}\right), \\
S^{*}=v_{e}, \quad k \in\left[k^{E D}, k^{P E}\right), \\
S^{*}=v_{i i}, k>k^{P E} .
\end{array}\right.
$$

Note that Result 2 implies that the incentive to innovate will be higher when the entrepreneur commercializes a high-quality innovation under bidding competition (since $v_{i i}>v_{e}$ for $k>$ $\left.k^{P E}\right) .{ }^{11} \mathrm{~A}$ direct implication is that while the consumer surplus increases when entry takes the market from duopoly to triopoly, consumers may still be better off from a sale in expected terms: Blocking an incumbent acquisition reduces the market power of incumbents. However, with a lower reward for the innovation (since $v_{e}<v_{i i}$ for $k>k^{P E}$ in Figure 2.1(iii)), the innovation effort is reduced, which reduces the probability that the cost-reducing innovation reaches the market.

We will now turn to the main model where we show under which conditions these results hold in a more general setting and how preemptive acquisitions can be identified in the data.

\section{The model}

The interaction is illustrated in Figure 3.1. Consider a market served by $n$ symmetric incumbent firms. There is also an entrepreneur, denoted $e$. In stage 1 , the entrepreneur decides how much to invest in research, thereby affecting the probability of discovering an invention with a fixed quality $k .{ }^{12}$ In stage 2 , if successful, the entrepreneur commercializes the invention into an innovation. She either sells the invention at a first-price perfect information auction, where the $n$ incumbent firms are the potential buyers, or enters the product market. There may then be exits of incumbent firms. Finally, in stage 3, the active firms in the product market compete in oligopoly interaction, setting an action $x_{i}$. Following the literature, we will use the term "invention" as long as $k$ has not reached the market, and the term "innovation" when $k$ is used in the product market.

\footnotetext{
${ }^{11}$ In this section, we do not allow for exits of incumbents, so implicitly we assume that $k \in\left[k^{P E}, k^{\text {max }}\right)$ where $k^{\max }$ is defined as the quality such $\pi_{N}^{T}(l)=0$. We do allow for exits below.

12 The quality of an invention $k$ for many types of inventions is fixed, such as for vaccines, or solutions to specific technical problems. However, for other inventions the quality of an invention can be affected, such as the capacity of a micro processor. We discuss the case where the entrepreneur chooses the quality in Section 6.6.
} 


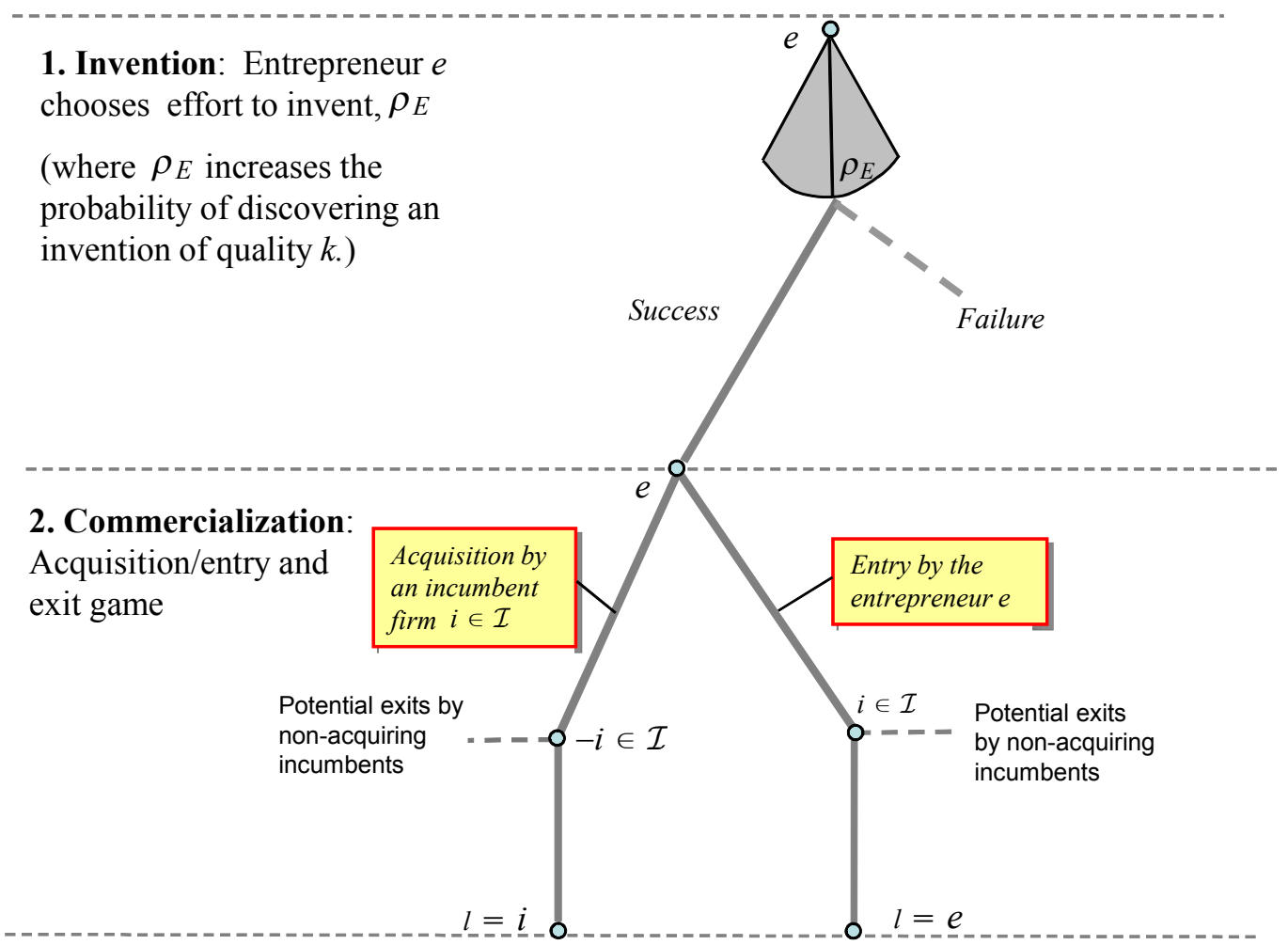

3. Product market interaction:

Oligopoly

$x_{h}(l)$
$x_{N A}(l)$$\quad\left\{\begin{array}{l}x_{A}(i) \\ x_{N A}(i)\end{array} \quad \begin{cases}x_{E}(e) & \text { Ex-ante symmetry } \\ x_{N A}(e) & \text { between incumbent firms }\end{cases}\right.$

Figure 3.1: The structure of the game. 


\subsection{Stage 3: Product-market equilibrium}

Let the set of firms in the industry be $\mathcal{J}=e \cup \mathcal{I}$, where $\mathcal{I}=\left\{i_{1}, i_{2} \ldots i_{n}\right\}$ is the set of incumbent firms. Denote the owner of the entrepreneur's invention, $k$, by $l \in \mathcal{J}$. Using backward induction, we start with product market interaction where firm $j$ chooses an action $x_{j} \in R^{+}$to maximize its direct product market profit, $\pi_{j}\left(x_{j}, \mathbf{x}_{-j}, l\right)-\tau$, which depends on its own and its rivals' market actions, $x_{j}$ and $\mathbf{x}_{-j}$, the identity of the owner of the invention, $l$, and a fixed cost $\tau$ to serve the market. We may consider the action $x_{j}$ as setting a quantity or a price, as will be shown in later sections. We assume there to exist a unique Nash-Equilibrium, $\mathbf{x}^{*}(l)$, defined as:

$$
\pi_{j}\left(x_{j}^{*}, x_{-j}^{*}: l, k\right) \geq \pi_{j}\left(x_{j}, x_{-j}^{*}: l, k\right), \quad \forall x_{j} \in R^{+},
$$

where we assume the product market profits to be positive.

From (3.1), we can define a reduced-form product market profit for a firm $j$, taking as given ownership $l$ :

$$
\pi_{j}(l) \equiv \pi_{j}\left(x_{j}^{*}(l), x_{-j}^{*}(l), l\right) .
$$

The assumption that incumbents $i_{1}, i_{2}, \ldots, i_{n}$ are symmetric before the acquisition takes place implies that we need only distinguish between two types of ownership; entrepreneurial ownership $(l=e)$ and incumbent ownership $(l=i)$. Note that there are then three types of firms of which to keep track, $h=\{e, A, N A\}$, i.e. the entrepreneurial firm (e), an acquiring incumbent $(A)$ and the non-acquiring incumbents $(N A)$.

Let us now define the quality of an invention in this setting in terms of the effect on firms' net profits $\pi_{j}(l)-\tau$ :

Definition 1. (i) $\frac{d \pi_{A}(i)}{d k}>0$, (ii) $\frac{d \pi_{E}(e)}{d k}>0$, and (iii) $\frac{d \pi_{N A}(l)}{d k}<0, l=\{e, i\}$.

Definition 1 is central: Part (i) and (ii) state that the reduced-form product market profit for the possessor is strictly increasing in the quality of the invention, whereas Definition 1 (iii) states that increased quality strictly decreases the rivals' profits. This definition will define increased quality as stronger reduction in variable costs or increased product value in most standard oligopoly models used in the literature. As shown in Example 1 below, it will hold for a process innovation (where an innovation with better quality leads to a larger reduction in the marginal cost of selling and producing for the product market) or an increase in quality for a product (by increasing consumers willingness to pay).

We should note that Definition 1 does not hold for fixed cost innovations: if $d \tau / d k<0$ part (iii) would not be fulfilled. Definition 1 also requires that the number of firms in the market is given: if the quality $k$ is increased so much that incumbents are forced to exit, the concentration effect thereof may induce an increase in $\pi_{N A}(l)$ again violating part (iii). Exit effects are discussed in detail in Sections 4.1 and Section 6.1, below.

Example 1 (The LC-model). As an example, we use a Linear-Cournot model (LC-model). This model is also used to derive more specific results. The oligopoly interaction in period 3 is Cournot competition. Firms face inverse demand $P_{j}=a-q_{j}-\gamma q_{-j}$, where $a>0$ is a demand parameter, $q_{j}$ is the output of firm $j$ and $q_{-j}$ is the output of its rivals. Goods are either 
homogenous $(\gamma=1)$ or differentiated $(\gamma \in(0,1))$. The product market profit is $\pi_{j}=\left(P-c_{j}\right) q_{j}$ where ownership of the invention reduces the marginal cost (or alternatively raises the demand intercept a). Making a distinction between firm types, we have for a marginal cost reduction:

$$
c_{N A}=c, \quad c_{A}=c-k, \quad c_{E}=c-k
$$

In the LC model, (3.1) takes the form $\frac{\partial \pi_{j}}{\partial q_{j}}=P_{j}-c_{j}-q_{j}^{*}=0 \forall j$, which can be solved for optimal quantities $\mathbf{q}^{*}(l)$. Noting that $\frac{\partial \pi_{j}}{\partial q_{j}}=0$ implies $P_{j}-c_{j}=q_{j}^{*}$, reduced-form profits are $\pi_{j}(l)=\left[q_{j}^{*}(l)\right]^{2}$, where $q_{A}^{*}(l)=\frac{\Lambda+k-\gamma Q^{*}(l)}{2-\gamma}, q_{E}^{*}(e)=\frac{\Lambda+k-\gamma Q^{*}(e)}{2-\gamma}, q_{N A}^{*}(l)=\frac{\Lambda-\gamma Q^{*}(l)}{2-\gamma}$ and $Q^{*}(l)=\frac{N(l) \Lambda+k}{2-\gamma+N(l) \gamma}$ for $l=e, i$, and where $\Lambda=a-c$ and $N(l)$ is the total number of firms in the market. Holding the total number of firms $N(l)$ fixed, it can then be checked that reduced-form profits $\pi_{j}(l)$ fulfill Definition 1.

\subsection{Stage 2: Commercialization}

In stage 2 , there is first an entry-acquisition game where the entrepreneur can decide either to sell the invention to one of the incumbents or enter the market at a fixed cost, $G$. Given the mode of commercialization, non-acquiring incumbents may then exit the market.

The exit process looks as follows: The firm in possession of the invention is assumed to always make positive profits, i.e. we assume the quality of the invention $k$ to be sufficiently large so that $\pi_{A}(l)>\tau$ and $\pi_{E}(e)>\tau+G$ hold. Non-acquiring incumbents will exit until the total number of firms on the market $N(l)$ fulfils the exit condition:

$$
\pi_{N A}(l: N(l))>\tau, \quad \pi_{N A}(l: N(l)+1)<\tau,
$$

where we assume that each non-acquiring incumbent has an equal positive exit probability if exit occurs. Note that the maximum number of firms under a sale is just the number of incumbents, i.e. $\max : N(i)=n$ and the maximum number of firms under entry is just the number of incumbents plus the entrepreneur, i.e. $\max : N(e)=n+1$.

The commercialization process is depicted as an auction where $n$ incumbents simultaneously post bids, and the entrepreneur then either accepts or rejects these bids. If the entrepreneur rejects these bids, she will enter the market. Each incumbent announces a bid, $b_{i}$, for the invention. $\mathbf{b}=\left(b_{1}, . . b_{i} . ., b_{n}\right) \in R^{n}$ is the vector of these bids. Following the announcement of $\mathbf{b}$, the invention may be sold to one of the incumbents at the bid price, or remain in the ownership of entrepreneur $e$. If more than one bid is accepted, the bidder with the highest bid obtains the invention. If there is more than one incumbent with such a bid, each obtains the invention with equal probability. The acquisition is solved for Nash equilibria in undominated pure strategies. There is a smallest amount $\varepsilon$ chosen such that all inequalities are preserved if $\varepsilon$ is added or subtracted.

There are three different valuations:

- $v_{i i}$ in (3.5) is the value of obtaining $k$ for an incumbent, when otherwise a rival incumbent would obtain $k$. The first term shows the profit when possessing the invention $k$. The second term shows the expected profit if a rival incumbent obtains $k$, where $\Gamma$ is an 
exogenous transaction cost associated with acquiring the invention $k$, and $\lambda(\mathrm{i})$ is the probability of staying in the market as a non-acquirer

$$
v_{i i}=\pi_{A}(i)-\tau-\Gamma-\lambda(\mathrm{i})\left[\pi_{N A}(i)-\tau\right]
$$

- $v_{i e}$ in (3.6) is the value of obtaining $k$ for an incumbent, when otherwise the entrepreneur would keep it. The profit for an incumbent of not obtaining invention $k$ is different in this case, due to the change of identity of the firm that otherwise would possess the assets

$$
v_{i e}=\pi_{A}(i)-\tau-\Gamma-\lambda(\mathrm{e})\left[\pi_{N A}(e)-\tau\right] .
$$

- $v_{e}$ in (3.7) is the value for the entrepreneur of keeping an invention with quality $k$ and entering the market

$$
v_{e}=\pi_{E}(e)-\tau-G
$$

where $G$ is the fixed exogenous entry cost. Note we assume that $\pi_{E}(i)=0$, so the entrepreneur cannot enter the market without ownership of the invention.

We can now proceed to solve for the Equilibrium Ownership Structure (EOS). Since incumbents are symmetric, valuations $v_{i i}, v_{i e}$ and $v_{e}$ can be ordered in six different ways, as shown in Table 3.1. These inequalities are useful for solving the model and illustrating the results. The following lemma can be stated:

Lemma 1. Equilibrium ownership $l^{*}$, acquisition price $S^{*}$ and entrepreneurial reward $R_{E}$ are described in Table 3.1:

Proof. See the Appendix.

Table 3.1: The equilibrium ownership structure and the acquisition price.

\begin{tabular}{ccccc}
\hline Inequality: & Definition: & Ownership $l^{*}:$ & Acquisition price, $S^{*}:$ & Entrepreneurial reward, $R_{E}:$ \\
\hline$I 1:$ & $v_{i i} \geq v_{i e}>v_{e}$ & $i$ & $v_{i i}$ & $v_{i i}$ \\
$I 2:$ & $v_{i i}>v_{e} \geq v_{i e}$ & $i$ or $e$ & $v_{i i}$ & $v_{i i}$ or $v_{e}$ \\
$I 3:$ & $v_{i e} \geq v_{i i}>v_{e}$ & $i$ & $v_{i i}$ & $v_{i i}$ \\
$I 4:$ & $v_{i e}>v_{e} \geq v_{i i}$ & $i$ & $v_{e}$ & $v_{e}$ \\
$I 5:$ & $v_{e} \geq v_{i i}>v_{i e}$ & $e$ &. & $v_{e}$ \\
$I 6:$ & $v_{e} \geq v_{i e}>v_{i i}$ & $e$ &. & $v_{e}$ \\
\hline
\end{tabular}

Lemma 1 shows that when one of the inequalities $I 1, I 3$, or $I 4$ holds, $k$ is obtained by one of the incumbents. Under $I 1$ and $I 3$, the acquiring incumbent pays the acquisition price $S=v_{i i}$, and $S=v_{e}$ under $I 4$. Note that we here assume that the incumbents can coordinate on who will be the buyer in this equilibrium. When $I_{5}$ or $I_{6}$ holds, the entrepreneur retains its assets. When $I 2$ holds, there exist multiple equilibria. The last column summarizes the reward $R_{E}$ accruing to the entrepreneur. 
Note that we restrict our attention to pure strategy equilibria. This implies that under I4 the acquiring incumbent is worse off compared to a non-acquiring incumbent. If we would allow for mixed strategy equilibria incumbents would bid $v_{e}$ with some probability $\varrho$ and not bid with probability $1-\varrho$. There are then two possible outcomes: at least one incumbent bids $v_{e}$ and an acquisition takes place, or no incumbent bid and entry occurs. However, allowing for mixed strategies will not affect the main thrust of the paper, since the acquisition price still is $v_{e}$ under I4, if an acquisition takes place.

\subsection{Stage 1: Effort by the entrepreneur}

In stage 1, entrepreneur $e$ invests in research $\rho_{E}$ to succeed with the invention $k$. For simplicity, assume the probability of succeeding with an invention is simply the effort, i.e. $\rho_{E} \in[0,1]$, and that effort is associated with an increasing and convex cost $y(\rho)$, i.e. $y^{\prime}(\rho)>0$, and $y^{\prime \prime}(\rho)>0$. With $R_{E}(l)$ given from Lemma $1, \Pi_{E}=\rho_{E} R_{E}(l)-y\left(\rho_{E}\right)$ is the expected net profit for the entrepreneur of undertaking a research effort. The optimal effort $\rho_{E}^{*}$ is given from:

$$
\frac{d \Pi_{E}}{d \rho_{E}}=R_{E}(l)-y^{\prime}\left(\rho_{E}^{*}(l)\right)=0,
$$

with the associated second-order condition (omitting the ownership variable $l$ ), $\frac{d^{2} \Pi_{E}}{d \rho_{E}^{2}}=-y^{\prime \prime}(\rho)<$ 0 .

Applying the implicit function theorem in (3.8), we can state the following Lemma:

Lemma 2. The equilibrium effort by the entrepreneur in stage $1, \rho_{E}^{*}(l)$ and hence, the probability of a successful invention, increases with the expected reward for an invention, i.e. $\frac{d \rho_{E}^{*}(l)^{*}}{d R_{E}}>0$.

\section{Mode of commercialization and the quality of the invention}

In Section 2 we showed (i) why entrepreneurs sell their best inventions and (ii) why preemptive acquisitions may promote the process of creative destruction. We now derive these results in a more general setting. We also discuss welfare implications of the creative destruction and productive preemption process proposed in this paper.

\subsection{Why entrepreneurs sell their best inventions}

In this section, we examine how the mode of commercialization - by entry or by sale - is related to the quality of the invention, $k$. We will in this and the next section show that higher quality $k$ will induce an entrepreneur to commercialize an invention by sale rather than by entry, and that higher quality will lead to bidding competition among incumbents. This competition will increase the entrepreneur's reward from sale above the reward from entry.

For expositional reasons, we will assume that entry is "large-scale" and "market-neutral". These assumptions are illustrated in Figure 4.1 and formalized below. In particular, these assumptions will imply that $v_{i e}>v_{i i}$, and thus that only inequalities $I 3, I 4$, or $I 6$ are relevant in the analysis. These assumptions do not qualitatively change the results. This has already 
been shown in Section 2, and is further shown in Section 6.1. In Section 6.3, we relax the "large-scale entry" assumption, and allow for all inequalities I1-I6 in Table 3.1 to arise.

To proceed, it is useful to define the net value of an incumbent acquisition, i.e. the difference between incumbents' valuations and the entry value for the entrepreneur, $v_{i l}-v_{e}$. In particular, note that from Lemma 1 under $I 3, I 4$, or $I 6$, commercialization by sale occurs as a unique equilibrium if and only if $v_{i e}-v_{e}>0$.

Using (3.5)-(3.7), we have:

$$
v_{i l}-v_{e}=\left[\pi_{A}(i)-\pi_{E}(e)+G-\Gamma\right]-\lambda(1)\left[\pi_{N A}(l)-\tau\right], \quad l=\{e, i\} .
$$

Examining the net value of an acquisition (4.1), the first term is an invention-transfer effect, showing the change in profits from a change of ownership of the invention, from the entrepreneur to an incumbent firm. The second term can be viewed as the opportunity cost of an ownership change, since this terms captures the profit for an incumbent when not acquiring the invention.

Large-scale entry We assume the entrant and the acquirer make a symmetric use of assets, and will attain a symmetric market position when exposed to the same market conditions, i.e. $\pi_{A}(i)=\pi_{E}(e)$ when the total number of firms on the market is $N=n(i)=n(e)$. We thus refer to such entry as "large scale entry". ${ }^{13}$

Market-neutral entry We also assume that entry does not change the number of firms in the market. To proceed, we then use the following definition of $\bar{k}(l)$ :

Definition 2. $\pi_{N A}(l, \bar{k}(l))=\tau$ for $l=\{e, i\}$.

$\bar{k}(l)$ is thus the maximum quality of the invention such that all non-acquirers can cover their fixed cost $\tau$ associated with serving the market. It follows that $\bar{k}(i)>\bar{k}(e)$, since nonacquirers' profits will be reduced with one more firm in the market. We then make the following assumption:

Assumption A1 Entry is Market-structure-neutral-entry iff $k \in(\bar{k}(e), \bar{k}(i))$.

As shown in Figure 4.1(iii), when $k \in(\bar{k}(e), \bar{k}(i))$, entry by the entrepreneur leads to the exit of one incumbent firm, i.e. $N(l)=n$. As shown in Figure 4.1(i), Assumption A1 thus implies the entrant attains exactly the same market position as would the acquiring incumbent in the case of a sale of the invention, i.e. $\pi_{A}(i)=\pi_{E}(e)$. In addition, as shown in Figure 4.1(ii), non-acquiring incumbents obtain the same profit regardless ownership of the invention, $\pi_{N}(e)=\pi_{N}(i)$. However, since one of the incumbents is forced out of the market under entry, the probability of remaining in the market for a non-acquiring incumbent is lower under entry, $\lambda(i)=1>\lambda(e)=\frac{n-1}{n}>0$.

Under Assumption A1, the net value for an incumbent in (4.1) can be written as:

$$
v_{i l}-v_{e}=\left\{\begin{array}{c}
v_{i e}-v_{e}=G-\Gamma-\left(\frac{n-1}{n}\right)\left[\pi_{N A}(e)-\tau\right], \quad l=e \\
v_{i i}-v_{e}=G+\tau-\Gamma-\pi_{N A}(i), \quad l=i
\end{array},\right.
$$

\footnotetext{
${ }^{13}$ The LC-model in Example 1 fulfills the large scale entry assumption.
} 
(i): The profits of the acquirer and the entrant

(ii) The profit of a non-acquirer under entry and sale

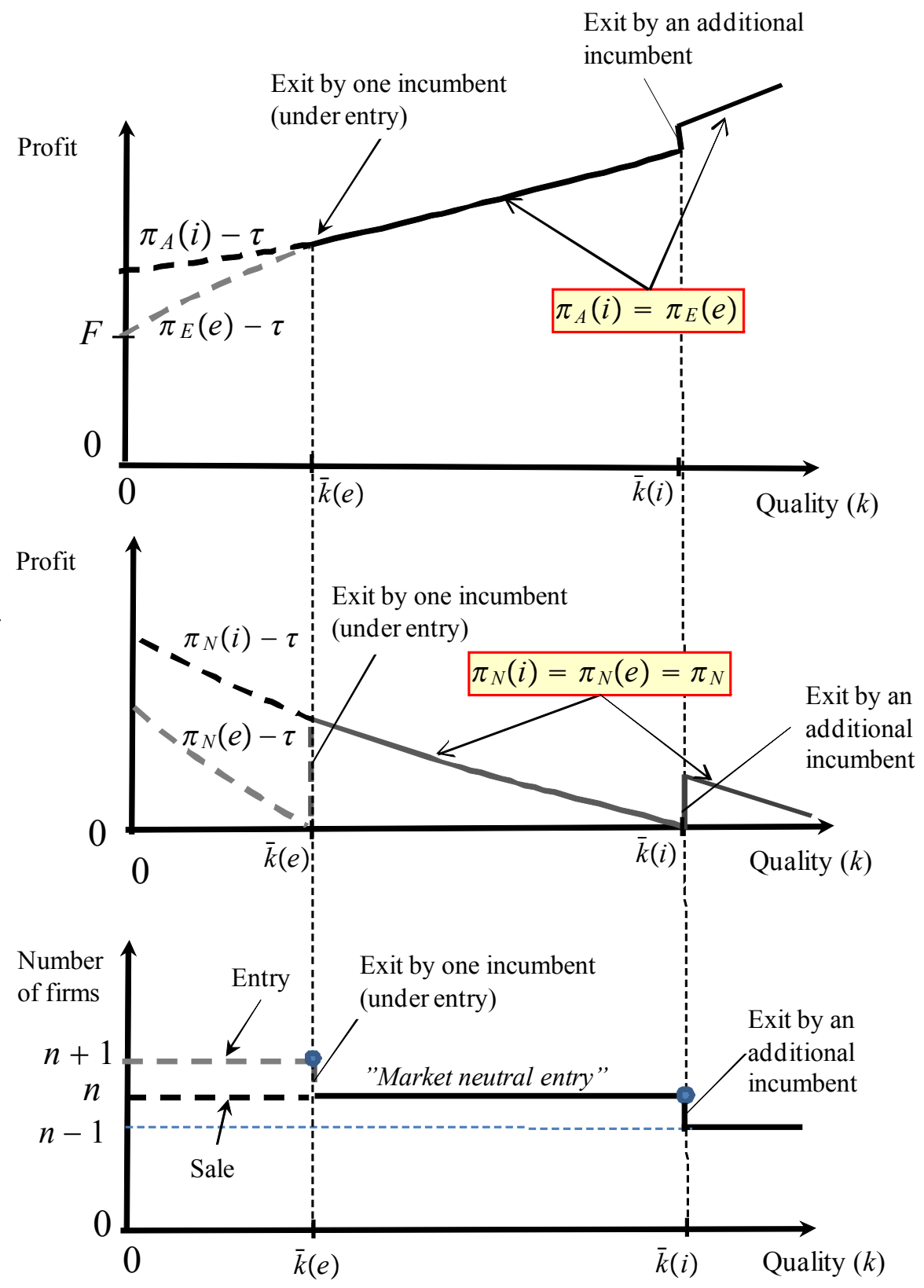

Figure 4.1: Illustrating Market-neutral entry and Large-scale entry. 
where the invention-transfer effect is now given from the net fixed cost savings, $G-T$. In (4.2), $v_{i e}-v_{e}$ thus represents the net value for an incumbent of deterring entry, whereas $v_{i i}-v_{e}$ represents the net value for an incumbent of preempting rivals from obtaining the entrepreneur's invention. Due to the risk of exit when not acquiring, net value of entry-deterrence is larger than the net value of preemption.

To characterize the entrepreneur's choice of mode of commercialization, we make use of the following definition:

Definition 3. Let $k^{E D}$ be defined from $v_{i e}\left(k^{E D}, \cdot\right)=v_{e}\left(k^{E D}, \cdot\right)$ and $k^{P E}$ be defined from $v_{i i}\left(k^{P E}, \cdot\right)=v_{e}\left(k^{P E}, \cdot\right)$.

$k^{E D}$ is thus the quality level where the entry-deterring motive for an incumbent acquisition just matches the entrepreneur's entry value, whereas $k^{P E}$ is the quality level where the preemptive motive for an incumbent acquisition is equal to the entrepreneur's entry value. Note that from (4.2), the existence of the cut-off qualities $k^{E D}$ and $k^{P E}$ requires that entry costs $G$ are larger than the transaction cost $\Gamma$. Moreover, from Definition 1, it follows that if $k^{E D}$ and $k^{P E}$ exist they are unique.

We then have the following Lemma:

Lemma 3. Suppose that Assumption $A 1$ holds and $k^{E D}$ and $k^{P E}$ exist. Then, (i) commercialization by entry takes place if the quality of the invention is sufficiently low, $k \in\left(\bar{k}(e), k^{E D}\right)$, (ii) commercialization by sale occurs at sales price $S^{*}=v_{e}$ if the quality of the invention is of intermediate size, $k \in\left[k^{E D}, k^{P E}\right)$, and (iii) commercialization by sale occurs at sales price $S^{*}=v_{i i}$ if the quality of the invention is sufficiently high, $k \in\left[k^{P E}, \bar{k}(i)\right)$.

Lemma 3 is proved below and also illustrated in Figure 4.2. Figure 4.2(i) solves the acquisition entry game as a function of the quality of the invention, $k$. When the quality of the invention is low $k \in\left(\bar{k}(e), k^{E D}\right)$, the net value for entry deterrence is negative, i.e. an incumbent's entry deterring valuation is lower than the entrant's entry value, $v_{i e}-v_{e}<0$. In this region, the entrepreneur will thus choose commercialization by entry $\left(l^{*}=e\right)$.

What happens if the quality of the invention increases? Differentiate the net value of entry deterrence $v_{i e}-v_{e}$ in $k$ to obtain

$$
v_{i e, k}^{\prime}-v_{e, k}^{\prime}=-\left(\frac{n-1}{n}\right) \frac{d \pi_{N A}(e)}{d k}>0,
$$

where we use $v_{k}^{\prime}$ as the notation for the derivative, $\frac{d v}{d k}$. Thus, the entry-deterring valuation of an incumbent $v_{i e}$ increases more than the entrepreneur's value of entry $v_{e}$ when the quality of the invention increases. To see why, note that the first term in $v_{i e}=\pi_{A}(i)-\tau-\Gamma-\lambda(\mathrm{e})\left[\pi_{N A}(e)-\tau\right]$ increases by the same amount as the first term in $v_{e}=\pi_{E}(e)-\tau-G$, since the acquiring incumbent and the entrepreneur have the same increase in profit from Assumption A1, $\pi_{A}(i)=$ $\pi_{E}(e)$. However, since the profit of a non-acquirer $\pi_{N}(e)$ decreases in $k$, there is an additional increase in the incumbent's valuation, implying $v_{i e, k}^{\prime}>v_{e, k}^{\prime}$. Thus, since an incumbent's net value of entry deterrence $v_{i e}-v_{e}$ is increasing in the quality of the invention $k$, an entry deterring acquisition at the acquisition price $S^{*}=v_{e}$ occurs at $k=k^{E D}$, as shown in Figure 4.2(ii). Other 


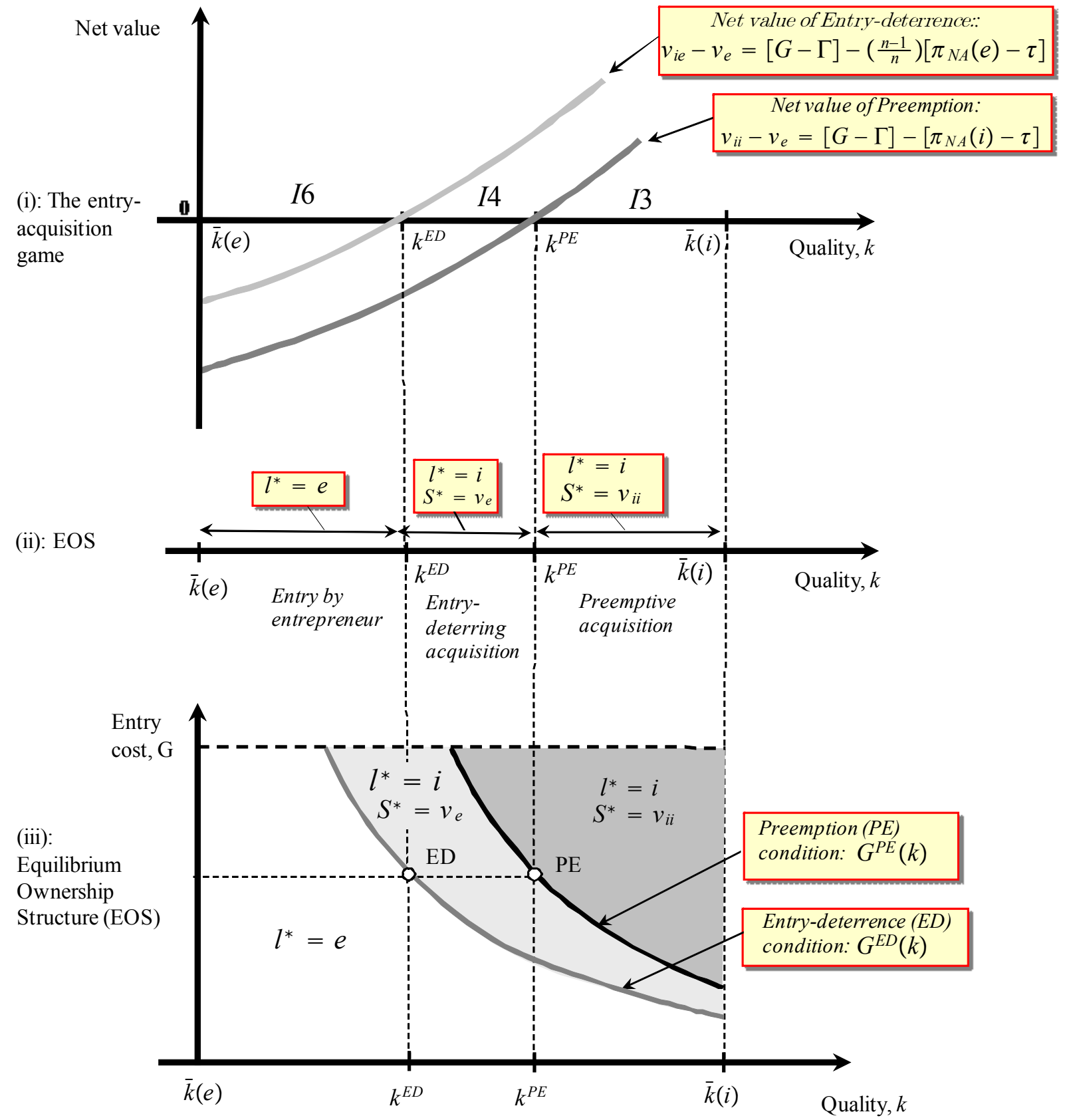

Figure 4.2: Solving for the equilibrium mode of commercialization. 
incumbents will not preempt a rival acquisition in the region $k \in\left[k^{E D}, k^{P E}\right)$, since the net value of preemption is negative, $v_{i i}-v_{e}<0$. Thus, the entrepreneur will commercialize by sale $\left(l^{*}=i\right)$ at price $S^{*}=\pi_{E}(e)-\tau-G$ in this region.

What if the quality increases even further? Since a higher quality decreases the profit of a non-acquiring incumbent also when there is an incumbent acquisition, the net value of preempting rivals is also increasing in quality. Differentiating $v_{i i}-v_{e}$ in $k$ we obtain

$$
v_{i i, k}^{\prime}-v_{e, k}^{\prime}=-\frac{d \pi_{N A}(i)}{d k}>0 .
$$

As shown in Figure 4.2(i), increasing the quality of the invention into the region $k \geq k^{P E}$ will then imply the net value of preemption is strictly positive, $v_{i i}-v_{e}>0$. This induces a bidding war between incumbents, driving the equilibrium sales price above the entry value for the entrepreneur, $S^{*}=v_{i i}=\pi_{A}(i)-\Gamma-\pi_{N A}(i)>v_{e}$. The entrepreneur will thus commercialize by sale $\left(l^{*}=i\right)$, receiving the sales price $S^{*}=v_{i i}$ in this region.

Let us now derive additional predictions. Figure 4.2(iii) shows how equilibrium ownership is jointly determined by the quality of the invention $k$ and the entry $\operatorname{cost} G$. Let $G^{E D}\left(k^{E D}\right)$ be the entry-deterrence condition (ED-condition) defined from $v_{i e}\left(k^{E D}, G\right)=v_{e}\left(k^{E D}, G\right)$, and let $G^{P E}\left(k^{P E}\right)$ be the preemption condition (PE-condition) defined from $v_{i i}\left(k^{P E}, G\right)=v_{e}\left(k^{P E}, G\right)$. Solving for $G$ in each equation, we have:

$$
G^{E D}(k)=\Gamma-\left(\frac{n-1}{n}\right) \tau+\left(\frac{n-1}{n}\right) \pi_{N A}(e), \quad G^{P E}(k)=\Gamma-\tau+\pi_{N A}(i) .
$$

The loci associated with both the takeover condition $G^{E D}\left(k^{E D}\right)$ and the preemption condition $G^{P E}\left(k^{P E}\right)$ are downward-sloping in the $k-G$ space. This follows from the profit of a non-acquirer $\pi_{N A}(l)$ decreasing in the quality of the invention $k$, and a lower fixed entry cost $G$ being needed to balance the incumbent's higher value of obtaining the invention. The equilibrium ownership structure involves commercialization by entry below the entry deterrence locus $G^{E D}(k)$, indicated as $l^{*}=e$. Entry deterring acquisitions occur for combinations of $k$ and $G$ between the takeover locus $G^{E D}(k)$ and the preemption locus $G^{P E}(k)$, indicated as $l^{*}=i$ and $S^{*}=v_{e}$. Preemptive acquisitions occur above the preemption locus $G^{P E}(k)$, as indicated by $l^{*}=i$ and $S^{*}=v_{i i}$. From (4.5), we also note increases in transaction costs $\Gamma$ shift both the entry deterrence locus $G^{E D}(k)$ and the preemption locus upwards in Figure 4.2(iii), reducing the region where commercialization by sale occurs, whereas increasing the fixed operating cost $\tau$ has the opposing effect.

Thus, we can state the following result:

Proposition 1. Assume that Assumption A1 holds. In the choice between commercializing by sale to incumbents or entering the market, an entrepreneur will then prefer sale when (i) the quality of the invention $k$ is high, (ii) entry costs $G$ are high, (iii) operating fixed costs $\tau$ are high, and (iv) the transaction costs associated with a sale $\Gamma$ are low.

\subsection{Why preemptive acquisitions may promote the process of creative destruction}

In this section, we will show that preemptive acquisitions will accelerate the process of creative destruction. To this end we state the following proposition concerning research incentives for 
the entrepreneur:

Proposition 2. Assume that Assumption A1 holds, then $\rho^{*}(i)>\rho^{*}(e)$ for $k \in\left[k^{P E}, \bar{k}(i)\right)$. That is, entrepreneurs with high-quality projects will be substantially more likely to succeed with an invention under commercialization by sale as compared to commercialization by entry.

The proposition is proved in Figure 4.3. Figure 4.3(i) derives the equilibrium commercialization strategy for the entrepreneur, and Figure 4.3(ii) depicts the reward of the entrepreneur $R_{E}(l)$ as a function of the quality of the invention $k$. When quality is low $k \in\left(\bar{k}(e), k^{E D}\right)$, commercialization by entry occurs and the reward is $R_{E}(e)=v_{e}=\pi_{E}(e)-\tau-G$ for the entrepreneur. From Definition $1, R_{E}(e)$ is increasing in quality and from Lemma 2, the research incentives are increased. The same holds if an entry deterring acquisition occurs in region $k \in\left[k^{E D}, k^{P E}\right)$ since $R_{E}(i)=S^{*}=v_{e}$.

However, at an even higher quality $k \geq k^{P E}$, preemptive acquisitions occur, and the bidding competition among incumbents for the benefits as an acquirer - as well as to avoid a weak position as a non-acquirer - drives the reward for commercialization by sale to be strictly higher than the reward for commercialization by entry, $R_{E}(i)=v_{i i}>v_{e}=R_{E}(e)$. Since the research effort, and hence the likelihood of a successful innovation $\rho^{*}(l)$ is increasing in the reward $R_{E}(l)$, it directly follows from Lemma 2 that there will be a higher probability of a successful invention under commercialization by sale. This is illustrated in Figure 4.3(iii) which shows that preemptive incumbent acquisitions of entrepreneurial inventions can be productive by substantially increasing the research incentives for entrepreneurs.

More generally, we may also note that Lemma 1 and Lemma 2 imply that preemptive incumbent acquisitions will always substantially increase the reward to research for entrepreneurs, since $S^{*}=v_{i i}>v_{e}$ and hence $\rho^{*}(i)>\rho^{*}(e)$ will hold for any of the inequalities I1, I2 or I3 in Table 3.1.

\subsection{Preemptive acquisitions and welfare}

In this section, we will show that preemptive acquisitions can increase welfare by increasing the innovation incentives.

Let us first examine how incumbent acquisitions of entrepreneurial inventions affect consumer welfare. To this end, we compare a Non-discriminatory (ND) policy (where incumbent acquisitions of entrepreneurial firms are allowed) to a Discriminatory (D) policy (which prohibits the acquisitions of small innovative firms). Consider a stage 0 where a government chooses between the two policies. Formally, let $\bar{\Gamma}$ be defined from $v_{i e}(\cdot, \bar{\Gamma})=0$. Under the ND-policy, $\Gamma<\bar{\Gamma}$, whereas under the D-policy, $\Gamma>\bar{\Gamma}$. This is a highly stylized comparison, but in its simplicity can be seen as a valuable way of capturing the effects of substantial changes of transaction costs for acquisitions due to changes in policies that might block or increase the cost of acquiring small innovative firms. ${ }^{14}$ The change in transaction costs could also stem from technological and institutional changes.

\footnotetext{
${ }^{14}$ Examples are a restrictive merger policy in R\&D industries, or tax policies concerning the sale of innovative firms.

An alternative policy with qualitatively the same effect would be a reduction in the cost of entry.
} 


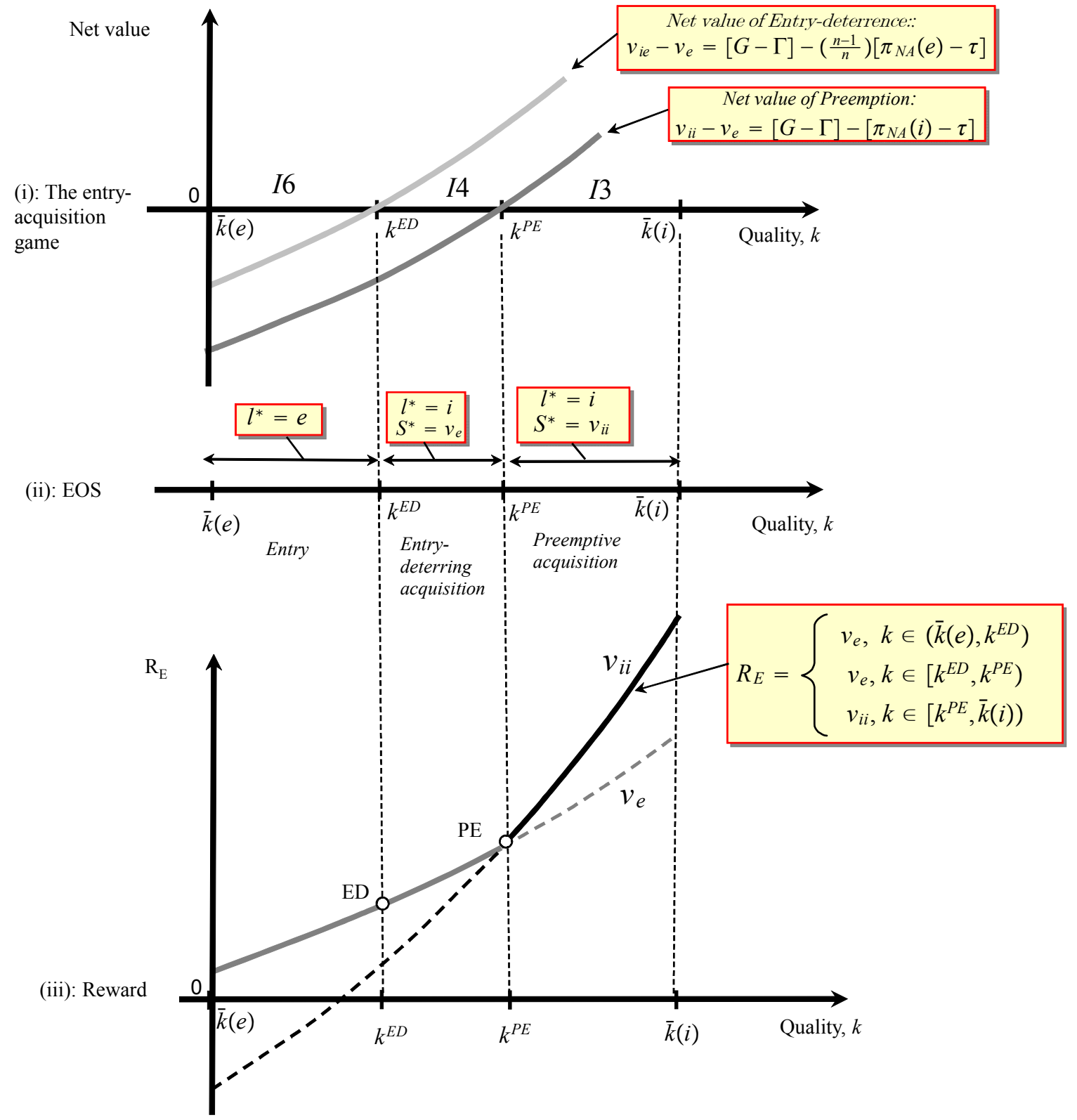

Figure 4.3: The equilibrium reward to innovation and the equilibrium probabality of success. 
Assume, everything else being equal, that consumers benefit both from the higher quality of an innovation and more firms being present in the market. Let the consumer surplus under ownership $l$ be denoted $C S(l)$, and let $C S(0)$ denote the consumer surplus when the entrepreneur fails. From Lemma 1, we have:

$$
C S^{N D-D}=\left\{\begin{array}{l}
0, \text { for } \mathrm{I} 5, \mathrm{I} 6 \\
\rho(e)[C S(i))-C S(e)] \leq 0, \text { for I4 } \\
\rho(i)[C S(i)-C S(0)]-\rho(e)[C S(e)-C S(0)] \text { for I1-I3 }
\end{array}\right.
$$

noting that $\rho(e)=\rho(i)$ under I4 in Table 3.1.

If incumbent acquisitions are driven by entry deterrence motives, consumers will be better off from the Discriminatory policy, as shown by $C S^{N D-D} \leq 0$ under I4. However, the differential $C S^{N D-D}$ in (4.6) also reveals that consumers may prefer the ND-policy when inventions are sold under bidding competition, since a successful invention is more likely, i.e. $\rho_{E}^{*}(i)>\rho_{E}^{*}(e)$ under inequalities I1-I3 in Table 3.1. Inasmuch as the higher quality of an invention will induce bidding competition among incumbents, its reasonable to infer that consumers may prefer the ND-policy when potential innovations are of high quality. This is shown by the following proposition:

Proposition 3. If inventions have a sufficiently high quality $k>\bar{k}(e)$, consumers will prefer the ND-policy over the D-policy, $C S^{N D-D}>0$.

Proof. First, note that $k>\bar{k}(e)$ implies that $n(i)=n(e)$ from Definitions 2 and 3 and, hence, $C S(i)=C S(e)$, since no market power effect then arises from the acquisition. The higher entrepreneurial research effort under the ND policy $\rho_{E}^{*}(i)>\rho_{E}^{*}(e)$ then implies $C S^{N D-D}>0$ for $k>\bar{k}(e)$

Thus, preemptive incumbents' acquisitions may benefit consumers by giving entrepreneurs stronger incentives to succeed with high-quality inventions. For inventions of lower quality $k<\bar{k}(e)$, the market power effect may dominate the higher probability of a successful invention.

Let us conclude this argument with a brief remark on how the total surplus is affected by policy. It directly follows that the entrepreneur gains from the ND-policy, since the bidding competition may give premium reward to successful invention. ${ }^{15}$ What about incumbents? Let $\pi_{N}(0)$ denote the profit for incumbents absent the invention. From Lemma 1, we can then derive the difference in expected incumbents' profits from the two polices:

$$
P S^{N D-D}=\left\{\begin{array}{l}
0, \text { for I5,I6 } \\
\rho^{*}(e)\{n\{\underbrace{\lambda(i)\left[\pi_{N}(i)-\tau\right]-\lambda(e)\left[\pi_{N}(e)-\tau\right]}_{>0}\}+\underbrace{v_{i i}-v_{e}}_{<0}\}, \text { for I4 } \\
\{\underbrace{\rho^{*}(e)-\rho^{*}(i)}_{<0}\} \pi_{N}(0)+n\{\underbrace{\rho^{*}(i) \lambda(i)\left[\pi_{N}(i)-\tau\right]-\rho^{*}(e) \lambda(e)\left[\pi_{N}(e)-\tau\right]}_{>0}\}, \text { I1-I3. }
\end{array}\right.
$$

\footnotetext{
${ }^{15}$ To see this, define the reduced-form entrepreneurial profit as $\Pi_{E}(l)=\rho^{*}(l) R_{E}(l)-y\left(\rho^{*}(l)\right)$. Since $R_{E}^{N D}(l)=R_{E}^{D}=v_{e}$ under I4, I5 or I6 in Table 3.1, whereas $R_{E}^{N D}(l)=S^{*}=v_{i i}>R_{E}^{D}=v_{e}, \Pi_{E}^{N D}(l) \geq$ $\Pi_{E}^{D}(l)$.
} 
Expression (4.7) reveals incumbents' preference for a particular policy is ambiguous. For instance, under preemptive acquisitions, when one of the inequalities I1-I3 in Table 3.1 is fulfilled, there is a larger expected loss of ex ante rents due to higher research efforts under the ND policy (as shown by the first term in the third line). But, given the circumstance the entrepreneur succeeds, which occurs with probability $\rho^{*}(l)$, the expected profit is higher under the ND-policy. This is because incumbents gain either from a higher concentration by avoiding entry, or by avoiding a less uncertain position as a non-acquirer (as shown by the second term in the third line).

\section{Empirical analysis}

We now turn to the empirical analysis. We first derive a probit model from the entrepreneur's decision on the mode of commercialization in stage 2 , which is then estimated on a unique dataset reporting patents granted to Swedish small firms and individual inventors.

\subsection{Deriving an estimation equation for the mode of commercialization}

To determine if the model is consistent with the data, and with preemptive acquisitions in particular, we will estimate the entrepreneur's choice of commercialization in Stage 2. Then, let $R_{e, m}$ be the reward for an entrepreneur $e$ choosing commercialization mode $m=$ (Sale, Entry), consisting of the reward $R_{E, m}\left(k_{e}, \tau_{e}, \Gamma_{e}, G_{e}\right)$ given from Lemma 1 and a stochastic term $\varepsilon_{e, m}$, i.e.

$$
R_{e, m}=R_{E, m}\left(k_{e}, \tau_{e}, \Gamma_{e}, G_{e}\right)+\varepsilon_{e, m}, \quad m=(\text { Sale }, \text { Entry })
$$

where $\varepsilon_{e, m}$ captures idiosyncractic factors affecting entrepreneur $e$ 's choice of commercialization not captured in the theory. In what follows, we assume that the entrepreneur knows $R_{e, m}$ and its components, while the error term is unknown to the econometrician.

To proceed, we linearize $R_{E, m}\left(k_{e}, \tau_{e}, \Gamma_{e}, G_{e}\right)$ in its components. Noting that $R_{E, E n t r y}\left(k_{e}, \tau_{e}, \Gamma_{e}, G_{e}\right)=$ $v_{e}$ under entry, whereas $R_{E, \text { Sale }}\left(k_{e}, \tau_{e}, \Gamma_{e}, G_{e}\right)=S^{*}$ under sale, we have:

$$
\begin{gathered}
R_{E, \text { Entry }}\left(k_{e}, \tau_{e}, \Gamma_{e}, G_{e}\right) \approx \alpha_{0}+\underset{(+)}{\alpha_{k}} k_{e}+\underset{(-)}{\alpha_{G}} G_{e}+\underset{(0)}{\alpha_{\Gamma} \Gamma_{e}+\underset{(-)}{\alpha_{\tau}} \tau_{e}=\mathbf{x}_{e}^{\prime} \boldsymbol{\alpha}} \\
R_{E, \text { Sale }}\left(k_{e}, \tau_{e}, \Gamma_{e}, G_{e}\right) \approx \beta_{0}+\beta_{k} k_{e}+\beta_{G} G_{e}+\beta_{\Gamma} \Gamma_{e}+\beta_{\tau} \tau_{e}=\mathbf{x}_{e}^{\prime} \boldsymbol{\beta} .
\end{gathered}
$$

To identify preemptive acquisitions in the data, we proceed as follows. First, note that the signs in (5.2) directly follow from (3.7) and Definition 1. In (5.3), we note that when an entry-deterring acquisition takes place, $S^{*}=v_{e}$, and $\boldsymbol{\beta}=\boldsymbol{\alpha}$. In contrast, when an acquisition is preemptive, the bidding competition between incumbents drives up the the acquisition price to $S^{*}=v_{i i}>v_{e}$, which implies $\boldsymbol{\beta} \neq \boldsymbol{\alpha}$. To see this, first note that (4.4) implies $\beta_{k}-\alpha_{k}>0$, which is illustrated in Figure 4.3(iii) where the reward-locus under sale and bidding competition, $R_{E}=v_{i i}$, is steeper in quality $k$ than the corresponding reward under innovation for entry, $R_{E}=v_{e}$. Then, note that (3.5) and (3.7) directly imply $\beta_{G}-\alpha_{G}>0, \beta_{\Gamma}-\alpha_{\Gamma}<0$ and $\beta_{\tau}-\alpha_{\tau}>0$.

Using (5.1)-(5.3), we can now write down the probability that the entrepreneur will choose 
commercialization by sale as:

$$
\begin{aligned}
\operatorname{Prob}\left[\text { Sale }_{e}\right] & =\operatorname{Prob}\left[R_{e, \text { Sale }}>R_{e, \text { Entry }}\right]=\operatorname{Prob}\left[\varepsilon_{e, \text { Entry }}-\varepsilon_{e, \text { Sale }}<\mathbf{x}_{e}^{\prime}(\boldsymbol{\beta}-\boldsymbol{\alpha})\right] \\
& =\operatorname{Prob}\left[\varepsilon_{e}<\mathbf{x}_{e}^{\prime} \boldsymbol{\gamma}\right]=\int_{-\infty}^{\mathbf{x}_{e}^{\prime} \boldsymbol{\gamma}} f\left(\varepsilon_{e}\right) d \varepsilon_{e}=F\left(\mathbf{X}_{e}^{\prime} \boldsymbol{\gamma}\right),
\end{aligned}
$$

where $\boldsymbol{\gamma}=\boldsymbol{\beta}-\boldsymbol{\alpha}$ and $f\left(\varepsilon_{e}\right)$ is the density of the error term, $\varepsilon_{e}=\varepsilon_{e, \text { Entry }}-\varepsilon_{e, \text { Sale. }}$. If $\varepsilon_{e, m}$ is distributed according to the Gumbel distribution, then $\varepsilon_{e}$ will be distributed according to the logistic distribution and $F\left(\mathbf{x}_{e}^{\prime} \gamma\right)=\Lambda\left(\mathbf{x}_{e}^{\prime} \gamma\right)$, where $\Lambda(\cdot)$ is the cumulative density function of the logistic distribution. When $\varepsilon_{e, m}$ are mean-zero normally distributed, $\varepsilon_{e}$ will also be normally distributed and $F\left(\mathbf{x}_{e}^{\prime} \gamma\right)=\Phi\left(\mathbf{x}_{e}^{\prime} \gamma\right)$, where $\Phi(\cdot)$ is the cumulative density function of the normal distribution. In either case, parameters $\gamma$ can be estimated by maximizing the likelihood function:

$$
\mathcal{L}=\prod_{e} F\left(\mathbf{x}_{e}^{\prime} \gamma\right)^{m_{e}} F\left(1-\mathbf{x}_{e}^{\prime} \gamma\right)^{1-m_{e}},
$$

where $m_{e}=1$ when commercialization by sale is chosen, and $m_{e}=0$ when commercialization by entry is chosen.

Thus, using the fact that $\boldsymbol{\gamma}=\boldsymbol{\beta}-\boldsymbol{\alpha}$ in (5.4), we can derive a testable hypothesis on the nature of incumbent acquisitions from our proposed model. We have the following proposition:

Proposition 4. Suppose that Assumption A1 holds. Then:

(i) If commercialization by sale takes place by entry-deterring acquisitions at $S^{*}=v_{e}$, then $\boldsymbol{\gamma}=\mathbf{0}$, or equivalently, $\boldsymbol{\beta}=\boldsymbol{\alpha}$.

(ii) If commercialization by sale takes place by preemptive acquisitions at $S^{*}=v_{i i}>v_{e}$, $\boldsymbol{\gamma} \neq \mathbf{0}$, or equivalently, $\boldsymbol{\beta} \neq \boldsymbol{\alpha}$. More specifically, $\gamma_{k}=\beta_{k}-\alpha_{k}>0, \gamma_{G}=\beta_{G}-\alpha_{G}>0$, $\gamma_{\Gamma}=\beta_{\Gamma}-\alpha_{\Gamma}<0$ and $\gamma_{\tau}=\beta_{\tau}-\alpha_{\tau}>0$.

If there are no preemptive acquisitions, the entrepreneur will only receive his reservation price, both when entry or entry-deterring acquisition occurs. In the case of preemptive acquisition, the reward will be higher due to bidding competition. Thus, if we can reject that the reward functions for sale and entry are equal, $\gamma=\mathbf{0}$, then the first condition for evidence of preemptive bidding competition is fulfilled. The second condition that must be fulfilled is that the individual parameters $\left(\gamma_{k}=\beta_{k}-\alpha_{k}>0, \gamma_{G}=\beta_{G}-\alpha_{G}>0, \gamma_{\Gamma}=\beta_{\Gamma}-\alpha_{\Gamma}<0\right.$ and $\gamma_{\tau}=\beta_{\tau}-\alpha_{\tau}>0$ ) must have the correct sign. In terms of Figure 4.2(iii), Proposition 4(ii) implies that incumbent acquisitions take place in the dark-shaded area where acquisitions are preemptive at $S^{*}=v_{i i}$, whereas Proposition 4(i) would correspond to acquisitions taking place in the light-shaded area, where acquisitions are entry-deterring at $S^{*}=v_{e}$. Rejecting our proposed theory on the mode of commercialization of entrepreneurial inventions requires $\gamma \neq \mathbf{0}$, as well as a reversal of all signs in Proposition 4(ii).

\subsection{Data}

To estimate (5.4), we will use a dataset on patents granted to small firms (less than 200 employees) and individual inventors. Most reported sales in the data involved large incumbent 
acquirers. The dataset is based on a survey of Swedish patents granted in $1998 .^{16}$ In that year, 1082 patents were granted to Swedish small firms and individuals. ${ }^{17}$ Information about inventors, applying firms, their addresses and the application date for each patent was obtained from the Swedish Patent and Registration Office (PRV). Thereafter, a questionnaire was sent out to the inventors of the patents in 2004. ${ }^{18}$ They were asked where the invention was created, if and when the invention had been commercialized, which mode of commercialization was chosen, type of financing, etc. 867 out of 1082 inventors filled out and returned the questionnaire, i.e., the response rate was 80 percent. The falling off was not systematic. ${ }^{19}$ The survey data set was complemented with data on forward citations from www.espacenet.com.

From the theory, we are interested in those patents where the inventors can decide themselves whether to commercialize the patent. ${ }^{20}$ Therefore, we begin the analysis by considering the 624 patents where the inventors have some ownership. 364 of these 624 patents were commercialized, that is, a product based on the patent was introduced in the market. ${ }^{21}$ Among the 364 commercialized patents, 91 patents were commercialized by selling or licensing the patent, while 273 were commercialized through entry. Since the mode of commercialization is chosen from maximizing the reward or income from an innovation, $R_{E}$ in (5.1), we will use commercialized patents when estimating (5.4). The potential problems arising from 260 out of 624 patents in the sample not being commercialized will be dealt with in Section 6.2, where we extend the theory and empirical analysis to also include the decision not to commercialize.

\footnotetext{
${ }^{16}$ A further description of the data can be found at http://www.ifn.se/web/Databases_9.aspx and in Svensson (2007).

${ }^{17}$ In 1998, 2760 patents were granted in Sweden. 776 of these were granted to foreign firms, 902 to large Swedish firms with more than 1000 employees, and 1082 to Swedish individuals and firms with less than 1000 employees. In a pilot survey carried out in 2002, it turned out that large Swedish firms refused to provide information on individual patents. Furthermore, it is impossible to persuade foreign firms to fill out questionnaires about patents. The majority of these foreign firms are large multinationals.

${ }^{18}$ Each patent always has at least one inventor and often an applying firm. The inventors or the applying firm can be the owner of the patent, but the inventors can also indirectly be owners of the patent, via the applying firm. Sometimes, the inventors are only employed in the applying firm which owns the patent. If the patent had several inventors, the questionnaire was sent to one inventor only.

${ }^{19}$ The falling off was due to $10 \%$ of the inventors having old addresses, $5 \%$ having correct addresses but we did not get any contact with the inventors and $5 \%$ refusing to reply. The only information we have about the non-respondents is the IPC-class of the patent and the region of the inventors. For these variables, there was no systematic difference between respondents and non-respondents.

${ }^{20}$ We also undertake estimations where the entrepreneurial firm has less than 100 employees, irrespective of inventor ownership. This give us a sample 454 commercialized patents. The results remain unchanged for this different sample. See the Appendix.

${ }^{21}$ The commercialization rate for our sample is 58 percent. This rate should be compared to the few available studies which have measured the commercialization of patents: 47 percent for American patents found by Morgan, Kruytbosch and Kannankutty (2001) and 55 percent in the studies surveyed by Griliches (1990). The higher commercialization rate in the present study is explained by the fact that only patents directly or indirectly owned by the inventors are included - large (multinational) firms have a much larger number of defensive patents. Griliches (1990) confirms this view and reports the commercialization rate is 71 percent for small firms and inventors.
} 


\subsubsection{Dependent variable: mode of commercialization}

As the dependent variable in (5.4), we thus define a binary variable Sale taking the value of one if the patent was sold or licensed to another firm, and zero if the patent was commercialized internally by the inventor. Note that a sale of an invention and an exclusive licence of an invention are equivalent in our theory. Since the licensing contracts are almost only exclusive in the data, we treat licence contracts and sales as symmetric in the empirical analysis. Note that 30 of the 91 patents which are sold are first commercialized by entry and thereafter sold. These patents are treated as commercialisation by sale. In section 7, we also extend the theory and empirical analysis to explain these late sales. In general, the buyers/licensees of the patents are considerably larger firms than the seller/licensor in the data set.

\subsubsection{Measuring the quality of an invention, $k$}

The explanatory variables used in estimating (5.4) and their expected signs are given in Table 5.1. The main variable of interest is the quality of an invention, $k$. To measure $k$, we use the number of forward citations (excluding self-citations) that a patent had received from the application date until November 2007. With patents having different application years, the length of the time periods they can be cited differs. Therefore, in our estimations, we adjust our citation variable so that they measure the number of forward citations in a five-year period. ${ }^{22}$

Forward citations are seen as the most important quality indicator of patents in the literature (Harhoff et al., 1999; Lanjouw and Schankerman, 1999; Hall, Jaffe and Trajtenberg., 2005). The basic idea for why forward citation measure inherent quality is that competitors in an industry undertake $R \& D$ with similar type objectives. When rival firms or other entrepreneurs discover new inventions they will need to patent them in order to protect them. When applying for patent protection, inventors will need to cite important previous inventions which either is in the process of applying for patent protection, or have approved patent protection.

A previous high quality invention in a certain industry will be relatively more important for the performance in that industry. For example, a high-quality drug patent, which largely affects competitors' profit flows, should have more citations from future patents of drugs than from say patents of semi-conductors. We therefore divide forward citations into two groups: (i) forward citations where the cited and citing patents have at least one common technology class at the four-digit ISIC-level, denoted as $W_{-} C I T$; and (ii) forward citations where they have no common technology class at the four digit ISIC-level, denoted as B_CIT. Proposition 4(ii) implies that if incumbent acquisitions are driven by preemptive motives, we would expect $\gamma_{k}=\beta_{k}-\alpha_{k}>0$. The quality of the invention $k$ driving the strategic incentives for the commercialization mode identified in our theory should then be reflected in obtaining a positive estimate on $W_{-} C I T$ rather than for $B \_C I T$.

The 624 patents in the sample together have 632 forward citations within technologies and 81 between technologies. In Table 5.2, the relationship between commercialization mode and forward citations within technologies ( $\left.W_{-} C I T\right)$ is shown. Most patents (64 percent) have no

\footnotetext{
${ }^{22}$ Here, we follow the approach of Trajtenberg (1990) and weight the number of received patent citations by a linear time trend.
} 


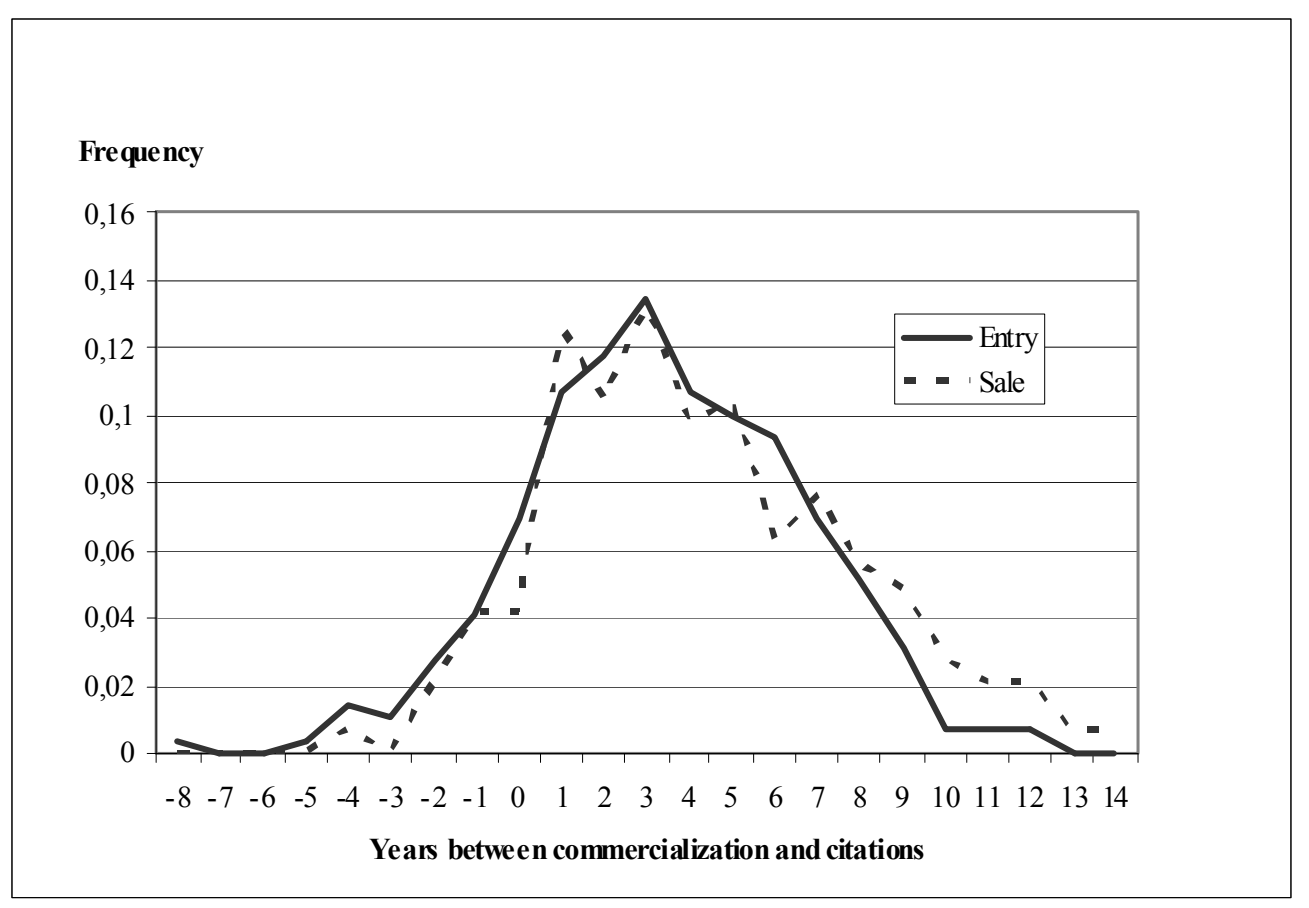

Figure 5.1: The distribution of forward citations around the year of commersialization.

forward citations at all, and cited patents seldom have more than three citations. Among noncommercialized patents, only 28 percent are cited, whereas 40 and 46 percent of the entry and sale patents, respectively, are cited. In line with the theory, we note that patents commercialized through sale have a higher average number of forward citations than patents which are commercialized through entry, although the difference is not statistically significant using a simple t-test. Since the distribution of forward citations are skewed to the right, we also transform the citation variables $W_{-} C I T$ and $B_{-} C I T$ into binary variables, $D \_W \_C I T$ and $D_{-} B_{-} C I T$, thereby indicating whether a patent received a citation.

\subsubsection{Endogeneity of forward citations}

A potential concern in identifying the effect of higher quality on the mode of commercialization in equation (5.4) is reverse causality. Since many forward citations in general occur after the patents have been commercialized, forward citations may, in principle, be influenced by the commercialization mode of the patent.

However, if the commercialization mode affects forward citation, we should expect the time pattern of forward citations to differ across commercialization modes. Figure 5.1 shows the time path of forward citations as measured around the commercialization year for patents commercialized by entry and sale. These distributions are remarkably similar. Irrespective of commercialization mode, citations reach a peak two to three years after commercialization and then taper off. A simple Chi-square test cannot reject the null-hypothesis of similarity between the two distributions. ${ }^{23}$

So why does the commercialization mode not affect patent citations? At first sight, one

\footnotetext{
${ }^{23}$ A grouped chi-square test equals 6.7 (5 d.f.).
} 


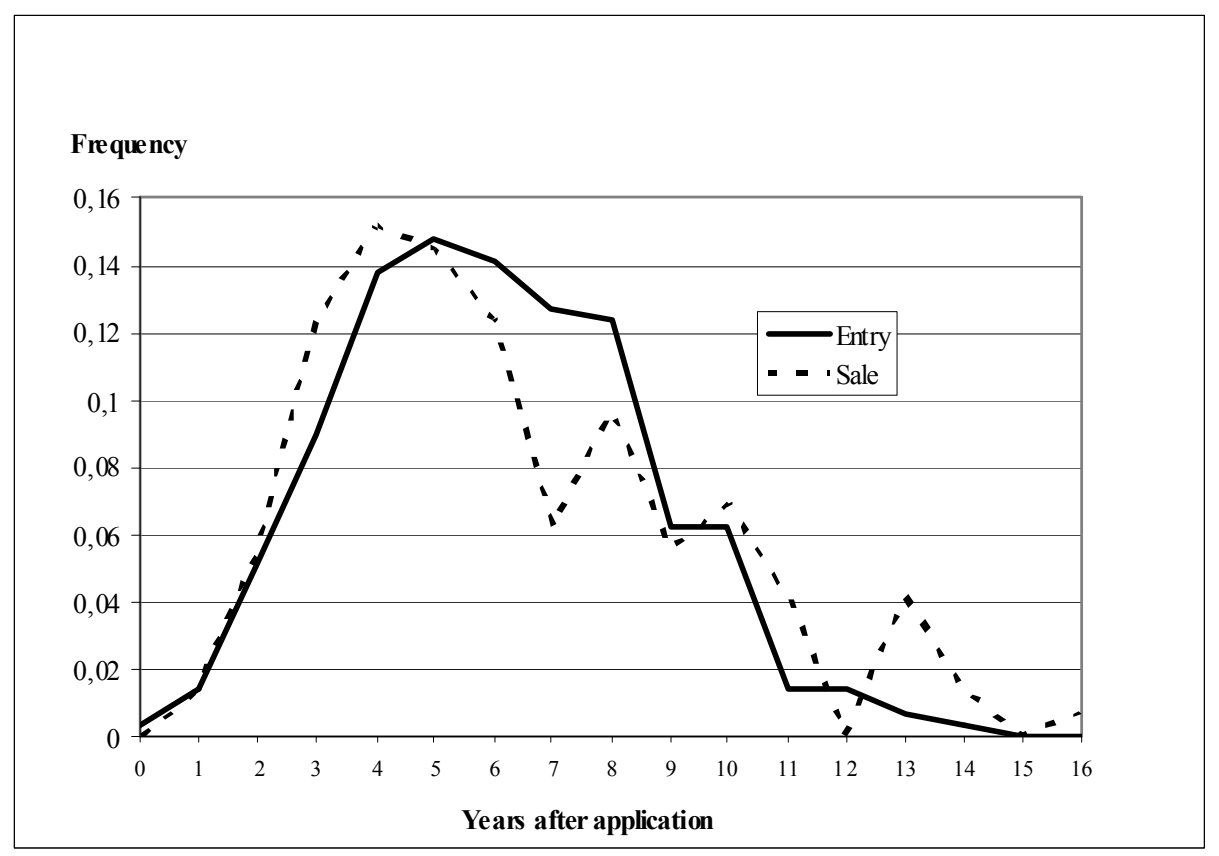

Figure 5.2: The distribution of forward citations around the year of application.

might believe that the commercialization mode should affect the information set of potential citers. For instance, a sale to a well-known incumbent might make the patent more visible. However, the way the patent institutions are set up implies that forward citations should be exogenous to the mode of commercialization. The examiners at the patent office are unlikely to be aware of the commercialization status of a given patent - what patent officers keep track of are previously approved patents. Indeed, as pointed out by Hall et al (2005), although the applicants may or may not cite relevant patents in the application, the final decision regarding what patents are cited in the US is made by the examiner at the patent office. This institutional framework also applies in Europe (and Sweden) where the decision to cite is solely with the patent examiners at the EPO or the national patent offices.

The act of commercialization may not even reveal significant new information about the existence of the patent. Both in Europe and the U.S., information about patent applications becomes publicly available 18 months after the application date. Thus, even before the patent is granted, rival firms and inventors can directly source information about the new invention. The patent application becomes searchable in large databases such as Espacenet. In addition, there exists a large number of firms that specialize in keeping firms and inventors updated about patent development within their field.

If subsequent patents are applied as a response to the disclosure of the original patent, such applications should start 18 months after the application date of the original patent (when the information becomes publicly available). In Figure 5.2, we examine the time pattern of citations measured from the application date. Note that there is indeed a strong increase in the number of citations after two years, as would be expected. Once more, we also see a very similar pattern of citations between commercialization by sale and entry. Also in this case, a Chi-square test cannot reject the hypothesis that the distributions are similar. 
Consequently, we conclude that the way in which patent institutions are set up implies that we do not face a problem of reverse causality, i.e. the commercialization mode does not affect forward patent citations.

\subsubsection{Other Explanatory variables}

Entry costs, $G$ To measure the costs of commercialization under entry $G$, we use additive dummies for different firm sizes. Firms which already have marketing, manufacturing and financial resources in-house should have lower costs of entering the market with a new product, $G$. We define the variable $S M A L L$ taking on the value of 1 for firms with 11-200 employees, and 0 otherwise, and $M I C R O$ equals 1 for micro companies with 2-10 employees, and 0 otherwise. Entrepreneurial firms with either of these characteristics should face lower entry costs than the reference group of inventors without any employees. Proposition 4(ii) implies that if incumbent acquisitions are driven by preemptive motives, we would expect $\gamma_{G}=\beta_{G}-\alpha_{G}>0$. Since larger

firms should face lower entry costs $G$, we predict that $\gamma_{G_{\text {Micro }}}<0$ and $\gamma_{G_{\text {Small }}}<0$, lower entry cost leads to lower probability of entry. In Table 5.3, the commercialization mode rates are shown for different firm sizes. Commercialization by sale is more frequent the smaller the firm size, whereas entry is more frequent the larger the firm, which is consistent with Proposition 4 (ii).

Transaction costs, $\Gamma$ As a measure of transaction costs we use the variable $P V C$, the percentage of the R\&D-stage that was financed by private venture capitalists or business angels. Gans, Hsu and Stern (2002) find evidence that the involvement of private venture capitalists increased the probability of commercialization by sale. They argue that such agents participate in networks with firms, thereby decreasing the search and transaction costs associated with finding an external buyer. Thus, if a stronger participation of venture capitalists in the commercialization process reduces the transaction costs $\Gamma$, it follows from Proposition 4 that preemptive acquisitions by incumbents of entrepreneurial innovations imply $\gamma_{\Gamma_{P V C}}>0$.

Operational fixed costs, $\tau$ We do not have any measure of fixed operation costs, $\tau$. Instead we use additive dummies (fixed effects) for technologies and regions as well as a trend variable for the application year, broadly controlling for unobservable technology-, region- and time-specific factors. Patents are divided into technology groups based on the patents' main IPC-Class, according to Breschi, Lissoni and Malerba (2004). The data is also divided into six different regions. Five additive dummies are included for these six groups in the estimations. A trend variable $A P P L Y$ is also included, measuring the application year.

\subsection{Results}

The results of estimating the probit model (5.4) are shown in Table 5.4. Let us first examine if these results are consistent with preemptive acquisitions by incumbents. We start with specification A containing the core variables from the theory, W_CIT, PVC, SMALL and MICRO, as well as fixed effects for technologies and regions. The Wald test on the core variables shows that $\boldsymbol{\gamma}=\mathbf{0}$ in (5.4) or, equivalently, $\boldsymbol{\beta}=\boldsymbol{\alpha}$ is rejected. The individual parameters $\left(\gamma_{k}, \gamma_{\Gamma}\right.$ and 
$\left.\gamma_{G}\right)$ also have the correct signs. This is also the case in the Wald test on the full specification of specification A. Thus, the reward functions for sale and entry are significantly different from each other and there is evidence of preemptive acquisitions of entrepreneurial inventions.

Next, we turn to individual estimates. A higher quality of the invention as measured by more forward citations ( $W_{-} C I T$ ) increases the probability of an invention being commercialized by sale to incumbents. On the other hand, presence in the market as measured by either being a small or a micro firm (SMALL and MICRO) decreases the probability of sale. All of these variables are statistically significant. The estimated coefficient of $P V C$ has the correct sign, but is not significant. Since we can reject $\boldsymbol{\gamma}=\mathbf{0}$ and since the coefficients of the core variables are consistent with $\gamma_{k}=\beta_{k}-\alpha_{k}>0, \gamma_{\Gamma}=\beta_{\Gamma}-\alpha_{\Gamma}<0$ and $\gamma_{G}=\beta_{G}-\alpha_{G}>0$, Proposition 4(ii) implies that the estimates identify incumbent acquisition as being preemptive in nature. ${ }^{24}$

In specifications $\mathrm{B}$ and $\mathrm{C}$ we add citations between technologies, $B_{-} C I T$, and the application year $A P P L Y$, without qualitative changes in results. The Wald tests and individual estimates are again consistent with Proposition 4(ii). Calculating marginal effects shows that if a patent receives one more forward citation during a five-year period, the probability of sale increases by about five percentage points in specifications A-C. If the inventor has a small firm as compared to the case where she has no firm, the probability of sale decreases by around 20 percentage points.

We reestimate (5.4) with the citation dummies $D \_W \_C I T$ and $D \_B \_C I T$, indicating whether a patent received any citations or not. These results are shown in Table 5.5. The Wald tests again reject $\boldsymbol{\gamma}=\mathbf{0}$, whereas the results for individual estimates are consistent with $\gamma_{k}=\beta_{k}-\alpha_{k}>0$, $\gamma_{\Gamma}=\beta_{\Gamma}-\alpha_{\Gamma}<0$ and $\gamma_{G}=\beta_{G}-\alpha_{G}>0$. Once more, the results are thus consistent with Proposition 4(ii) that there are preemptive acquisitions, albeit some estimates are less significant.

Additional specifications We also re-estimate Table 5.4 with logit and OLS specifications without finding any qualitative changes in the results (see Appendix Tables A1 and A2). The results are also unaffected by adding a number of control variables such as the share of ownership in the entrepreneurial firms held by the inventor, notwithstanding if the inventor had complementary patents or more patents, individual characteristic of the inventor such a sex, or whether the patent was applied in research at a university (Appendix Table A3).

Broadening the sample We then re-estimate Table 5.4 with an extended sample. An objection against the sample could be that the potential buyer/licensee does not care whether the inventor is the owner of the patent or not. Instead of using the sample of patents owned by inventors, there is an alternative sample to use when estimating the models - all patents owned by individuals or firms with less than 100 employees. This implies that the entrepreneur will be small compared to the incumbent firms, as assumed in the theoretical model. Such a sample has 751 patents, of which 449 are commercialized. Among these, 99 patents are commercialized by sale and 350 by entry.

\footnotetext{
${ }^{24}$ The exception is $\gamma_{\tau}=\beta_{\tau}-\alpha_{\tau}=0$ since we have no direct measure of operating fixed costs, $\tau$. The impact of $\tau$ is indirectly estimated through the Wald test on $\gamma=\beta-\alpha=0$, where the impact of $\tau$ is (imprecisely) accounted for in the technology and region-fixed effects.
} 
In Appendix Table A4, the Probit model is estimated for the new sample. This gives approximately the same result as in Table 5.4. The Wald tests show that there is evidence of preemptive acquisitions in the market for entrepreneurial inventions, and the quality of the invention $(k)$ and the entry costs $(G)$ have significant impacts on the commercialization mode.

\section{Robustness}

Our theory predicts that high quality inventions are sold to incumbents under bidding competition. From the theory we have derived an estimation equation which can be used to identify bidding competition among incumbents. Using a unique data set of commercialization of entrepreneurial inventions, we have also shown that commercialization by sale occurs under bidding competition. In this section, we examine the robustness of these results. We relax assumptions made in the theoretical model. We also present new empirical results based on the extensions.

\subsection{Entry is not "market-neutral" (no exit and multi-firm exit)}

No exit Assumption A1 implies that entry by the entrepreneur does not affect the equilibrium number of firms in the product market. Formally, we have assumed that the quality of the invention is medium high, $k \in \bar{k}(i), \bar{k}(e))$. Let us now assume $k \in(0, \bar{k}(i)$. As illustrated in Figure 4.1(iii), from Definition 2 this implies that entry by the entrepreneur does not lead to exits by incumbents. Assuming that entry is profitable $\pi_{E}(e)-\tau>G$, entry then reduces market concentration, as the number of firms in the market fulfils $N(e)=n+1>N(i)=n$.

Assumption A1 is not needed for our results. Using a standard work horse Cournot model, where the innovation decreases marginal cost, and where entry or sale does not trigger exit, we showed in Section 2 that (i) entrepreneurs sell their best inventions (Proposition 1) and (ii) the sale of their very best innovations increase innovation incentives through a high sales premium (Proposition 2).

To show that entrepreneurs still sell their best inventions (Proposition 1) and that our identification strategy for preemptive acquisitions remains valid (Proposition 4) in a more general setting than the Cournot model we need to ensure that the net value of an incumbent acquisition $v_{i l}-v_{e}$ is increasing the quality of the invention, $k$. Differentiate the ED- and PE-condition $v_{i l}=v_{i i}$ in entry costs $G$ and quality of the invention $k$ to obtain:

$$
\frac{d G^{E D}}{d k}=\frac{v_{i e, k}^{\prime}-v_{e, k}^{\prime}}{v_{e, G}^{\prime}}, \quad \frac{d G^{P E}}{d k}=\frac{v_{i i, k}^{\prime}-v_{e, k}^{\prime}}{v_{e, G}^{\prime}}
$$

Consider the region in Figure 6.1(i), with combinations of quality $k$ and entry costs $G$ below the Entry-condition traced out by the locus of $G=\pi_{E}(e)-\tau$ where entry is just profitable, $v_{e}=0$ and above $G=0$ (the $k$-axis). Since $v_{e, G}^{\prime}<0,(6.1)$ reveals that when $v_{i l, k}^{\prime}-v_{e, k}^{\prime}>0$ holds the ED- and PE locuses are downward-sloping as shown in Figure 6.1(i), where the ED-locus is to the left of the PE-locus (since entry lowers incumbent profits, $\pi_{N A}(e)<\pi_{N A}(i)$ and hence $\left.v_{i e}>v_{i i}\right)$. Therefore, when $v_{i l, k}^{\prime}-v_{e, k}^{\prime}>0$ holds, higher quality inventions are commercialized by sale: first at the reservation price $S^{*}=v_{e}$ and at even higher quality under bidding competition, 
$S^{*}=v_{i i}$

Without exits of incumbents, $\lambda(l)=1$ in (4.1). Hence, $v_{i l, k}^{\prime}-v_{e, k}^{\prime}$ can be written:

$$
v_{i l, k}^{\prime}-v_{e, k}^{\prime}=\frac{d \pi_{A}(i)}{d k}-\frac{d \pi_{E}(e)}{d k}-\frac{d \pi_{N A}(l)}{d k}
$$

Assumption A1 of "market-neutral entry" implies $\frac{d \pi_{A}(i)}{d k}=\frac{d \pi_{E}(e)}{d k}$ and hence always fulfills $v_{i l, k}^{\prime}-v_{e, k}^{\prime}>0$. So, while Assumption A1 is very useful for the exposition, it is not necessary for our results. From (6.2), $v_{i l, k}^{\prime}-v_{e, k}^{\prime}>0$ may hold even if the effect of higher quality on the entry profit of the entrepreneur is stronger than the effect on the acquiring incumbent' profit (i.e. $\frac{d \pi_{A}(i)}{d k}-\frac{d \pi_{E}(e)}{d k}<0$ ), as long as this difference is not larger than the impact on a nonacquiring incumbent (i.e. $\frac{d \pi_{A}(i)}{d k}-\frac{d \pi_{E}(e)}{d k}>\frac{d \pi_{N A}(l)}{d k}<0$ ). In many oligopoly models, a larger incumbent acquirer (as compared to the entrant) may also have more to gain from increased quality (i.e. $\frac{d \pi_{A}(i)}{d k}>\frac{d \pi_{E}(e)}{d k}$ ) which directly gives $v_{i e, k}^{\prime}-v_{e, k}^{\prime}>0$.

In the remainder of this paper, we will use the following assumption. Define $\tilde{k}$ such that $v_{i l, k}^{\prime}=v_{e, k}^{\prime}$ holds. Then:

Assumption A2 $\frac{d \pi_{A}(i)}{d k}-\frac{d \pi_{E}(e)}{d k}>\frac{d \pi_{N A}(l)}{d k}<0$ for $k \in(0, \tilde{k})$, where $\tilde{k} \in\left(k^{P E}, \bar{k}(e)\right]$.

In Appendix 9.2, we show that Assumption A2 is fulfilled in the LC model in Example 1. Note that Assumption A2 directly implies that Proposition 1 is fulfilled, therefore Proposition 1 is fulfilled in the LC model without market neutral entry as shown in Section 2. Note also that Proposition 4(ii), $\gamma_{k}=\beta_{k}-\alpha_{k}>0$ that identifies bidding competition, is then a direct test of Assumption A2, since the latter implies $v_{i i, k}^{\prime}-v_{e, k}^{\prime}>0$ from (6.2). Note, finally, that if our data would predominantly consist of patents giving their owners (close to) product market monopoly, $k>\tilde{k}$, we would have $v_{i i, k}^{\prime}-v_{e, k}^{\prime}<0$ and $\gamma_{k}=\beta_{k}-\alpha_{k}<0$ under bidding competition. ${ }^{25}$ This is, however, rejected by the data.

Thus, our empirical results in Table 5.4 identify bidding competition between incumbents under commercialization by sale in a setting where entry is not "market neutral" and where product markets remain sufficiently competitive after commercialization.

Multiple exits What would happen if inventions have such high quality that multiple exits of incumbents occur when the invention is commercialized? Let us still examine what happens when the innovation approaches $k=\bar{k}(i)$ in Figure 4.1(i). As shown in the figure, $\pi_{A}(i)=\pi_{E}(e)$ and hence $v_{i l}-v_{e}=G-\Gamma-\lambda(\mathrm{l})\left[\pi_{N A}(l)-\tau\right]$. It is not straightforward to differentiate $v_{i l}-v_{e}$ in $k$ because profits $\pi_{h}(l)$ and the probability $\lambda(l)$ will exhibit discontinuous jumps when exits of incumbents occur. In particular, note that $\pi_{N A}(l)$ will "jump up" at $\bar{k}(i)$ which violates Definition 1(iii). In the Linear Cournot model, it can be shown that the exit of an incumbent at $\bar{k}(i)$ will discretely increase $\pi_{N A}(l)$ more than $\lambda(1)$. A marginal increase in $k$ then switches the equilibrium from commercialization by sale under bidding competition to commercialization by entry. However, increasing quality additionally (without further exits) will give rise to entrydeterring acquisitions, and at even higher quality commercialization by sale under bidding

\footnotetext{
${ }^{25}$ This can be shown in the LC model.
} 
competition will occur ${ }^{26}$. Note that Proposition 4(ii), $\gamma_{k}=\beta_{k}-\alpha_{k}>0$, can still be used to identify bidding competition in commercialization by sale since the latter is yet again a direct test of Assumption A2, which in discrete changes becomes $\Delta v_{i l}-\Delta v_{e}>0$. We should then note that our estimates in Table 5.4 reject the hypothesis that higher concentration induced by exits of incumbents makes commercialization by entry more likely at higher innovation quality, $\gamma_{k}=\beta_{k}-\alpha_{k}<0$.

The equilibrium mode of commercialization and the reward to innovation when allowing for non-commersialization.

\subsection{All patents are not commercialized}

We have assumed that the entrepreneur can always commercialize through entry. In contrast, 260 of the 624 patents in our data were not commercialized How would our results change if we were to include non-commercialized patents in the model?

Consider the region in Figure 6.1(i) above the entry condition where $G>\pi_{E}(e)-\tau$. In this region, the ED-condition becomes $v_{i e}\left(k_{0}^{E D}\right)=0$ and $v_{i e}\left(k_{0}^{P E}\right)=0$ since $v_{e}=0$ (the entrepreneur cannot enter). The ED-locus is the vertical line at $k_{0}^{E D}$, whereas the PE-locus is the vertical locus at $k_{0}^{P E}$, where $k_{0}^{E D}<k_{0}^{P E}$. Note that inventions of lower quality than $k_{0}^{E D}$ (associated with entry costs $\left.G>\pi_{E}(e)-\tau\right)$ will never be commercialized.

It is now straightforward to extend the empirical analysis and the identification of preemptive acquisitions in Proposition 1 to take into account that some inventions are not commercialized. This is illustrated in Figure 6.1(iii) which shows the reward to commercialization for a given level of entry costs $\tilde{G}$. Note that there is no commercialization for very low qualities $k<$ $k^{N o}$, where $\tilde{G}=\pi_{E}\left(e: k^{N o}\right)$. The reward to commercialisation is then zero, $R_{E}=0$. Let $R_{e, N o}(k, \tau, \Gamma, G)=R_{E, N o}\left(k_{e}, \tau_{e}, \Gamma_{e}, G_{e}\right)+\varepsilon_{e, N o}$ be the reward for "No commercialization". $R_{E, N o}\left(k_{e}, \tau_{e}, \Gamma_{e}, G_{e}\right)=0$ can be (trivially) linearized in its arguments to get:

$$
R_{e, N o}\left(k_{e}, \tau_{e}, T_{e}, G_{e}\right)=\underset{(0)}{\psi_{0}}+\underset{(0)}{\psi_{k}} k_{r}+\underset{(0)}{\psi_{F}} F_{r}+\underset{(0)}{\psi_{T}} \Gamma_{r}=\mathbf{x}_{e}^{\prime} \boldsymbol{\psi}
$$

Let $m, l=($ Sale, Entry, No). The probability that the entrepreneur will choose commercialization mode $m$ instead of commercialization mode $l$ is then $\operatorname{Prob}\left[m_{e}\right]=\operatorname{Prob}\left[R_{e, m}>R_{e, l}\right] \forall m \neq l$, or $\operatorname{Prob}\left[m_{e}\right]=\operatorname{Prob}\left[\varepsilon_{e, l}-\varepsilon_{e, m}<R_{E, m}(k, \tau, \Gamma, G)-R_{E, l}(k, \tau, \Gamma, G)\right] \forall m \neq l$. Assuming that $\varepsilon_{e, m}$ is distributed according to the Gumbel distribution, $\varepsilon_{e}=\varepsilon_{e, m}-\varepsilon_{e, l}$ will be distributed according to the logistic distribution. Under the assumption that $\varepsilon_{e, N o}, \varepsilon_{e, \text { Sale }}$ and $\varepsilon_{e, \text { Entry }}$ are not correlated, this gives rise to a multinomial logit model, where:

$$
\operatorname{Prob}\left[\text { Sale }_{e}\right]=\frac{e^{\mathbf{x}_{e}^{\prime} \boldsymbol{\beta}}}{e^{\mathbf{x}_{e}^{\prime} \boldsymbol{\beta}}+e^{\mathbf{x}_{e}^{\prime} \boldsymbol{\alpha}}+e^{\mathbf{x}_{e}^{\prime} \boldsymbol{\psi}}}, \quad \operatorname{Prob}\left[\text { Entry } y_{e}\right]=\frac{e^{\mathbf{x}_{e}^{\prime} \boldsymbol{\alpha}}}{e^{\mathbf{x}_{e}^{\prime} \boldsymbol{\beta}}+e^{\mathbf{x}_{e}^{\prime} \boldsymbol{\alpha}}+e^{\mathbf{x}_{e}^{\prime} \boldsymbol{\psi}}}
$$

Maximum Likelihood can now be used to estimate $\boldsymbol{\gamma}^{\text {Sale }}=\boldsymbol{\beta}-\boldsymbol{\psi}$ and $\boldsymbol{\gamma}^{\text {Entry }}=\boldsymbol{\alpha}-\boldsymbol{\psi}$, where

\footnotetext{
${ }^{26}$ This process is repeated until we enter the case of a drastic innovation. Let $\pi^{m}$ denote the monopoly profit where $\pi_{A}(i)=\pi_{E}(e)=\pi^{m}$ for $k=k^{m o n}$. The net value for of an acquisition from (4.1) is then $v_{i l}-v_{e}=G-\Gamma$ Hence, if the quality reaches $k=k^{\text {max }}$ there will be commercialization by sale if $G>\Gamma$.
} 


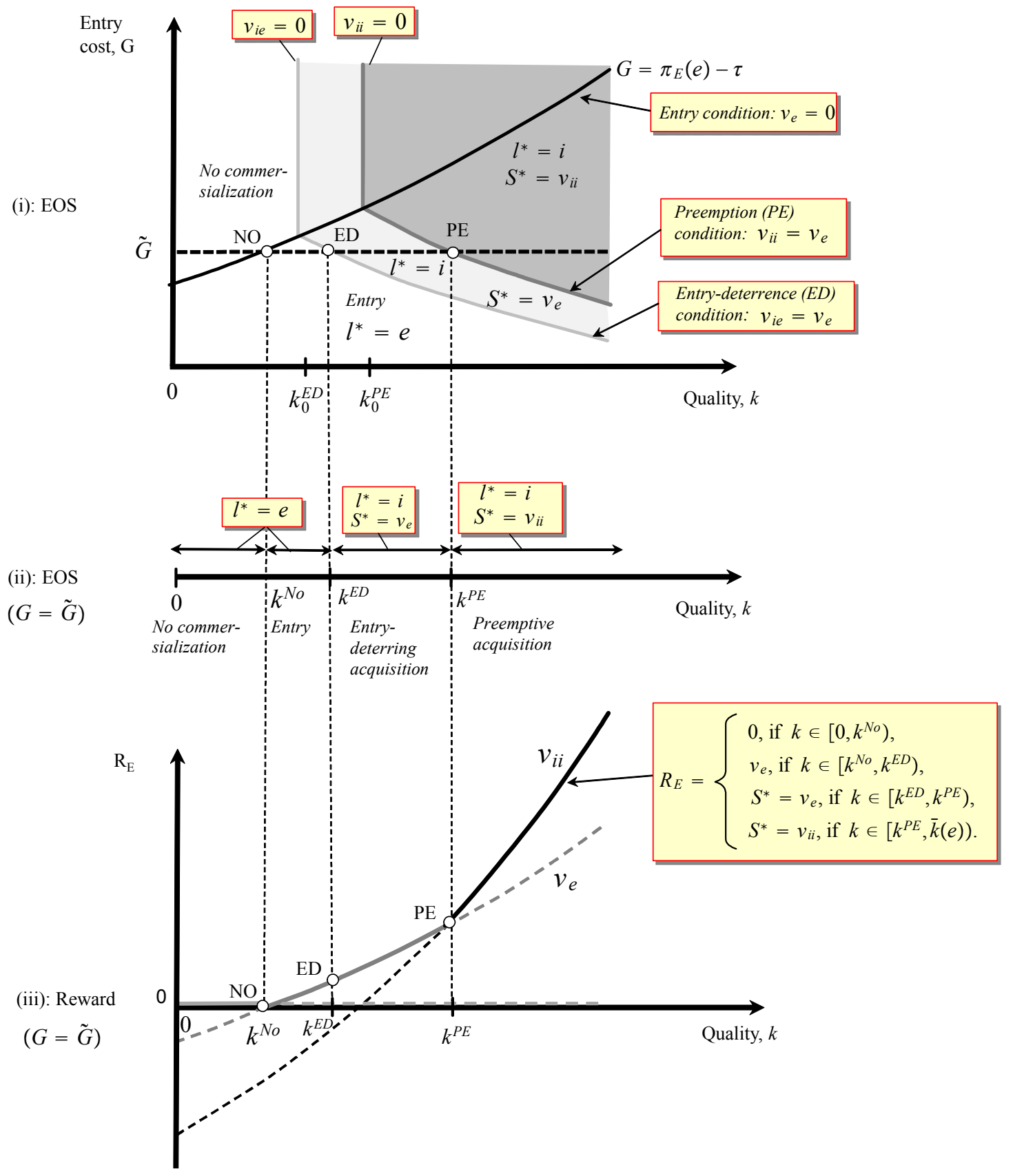

Figure 6.1: The equilibrium mode of commersialization and the reward to innovation when allowing for non-commersialization. 
$\boldsymbol{\psi}=\mathbf{0}$ from (6.3) identifies vectors $\boldsymbol{\beta}$ and $\boldsymbol{\alpha}$ from (5.2) and (5.3).

In Table 6.1, we show the results from estimating (6.4) for the 364 patents which are commercialized (by Sale or Entry) and the 163 patents where we know that the holder actively chose not to commercialize (i.e. the patent expired without any product introduced in the market). ${ }^{27}$ Given the identifying assumption of $\boldsymbol{\psi}=0$, Wald tests show that $\boldsymbol{\beta}=\mathbf{0}, \boldsymbol{\alpha}=\mathbf{0}$ and $\boldsymbol{\beta}=\boldsymbol{\alpha}$ can all be rejected. Moreover, the parameter estimates and Wald tests on the citation variable $W_{-} C I T$ and, in particular, the citation dummy $D_{-} W_{-} C I T$, indicate evidence of $\alpha_{k}>0$ in (5.2), $\beta_{k}>0$ in (5.3) and $\beta_{k}>\alpha_{k}$. Calculating marginal effects shows that if a patent receives one more forward citation during a five-year period, the probability of sale increases by 3.8 percentage points, entry increases by 2.6 percentage points and no commercialization decreases by 6.4 percentage points. From the estimates of $S M A L L$ and $M I C R O$, we also note that the Wald tests are largely consistent with $\alpha_{G}<0, \beta_{G}=0$ and that $\beta_{G}>\alpha_{G}$. Thus, the results are again consistent with Proposition 4(ii) identifying preemptive acquisitions.

The multinomial logit model gives additional evidence for the theory in terms of the reward function in (5.2) and (5.3), while identifying that incumbents' acquisitions are preemptive in nature. While the multinomial logit model is informative, it has its drawbacks. As mentioned, it assumes that the error terms in different commercialization modes, $\varepsilon_{e, m}$ are not correlated. ${ }^{28}$ To check this we also estimated a probit model with selection, where the selection stage modelled the commercialization decision and the second stage the model of commercialization. This gave qualitatively the same results. We also found that the error terms on the two stages were uncorrelated. $^{29}$

\subsection{Entry is not "large-scale" (synergies and multiple equilibria)}

For expositional reasons, we have assumed that entry is "large-scale", i.e. incumbents and the entrepreneur make symmetric use of the invention $k$. Let us now allow for synergies between incumbents' assets and the invention. The main implication of allowing for synergies is that multiple equilibria under I 2 in Table 3.1 can arise. We will now show that Proposition 1, which shows that entrepreneurs will sell their best inventions, and Proposition 4(ii), which identifies preemptive acquisitions, are also valid in this setting.

To proceed, let $\tilde{k}(k, \kappa)$ be the effective size of the invention, where $k$ is the "original" quality and $\kappa>0$ is the level of synergies, with $\frac{\partial \tilde{k}(k, \kappa)}{\partial \kappa}>0$. Let Definition 1 hold in terms of effective size of quality $\tilde{k}$. Let $\tilde{k}(e) \equiv \tilde{k}(k, 1)=k$ and let $\tilde{k}(i)=\tilde{k}(k, \kappa)>\tilde{k}(e)$ for $\kappa>1$ and $\tilde{k}(i)=$ $\tilde{k}(k, \kappa)<\tilde{k}(e)$ for $0<\kappa<1$.

Assuming away exits of incumbents, and setting $\lambda(l)=1$ in (4.1), (4.3) and (4.4) now take

\footnotetext{
${ }^{27}$ We omit the remaining 97 observations since we do not know the commercialization decision for these patents.

${ }^{28}$ We tried to estimate a multinomial probit model which allows for estimating the correlation structure between the error terms. However, we then encountered the problem that our data lacks alternativespecific variables (variables which are constant over commercialization mode).

${ }^{29}$ Results available from the authors upon request.
} 


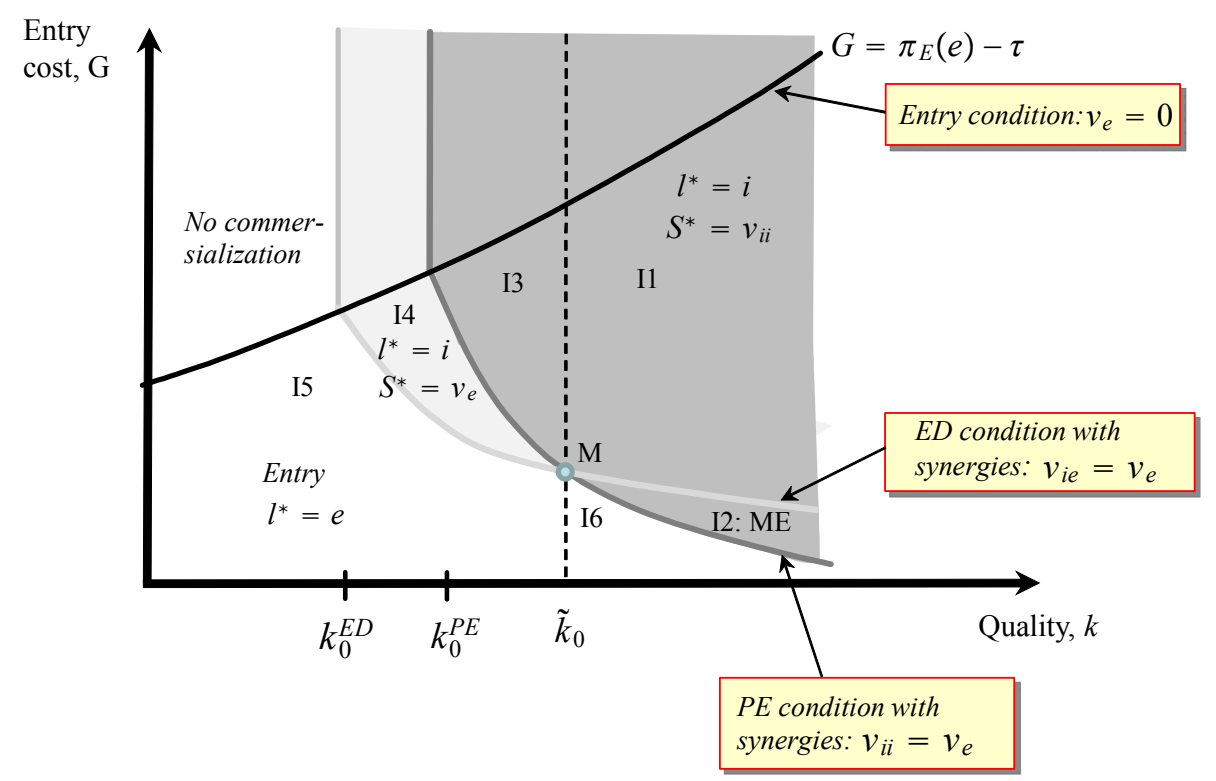

Figure 6.2: Solving for the Equilibrium Ownership Structure (EOS) with synergies and multiple equilibria (ME).

the form:

$$
\begin{aligned}
v_{i e, k}^{\prime}-v_{e, k}^{\prime} & =\left[\frac{d \pi_{A}(i)}{d \tilde{k}} \frac{\partial \tilde{k}(k, \kappa)}{\partial k}-\frac{d \pi_{E}(e)}{d \tilde{k}}\right]-\frac{d \pi_{N A}(e)}{d \tilde{k}} \\
v_{i i, k}^{\prime}-v_{e, k}^{\prime} & =\left[\frac{d \pi_{A}(i)}{d \tilde{k}} \frac{\partial \tilde{k}(k, \kappa)}{\partial k}-\frac{d \pi_{E}(e)}{d \tilde{k}}\right]-\frac{d \pi_{N A}(i)}{d \tilde{k}} \frac{\partial \tilde{k}(k, \kappa)}{\partial k}
\end{aligned}
$$

where we have used the fact that $\frac{d \tilde{k}(e)}{d k}=1$. It is straightforward to show that synergies must be sufficiently large for an acquisition by an incumbent to be profitable.

Consider the case where true synergies arise, $\kappa>1$. Comparing (6.2) with (6.5) and (6.6), we note that synergies will shift the ED and PE conditions to the left in Figure 6.1, making them steeper. Equations (6.5) and (6.6) also imply that synergies will increase incumbents' willingness to pay to preempt rivals more than the value of deterring entry, $v_{i i, k}^{\prime}>v_{i e, k}^{\prime}$. From (6.1), the PE-condition $G^{P E}(k)$ will then have a steeper slope than the ED-condition $G^{E D}(k)$ and the curves will intersect at some quality level $\tilde{k}_{0}$. This is illustrated in Figure 6.2. For $k_{0}<\tilde{k}_{0}$ we note that inequalities I5, I4 or I3 in Table 3.1 arise and for $k_{0}>\tilde{k}_{0}$ inequalities I6, I 2 or I1 arise. Multiple equilibria emerge under I2 - either the entrepreneur enters the market or there is a preemptive acquisition at price $S^{*}=v_{i i}$.

Suppose then that commercialization by entry occurs under I2. Proposition 1 will once more be fulfilled and Proposition 4 will still test if commercialization occurs under bidding competition. To see this, note that the ED- and PE conditions intersect at point $\mathrm{M}$ in Figure 6.2. Since synergies make the PE condition steeper than the ED condition, it follows that when increasing quality $k$, we cannot move from an equilibrium with commercialization by sale (I1, I3 or I4) to an equilibrium with commercialization by entry (I2, I5 or I6). We can only move from an equilibrium with commercialization by entry to an equilibrium with commercialization by sale. 

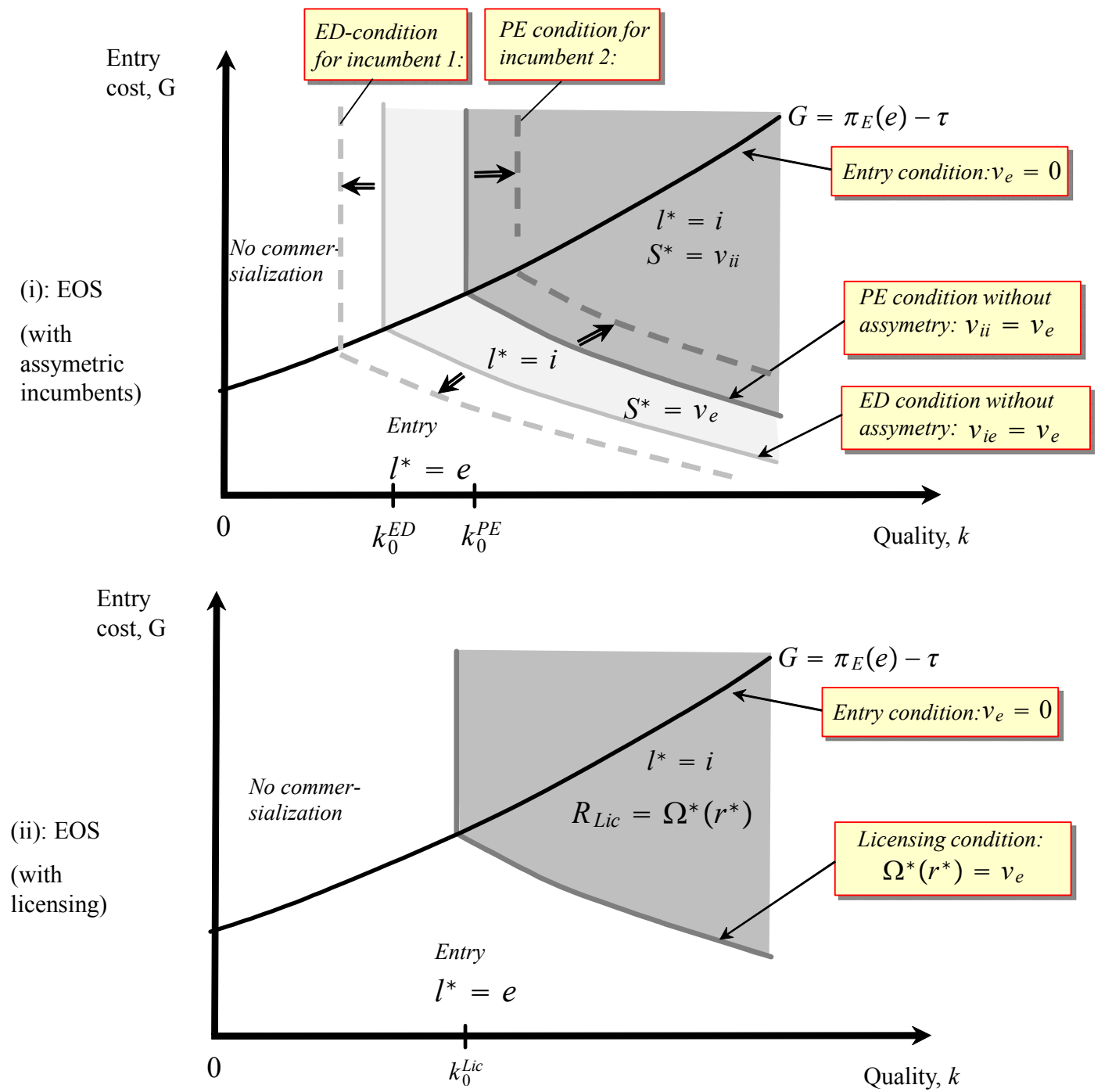

Figure 6.3: The Equilibrium Ownership Structure (EOS) when allowing for (i) assymetric incumbents and (ii) multi-firm licensing. 


\subsection{Incumbents are asymmetric ex-ante}

We have also assumed that incumbents are symmetric ex-ante. This may be a reasonable assumption in some industries. Other industries are dominated by large incumbent firms, such as Microsoft and Intel in the computer industry. How would our results and identification strategy be affected if we allowed incumbents to be ex-ante asymmetric?

Incumbents will then have different valuations of the invention, and the auction game will be harder to solve with many possible orderings of valuations. While this complicates the analysis, there is no qualitative change in results. Let us illustrate using an example with two incumbent firms. The incumbents valuations are then $v_{i i}^{1}=\left[\pi_{A_{1}}(i)-\pi_{N A_{1}}(i)\right]$ and $v_{i e}^{1}=$ $\left[\pi_{A_{1}}(i)-\pi_{N A_{1}}(d)\right]$ for Incumbent 1 , whereas for Incumbent 2 we have $v_{i i}^{2}=\left[\pi_{A_{2}}(i)-\pi_{N A_{2}}(i)\right]$ and $v_{i e}^{2}=\left[\pi_{A_{2}}(i)-\pi_{N A_{2}}(e)\right]$. Furthermore, we make the following assumption:

Assumption A3: (i) $\frac{d \pi_{A_{1}}(i)}{d k}>\frac{d \pi_{A}(i)}{d k}>\frac{d \pi_{A_{2}}(i)}{d k}>0$, (ii) $\frac{d \pi_{E}(e)}{d k}>0$, and (iii) $\frac{d \pi_{N A_{1}}(l)}{d k}<$ $\frac{d \pi_{N A}(l)}{d k}<\frac{d \pi_{N A_{2}}(l)}{d k}<0 . \quad l=\{e, i\}$

Assumption A3 implies that Incumbent 1 generates the largest gain in profits from higher quality, but Incumbent 1 is also the firm facing the largest profit loss as a non-acquirer at increasing quality. We also make the gain (loss) for Incumbent 1 larger (smaller) than in the case of ex-ante symmetry between incumbents. The opposite holds for Incumbent 2. To simplify further, suppose that $\left.\pi_{A_{j}}(i)\right|_{k=0}=\left.\pi_{N A_{j}}(i)\right|_{k=0}=\bar{\pi}$ holds. ${ }^{30}$

Note that Assumption A3 implies that Incumbent 1 will always have the highest valuation of the invention $v_{i l}^{1}>v_{i l}^{2}$, which implies that if an acquisition occurs, Incumbent 1 will be the acquirer. The equilibrium commercialization pattern is shown in Figure 6.3(i). In the figure the ED- and PE conditions are drawn as dashed curves for the case of ex-ante symmetry between incumbents. The ED- and PE conditions for the case of asymmetries are drawn as solid lines. Since the valuation of Incumbent 1 increases when compared to ex-ante symmetry $v_{i e}^{1}>v_{i e}$, an entry deterring acquisition now occurs for a lower quality. However, preemptive acquisitions occur for a higher quality than under ex-ante symmetry. This occurs because bidding competition occurs only when $v_{i i}^{2}>v_{e}$. From Assumption A3 it follows directly that a higher quality of the invention is needed for this to be fulfilled. Asymmetries will then expand the region of entry deterring acquisition. However, as shown by Figure 6.3(i), this does not invalidate Propositions 1 and 4. In particular, Proposition 4 can still be used to test whether commercialization occurs under bidding competition, that is, whether acquisitions occur in the light-gray area without bidding competition (at price $S^{*}=v_{e}$ ), or under bidding competition in the dark-gray area (at price $S^{*}=v_{i i}^{2}$ ). Consequently, the identification of bidding competition in the estimates of Table 5.4 are also consistent with a setting with asymmetric incumbents.

What would happen if $k$ was so high that one of the incumbent's would be forced out of the market in case of entry? We would have no entry in the model since a sale would always be better for the weak incumbent and entrant since entry costs would then be avoided. Also, in this setting we would have entry deterring acquisitions for low and medium quality innovations and preemptive acquisitions for high quality innovations. Thus our empirical specification as well

\footnotetext{
${ }^{30}$ Assumption A3 can be incorporated into the LC model by assuming that $k_{i}=\alpha_{i} k$, where $\alpha_{1}=1>$ $\alpha_{2}>0$.
} 
as our welfare results would hold. Moreover, in practise it is likely that some firms will be more worried that they face a higher risk of exit. However, in a more general setting with uncertainty most firms will likely put a positive probability of staying in the market facing entry. Thus our assumption of market structure neutral entry would still be relevant, but, would be a stronger simplification in a case with asymmetric firms.

On a final note, if the incumbent is a monopolist, there are no non-acquirers by assumption, and the preemption effect is thus not valid in such markets.

\subsection{Multi-Firm Licensing}

In the analysis, we have also assumed that the seller can only sell the innovation (or the innovative firm) exclusively to one buyer. In many cases, the "innovation" consists of a combination of assets in terms of capital, intellectual capital, and human capital, which cannot be used by many firms simultaneously. Indeed, in the data there are only 2 out of 48 licensed inventions have multiple licences.

Let us nevertheless set aside the exclusive single buyer scenario and examine how the results would be affected if we allowed several buyers to hold a licence to utilize the innovations. Allowing the seller to commit to the number of licences to sell, Katz and Shapiro (1986) show that there exists an equilibrium where some potential buyers are left without a licence. Consider a setting where the entrepreneur can decide on how many licences $r$ to licence if not entering. Let $\pi_{A}(i, r)$ denote the profit of a buyer of a licence when there are $r$ licenses for sale. Let $\pi_{N}(i, r)$ be the profit of a firm not buying a licence. Licensing by the entrepreneur gives the profit $\Omega=r\left[\pi_{A}(i, r)-\pi_{N}(i, r)\right]$. For simplicity treating $r$ as continuous, the optimal number of licenses is:

$$
\Omega_{r}^{\prime}=\underbrace{\left[\pi_{A}(i, r)-\pi_{N}(i, r)\right]}_{(+)}+r\left[\pi_{A, r}^{\prime}(i, r)-\pi_{N, r}^{\prime}(i, r)\right]=0
$$

In the Linear Cournot model it can be shown that $\pi_{A, r}^{\prime}(i, r)-\pi_{N, r}^{\prime}(i, r)<0, \pi_{A, r}^{\prime}(i, r)<0$ and $\pi_{N, r}^{\prime}(i, r)<0$, since more licenses increase aggregate output and lower the product market price, which affects a larger firm more adversely. Assuming that $\Omega_{r r}^{\prime \prime}<0$ and $m$ is sufficiently large, there exists an optimal $r^{*}<m$.

How does an increase in quality then affect the choice between licensing and entry? Define $\Omega^{*}\left(r^{*}\right) \equiv r^{*}\left[\pi_{A}\left(i, r^{*}\right)-\pi_{N}\left(i, r^{*}\right)\right]$ This gives:

$$
\begin{aligned}
\frac{d \Omega^{*}}{d k} & =\Omega_{r}^{\prime} \frac{d r^{*}}{d k}+\frac{\partial \Omega^{*}}{\partial k} \\
& =r^{*}\left[\frac{d \pi_{A}\left(i, r^{*}\right)}{d k}-\frac{d \pi_{N}\left(i, r^{*}\right)}{d k}\right]
\end{aligned}
$$

since $\Omega_{r}^{\prime}=0$ from (6.7). So, we may have it that $\frac{d \Omega^{*}}{d k}>\frac{d v_{e}}{d k}>0$ since $\frac{d \pi_{N}\left(i, r^{*}\right)}{d k}<0$. Thus, also in a setting with multiple licences, higher quality is conducive to innovation for sale. Noting that $R_{\text {Lic }}=\Omega^{*}\left(r^{*}\right)$ and $R_{\text {Entry }}=v_{e}$, we can still use Proposition 4 to test if higher quality of an invention will lead to the entrepreneur choosing licensing over entry. This is illustrated in Figure 6.3(ii).

The entrepreneur also has the choice to licence to all $\mathrm{n}$ incumbents. Katz and Shapiro (1986) 
show that each firm would then be willing to pay $\pi_{A}(i, n)-\pi_{N}(i, n-1)$ since the last firm could reject an offer knowing that the entrepreneur cannot threat to sell a license to another firm. It then follows directly that Proposition 4 again applies.

\subsection{Endogenous quality of inventions:}

Our results would also hold in a setting where the entrepreneur chooses the level of quality $k$ in stage 1 (rather than affecting the probability of discovering an invention of a given quality). To see this, let $C(k)$ be a strictly convex development cost. Assuming that Assumption A1 is fulfilled, (3.5) and (3.7) then imply $k^{\text {Sale }}=\arg \max _{k}\left[v_{i i}-C(k)\right]>k^{\text {Entry }}=\arg \max _{k}\left[v_{e}-C(k)\right]$. Thus, our theory would also predict that entrepreneurs choosing commercialization by sale will have a stronger incentive to develop inventions of higher quality. This suggests a potential endogeniety problem in (5.4). However, note that the entrepreneur will choose the mode of commercialization to maximize $R_{E, m}(\cdot)$ in (5.1) in stage 2 , where the quality of the innovation $k$ is given from stage 1. It then follows that we can use Proposition 4(iii) to identify preemptive acquisitions, irrespective of whether the quality of an innovation is exogenously given for the entrepreneur, or if the entrepreneur could affect the quality prior to commercialization.

\section{Asymmetric information and entry as verification}

So far, we have assumed away information problems. However, the inventor may have an informational advantage by better knowing the quality of the invention. The entrepreneur can then mitigate such information problems by verifying the value or quality of the invention by entering the market and revealing high profits, low costs or high sales, prior to selling the invention. This verification motive may explain the pattern in our data were 30 out of the 91 sold patents where first commercialized by entry and then sold at a later stage.

Entry should be a credible verification in most countries since mandatory disclosure laws and different type of auditing systems are built up to certify that information about firms' revenues, cost and profits are accurately reported. $.^{31},{ }^{32}$ These disclosure laws and auditing systems also imply that firms' cannot easily signal in the product market interaction.

Consider the following extension of the baseline model:

Stage 1 Initially, all players know what type of $\mathrm{R} \& \mathrm{D}$ project $(k)$ the entrepreneur has undertaken, and assign an exogenous probability of success of the entrepreneur's invention $\theta \in[0,1]$. At the end of the research stage, only the entrepreneur learns if the project was a failure $(k=0)$ or a success $(k>0)$.

Stage 2 In the commercialization stage, the entrepreneur can sell the invention under asymmetric information, where the incumbents still assign the probability of success of the entrepreneur's invention $\theta \in[0,1]$. If an incumbent obtains the invention, only the acquiring incumbent learns the quality of the invention after the purchase.

\footnotetext{
${ }^{31}$ There is a small literature on costly disclosure and debt financing (see Townsend (1979) and Gale and Hellwig (1985)).

32 Note that we abstract from appropriation problems since the entrepreneur has a patent.
} 
Stage 3 In the product market interaction at the beginning of stage 3 , information is asymmetric since non-acquiring incumbents can only estimate quality of the invention from the prior $\theta$. However, at the end of stage 3 profits, cost and output decisions are public information (by law in Sweden and in most other countries) and non-acquiring incumbents can infer the quality of the invention from this information.

Stage 4 Given that the entrepreneur has entered in stage 2 and competed in the product market in stage 3 , she can sell the invention under perfect information in this stage.

Stage 5 Given the commercialization mode of the invention in stage 2, firms compete in the product market under perfect information.

If the invention is not commercialized in stage 2 , all incumbents are symmetric and interact under full information in stages 3 and 5 . If there is no entry in stage 2 , the commercialization decision from stage 2 is unaltered. We now proceed to solve the game by backward induction:

\subsection{Stage 5: Product market interaction under full information.}

Suppose that the invention is commercialized in stage 2, and then used in the product market in stage 3. Firms will then have inferred the true quality of the invention $t=s, f$, where $s=$ success and $f=$ failure denote the outcomes for the entrepreneur in stage 1 . The Nashequilibrium is given from (3.1) and here denoted $\mathbf{x}^{*}(l, t)=\left(x_{j}^{*}(l, t), x_{-j}^{*}(l, t)\right)$. Let $\pi_{h}(l, t) \equiv$ $\pi_{h}\left(x_{h}^{*}(l, t), x_{N}^{*}(l, t), l, t\right)$ be the reduced-form profit the possessor for a firm of type $h=A, E, N A$. Since $\pi_{h}(l, s) \equiv \pi_{h}(l)$, Definition 1 applies for a successful invention $(t=s)$, whereas $\frac{d \pi_{h}(l, f)}{d k} \equiv 0$ since $k=0$ under a failed invention $(t=f)$. If the invention is not commercialized, there is a symmetric Nash-equilibrium where incumbents make profits $\pi_{N}(0)$.

\subsection{Stage 4: Post entry acquisition game}

We assume the entrepreneur has commercialized by entry in stage 2, and competed in the product market in stage 3. From the product market profit in stage 5, the entrepreneur's reservation price in stage 4 is:

$$
v_{e}(t)=\pi_{E}(e, t)-\tau
$$

where we note that the entry cost $G$ is sunk from stage 2 and hence not included in the reservation price.

An incumbent's valuations of the invention in stage 4 is:

$$
v_{i l}(t)=\pi_{A}(i, t)-\pi_{N}(l, t)-\Gamma
$$

We will assume that acquisitions driven solely by market power are not profitable, $v_{i l}(f)<$ $v_{e}(f)$. To examine the commercialization pattern for a successful invention, (7.1) and (7.2) gives:

$$
v_{i l, k}^{\prime}(s)-v_{e, k}^{\prime}(s)=\left[\frac{d \pi_{A}(i, s)}{d k}-\frac{d \pi_{E}(e, s)}{d k}\right]-\frac{d \pi_{N A}(l, s)}{d k} .
$$


Since $\pi_{h}(l, s) \equiv \pi_{h}(l)$, Assumption A2 implies the net gain of an acquisition $v_{i l}(s)-v_{e}(s)$ is increasing in quality $k$, as shown in Figure 7.1(i). Applying the reasoning behind Lemma 3, we have the following proposition:

Proposition 5. (Late sale): Suppose that $\breve{k}^{E D}$ defined from $v_{i e}(s)=v_{e}(s)$ and $\breve{k}^{P E}$ defined from $v_{i i}(s)=v_{e}(s)$ exist. Then, from Assumption A3:(i) commercialization by entry takes place if the quality of the invention is sufficiently low, $k \in\left(0, \breve{k}^{E D}\right)$, (ii) commercialization by sale occurs at sales price $S_{4}^{*}=v_{e}(s)$ if the quality of the invention is of intermediate size, $k \in\left[\breve{k}^{E D}, \breve{k}^{P E}\right)$, and (iii) commercialization by sale occurs at sales price $S_{4}^{*}=v_{i i}(s)$ if the quality of the invention is sufficiently high, $\breve{k} \in\left[\check{k}^{P E}, \bar{k}(i)\right)$.

In sum, if the entrepreneur has verified the quality choosing commercialization by entry in stage 2 and competed in the product market in stage 3 , she will sell the invention in stage 4 if the quality is high. For sufficiently high quality a sale will take place under bidding competition. This is shown in Figure 7.1(ii).

Figures (i) and (ii) solve for the entrepreneur's decision to sell given commercialization by entry in stage 1. Figures (iii) and (iv) solve the entrepreneurs commercialization decision in stage 1 in the case that incumbents have a high prior on the quality of the invention.

\subsection{Stage 3: Product market interaction under asymmetric information}

Let us now formalize how verification of quality takes place. Suppose that the invention is commercialized in stage 2, either by entry or sale. Since only the possessor of the invention (the entrepreneur or the acquiring incumbent) knows the true quality of the invention, the product market interaction takes place under asymmetric information. We will then assume a BayesianNash-equilibrium in the firms' product market actions $x_{j}$. Non-acquiring incumbents assign a probability $\theta$ that the possessor of the invention has a successful invention and probability $1-\theta$ that the possessor has a failed invention. The possessor knows how rivals infer quality, and rivals know that the possessor knows how they infer quality. A possessor $h=A, E$ of an invention of type $t$ maximizes her direct profit $\pi_{h}\left(x_{h}(t), x_{-h}, l, t\right)$ choosing an action $x_{h}(t)$, given the vector of actions of non-acquiring incumbents, $x_{-h}=\mathbf{x}_{N}$. A non-acquiring incumbent chooses an action $x_{N}$ to maximize her expected profit based on the prior $\theta, \bar{\pi}_{h}=\theta \pi_{h}\left(x_{N}, x_{-N}(s), l, s\right)+$ $(1-\theta) \pi_{h}\left(x_{N}, x_{-N}(f), l, f\right)$, where $x_{-N}(s)=\left(x_{h}(s), x_{N}, \ldots, x_{N}\right), x_{-N}(f)=\left(x_{h}(f), x_{N}, \ldots, x_{N}\right)$ are the action of her rivals. The Bayes-Nash equilibrium can then be written $\mathbf{x}^{*}(l, t, \theta)=$ $\left(x_{h}^{*}(l, s, \theta), x_{h}^{*}(l, f, \theta), \mathbf{x}_{N}^{*}(l, \theta)\right)$, where $x_{h}^{*}(l, s, \theta)$ for $h=A, E$ is the optimal action taken by a possessor of a successful invention, $x_{h}^{*}(l, f, \theta)$ for $h=A, E$ is the optimal action taken by a possessor of a failed invention, while $\mathbf{x}_{N}^{*}(l, \theta)$ is the vector of (symmetric) actions by nonacquiring incumbents (who do not know the true quality $t$ and thus cannot condition their optimal action on the type of invention). Let $\pi_{h}(l, t, \theta) \equiv \pi_{h}\left(\mathbf{x}^{*}(l, t, \theta), l, t\right)$ be the reduced-form profit for a firm of type $h=A, E, N$.

We will make the following assumptions on reduced-form profits, which are shown to hold for the LC model in the Appendix.

Assumption A4 Let $\theta \in[0,1]$. For $h=A, E:$ (i) $\frac{d \pi_{h}(l, s, \theta)}{d k}>0 \geq \frac{d \pi_{N}(l, s, \theta)}{d k}$, and $\frac{d \pi_{h}(l, f, 0)}{d k}=$ $\frac{d \pi_{N}(l, f, 0)}{d k}=0$, (ii) $\pi_{j}(l, s, \theta)>\pi_{j}(l, f, \theta)>\pi_{N}(l, f, \theta)>\pi_{N}(l, s, \theta)>0, j=A, E$. 


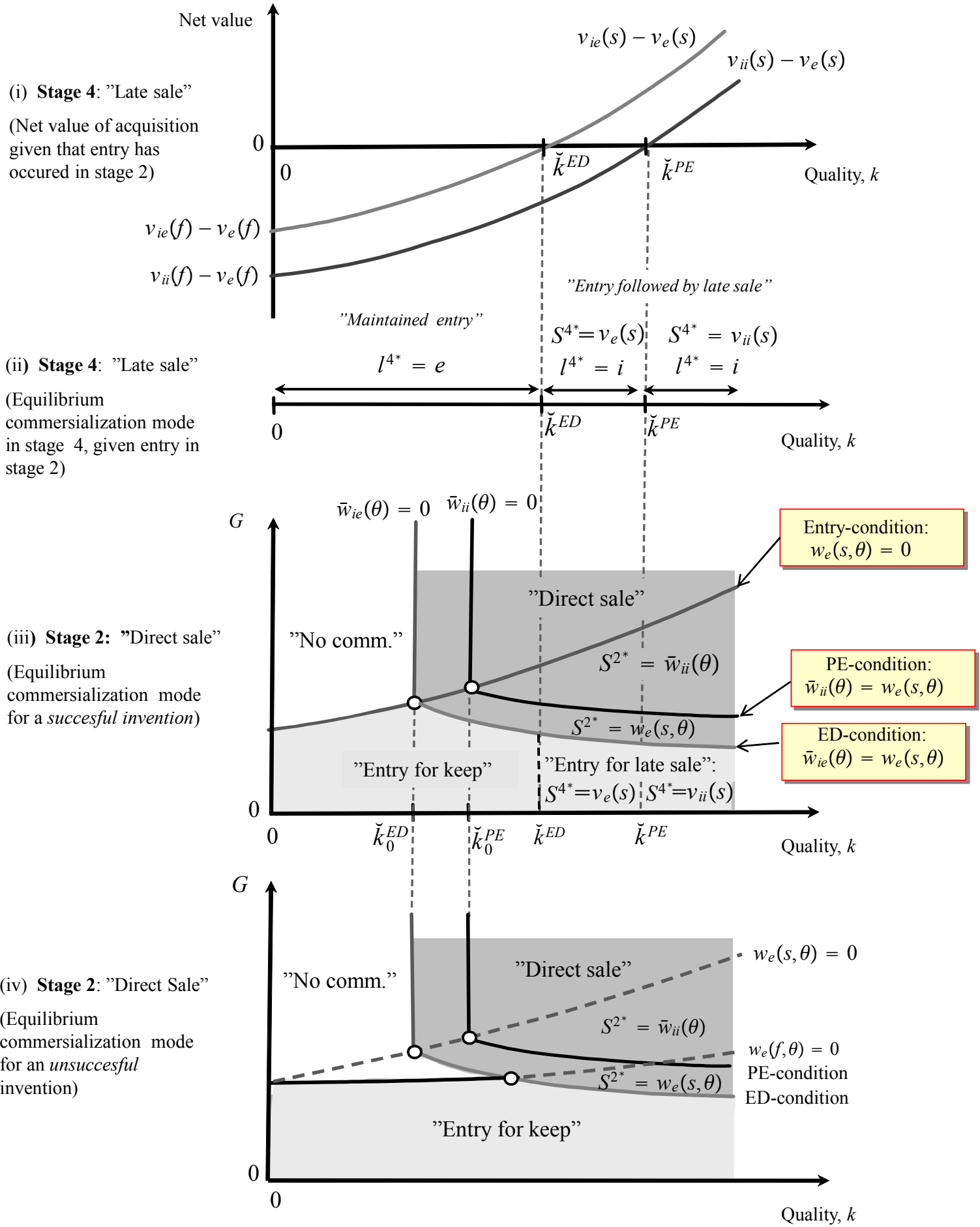

Figure 7.1: Figures (i) and (ii) solve for the entrepreneur's decision to sell given commercialization by entry in stage 1. Figures (iii) and (iv) solve the entrepreneurs commercialization decision in stage 1 in the case that incumbents have a high prior on the quality of the invention. 
Proof. See the Appendix.

Assumption A4(i) implies that Definition 1 holds for a successful invention. If the invention has failed and incumbents are certain that the invention has failed, quality will not affect firms' profits. To ensure that firms assign a positive value to the invention, Assumption A4(ii) states that the possessor of the invention has a higher reduced-form profit when the invention is successful than when it is unsuccessful. In turn, these profits are higher than the profits of a nonacquiring incumbent when the invention has failed, which in turn is higher than the profit of an acquiring incumbent when the invention is successful. Assuming that the latter profit is strictly positive, a non-acquiring incumbent's expected profit $\bar{\pi}_{N}(l, \theta)=\theta \pi_{N}(l, s, \theta)+(1-\theta) \pi_{N}(l, f, \theta)$ is then strictly positive. The Appendix gives more details on these profits for the LC-model.

Since profits are public information at the end of stage 3 , firms can infer the quality of the invention $t=s, f$ from their own or rivals' reduced-form profits $\pi_{h}(l, s, \theta)$, and we can state the following corollary:

Corollary 1. If the invention is commercialized in stage 2, the reduced-form profits in stage 3 reveal the type of the invention.

\subsection{Stage 2: Commercialization under asymmetric information}

Let us now solve for the commercialization decision in stage 2 . To determine the firms' valuations in stage 2 we need take into account how the game proceeds from stages 3 to 5 .

The reservation price for the entrepreneur Note that the value of entry arising from stage 5 profits is defined from $v_{e}(t)$ in (7.1). The value of entry from stage 3 profits for the entrepreneur is

$$
v_{e}(t, \theta)=\pi_{E}(e, t, \theta)-\tau-G
$$

where we note that the entry cost $G$ is paid in stage 2 .

The full reservation price in stage 2 for the entrepreneur with a successful invention, denoted $w_{e}(s, \theta)$, can then be written:

$$
w_{e}(s, \theta)=\left\{\begin{array}{l}
0, \text { for }, v_{e}(s, \theta)+\max \left\{v_{e}(s), v_{i i}(s)\right\}<0 \\
v_{e}(s, \theta)+v_{e}(s), \text { for } v_{e}(s, \theta)+v_{e}(s)>0, k \in\left[0, \breve{k}^{P E}\right), \\
v_{e}(s, \theta)+v_{i i}(s), \text { for } v_{e}(s, \theta)+v_{i i}(s)>0, k \in\left[\breve{k}^{P E}, k^{\max }\right) .
\end{array}\right.
$$

In (7.5), $v_{e}(t, \theta)$ is the value arising from product market entry in stage 3 . Since entry reveals the true quality, the term $\max \left\{v_{e}(s), v_{i i}(s)\right\}$ is the value from optimally choosing to keep the invention or to sell it under full information in stage 4. Note finally that if the reward from entry is negative, the entrepreneur has a zero reservation price.

If the entrepreneur has a failed invention, this will be revealed by the firms profits in stage 3 as shown in Corollary 1. Since incumbents have no incentive to buy a failed invention, the entrepreneur's reservation price for a failed invention is:

$$
w_{e}(f, \theta)=\left\{\begin{array}{l}
0, \text { for } v_{e}(f, \theta)+v_{e}(f)<0 \\
v_{e}(f, \theta)+v_{e}(f) \text { for } v_{e}(f, \theta)+v_{e}(f)>0 .
\end{array}\right.
$$


Incumbents valuations The value of the invention for an incumbent arising from stage 5 profits is $v_{i l}(t)$ and defined in (7.2). The value for an incumbent arising from stage 3 profits can be written:

$$
v_{i l}(t, \theta)=\pi_{A}(i, t, \theta)-\bar{\pi}_{N}(l, \theta)
$$

since only the possessor will know the type of the invention when entering into the product market competition in stage 3 . To avoid double-counting the transaction cost $\Gamma$ which is included in $v_{i l}(t)$, we do not include $\Gamma$ in (7.7).

When determining the value of the invention in stage 2 , incumbents will need to estimate the type of the invention using the prior $\theta$. Let $\bar{w}_{i l}(\theta)$ denote the expected valuation of the invention. This can be written:

$$
\bar{w}_{i l}(\theta)=\left\{\begin{array}{l}
\theta\left[v_{i l}(s, \theta)+v_{i l}(s)\right]+(1-\theta)\left[v_{i l}(f, \theta)+v_{i l}(f)\right], \text { for } \bar{w}_{i e}(\theta)>w_{e}(s, \theta) \\
v_{i l}(f)+v_{i l}(f), \text { for } \bar{w}_{i e}(\theta)<w_{e}(s, \theta)
\end{array}\right.
$$

In (7.8), the first line tells us incumbents will only value the invention according to its expected value if the value of deterring commercialization by entry is higher than the reservation price of an entrepreneur with a successful invention, $\bar{w}_{i e}(\theta)>w_{e}(s, \theta)$. The second line tells us that if this condition is not met, incumbents will rationally expect that only failed inventions will be for sale, following Akerlof's (1970) classic "lemons problem".

It is now straightforward to solve for the equilibrium commercialization pattern. This is illustrated in Figure 7.1(iii) and (iv), where we again depict the equilibrium ownership structure (EOS) in the space of the quality of the invention $k$ and the entry cost $G$.

Commercialization of a successful invention Consider first the EOS for a successful invention in Figure 7.1(iii). Note that the locus of the Entry-condition $w_{e}(s, \theta)=0$ is upwardsloping from Assumption A4(i), since $v_{e}(s, \theta)+\max \left\{v_{e}(s), v_{i i}(s)\right\}$ must increase in quality $k$. Since Assumption A4(i) also implies that the term $v_{i l}(s, \theta)+v_{i l}(s)$ in (7.8) increases in quality, an incumbent's valuation $\bar{w}_{i l}(\theta)$ also increases in quality. ${ }^{33}$ When entry is not profitable, $w_{e}(s, \theta)<$ 0 , the ED and PE locuses then becomes the vertical lines $\bar{w}_{i l}(\theta)=0$, at $\breve{k}_{0}^{E D}<\breve{k}_{0}^{P E}$. The latter inequality follows from the concentration effect of an acquisition, i.e. $\bar{w}_{i e}(\theta)>\bar{w}_{i i}(\theta)$, so that the ED-locus is again located to the left of the PE-locus. A direct acquisition of the entrepreneur's invention occurs at price $S^{2^{*}}=w_{e}(s, \theta)=0$ for $k \in\left[\breve{k}_{0}^{E D}, \breve{k}_{0}^{P E}\right)$, and $S^{2^{*}}=\bar{w}_{i i}(\theta)$ for $k \in\left[\breve{k}_{0}^{P E}, k^{\max }\right)$. For $k \in\left(0, \breve{k}_{0}^{E D}\right)$ the invention is not commercialized since $\bar{w}_{i l}(\theta)<0$.

Focus now on the region below the EC-condition $w_{e}(s, \theta)=0$, where the ED-condition does not hold, i.e. where $\bar{w}_{i e}(\theta)<w_{e}(s, \theta)$. In this region, the market for successful inventions initially breaks down, and the entrepreneur will commercialize by entry, an action that will reveal the true quality of the invention from Corollary 1 . The pattern of commercialization in stage 4 is then given by Proposition 5, as shown in Figure 7.1(i) and (ii).

Focus finally on the middle region between the EC-condition and the ED-condition in Figure

\footnotetext{
${ }^{33}$ Assumption A4 does inform us how the term $v_{i l}(f, \theta)$ in $(7.8)$ behaves in quality $k$. Under reasonable assumptions, however, $v_{i l}(f, \theta)$ terms are non-decreasing in quality. This is also shown in the Appendix for the LC model.
} 
7.1(iii). In the region between the ED- and PE locuses (where $\bar{w}_{i e}(\theta)>w_{e}(s, \theta)>\bar{w}_{i i}(\theta)$ ) there is sale at the reservation price $S^{2^{*}}=w_{e}(s, \theta)$, and in the region above the PE-locus (where $\left.\bar{w}_{i i}(\theta)>w_{e}(s, \theta)\right)$ there will be bidding competition, leading to the sales price $S^{2^{*}}=\bar{w}_{i i}(\theta)$. What then is the effect of higher quality on the entrepreneur's commercialization decision in this region? Differentiate the ED and PE-conditions in $k$ and $G$ to obtain:

$$
\frac{d G^{E D}}{d k}=\frac{\bar{w}_{i e, k}^{\prime}(\theta)-w_{e, k}^{\prime}(s, \theta)}{w_{e, G}^{\prime}(s, \theta)}, \quad \frac{d G^{P E}}{d k}=\frac{\bar{w}_{i i, k}^{\prime}(\theta)-w_{e, k}^{\prime}(s, \theta)}{w_{e, G}^{\prime}(s, \theta)}
$$

Since $w_{e, G}^{\prime}(s, \theta)<0$, whether higher quality still leads to commercialization by sale and bidding competition, depends on whether the net value of an early acquisition increases in quality. As illustrated in Figure 7.1(iii), if $\bar{w}_{i e, k}^{\prime}(\theta)-w_{e, k}^{\prime}(s, \theta)>0$ holds the ED and PE locuses are downward sloping, and higher quality leads to commercialization by sale and bidding competition. However, if $\bar{w}_{i e, k}^{\prime}(\theta)-w_{e, k}^{\prime}(s, \theta)<0$ the opposite holds. Without knowledge of the prior $\theta$ we cannot determine whether the net value for a direct acquisition increases or decreases in quality. This follows from the fact that incumbents valuations $\bar{w}_{i l}(\theta)$ in (7.8) are weighted by the prior $\theta$, whereas this is not the case for the reservation price of entrepreneur $w_{e}(f, \theta)$ in (7.5). If incumbents are "optimistic" their willingness to pay is high for high quality, and the entrepreneur can get a reward from selling high quality inventions. But if incumbents are "pessimistic" about the true quality ( $\theta$ is low) their willingness to pay in a direct acquisition is low. It will then be worthwhile for the entrepreneur to keep a successful invention, enter the product market in stage 3 and then - given that the quality is high - sell the invention at a high price by exploiting the bidding competition.

We have the following proposition which is proved in the Appendix:

Proposition 6. (Direct sale) Let $\theta \in[0,1]$. When entry is profitable for a successful invention, $w_{e}(s, \theta)>0$, higher quality of a successful invention will lead to commercialization by sale under bidding competition $S^{2^{*}}=\bar{w}_{i i}(\theta)>w_{e}(s, \theta)$ only if incumbents' prior that the invention is successful is sufficiently high.

Proof. See the Appendix.

Commercialization of a failed invention Turning to entrepreneurs with failed inventions, such entrepreneurs will sell their inventions whenever $\bar{w}_{i l}(\theta)>w_{e}(s, \theta)$ holds. From (7.8) incumbents know that only failed inventions are for sale when $\bar{w}_{i e}(\theta)<w_{e}(s, \theta)$. As shown in Figure 7.1(iv), entrepreneurs with failed invention will then enter if entry is profitable $w_{e}(f, \theta)>0$. Otherwise, no commercialization occurs.

\subsection{Estimating the model with asymmetric information}

It is straightforward to extend the empirical analysis to the asymmetric information model.

Late sale Start with the choice to sell late in stage 4. With commercialization by entry in stage 2, Corollary 1 implies that a late sale occurs under full information. We can apply the identification strategy in Proposition 4 with some adjustments. Since $\pi_{h}(l, s)=\pi_{h}(l)$, 
Proposition 5 (ii) implies we should observe $\gamma_{k}=\beta_{k}-\alpha_{k}>0$ when estimating (5.4). However, since entry costs $G$ are sunk when a late sale occurs, $\gamma_{G}=\beta_{G}-\alpha_{G}=0$. The estimates are shown in Table 7.1, where LATESALE $=1$ for the 30 patents which are first commercialized by entry and then are sold, and $L A T E S A L E=0$ for the remaining 273 patents which are commercialized by entry and remain in the inventor's ownership. Thus, the 61 patents sold directly are removed. As expected, the citation variable $W_{-} C I T$ is positive and significant, while the measure of entry costs, $S M A L L$ and $M I C R O$, are insignificant. This pattern remains true in all specifications. Consequently, we find support for the verification model that shows how entry can remove information problems and lead to a late sale under bidding competition.

Direct sale Now let's turn to the entrepreneur's choice of whether to sell the invention directly instead of entering the market in stage 2 . To estimate this choice we can use the multinomial logit model (6.4) derived in Section 6.2, with the difference that patents which are first commercialized by entry and then sold will be treated as commercialization by entry. Under Assumption A4(i), it follows that if the entrepreneur has a successful invention a higher quality $k$ will encourage entry and direct sale over non-commersialzation, i.e. $\beta_{k}>0$ and $\alpha_{k}>0 .{ }^{34}$ However, we also know from Proposition 6 that without knowledge of the prior $\theta$, we cannot know whether higher quality increases the probability of direct sale, or the probability of entry when the entrepreneur has a successful invention, and so $\beta_{k}-\alpha_{k}$ is ambiguous in sign. We cannot measure this prior in the data, so we will need to use the estimates to infer it.

Specification A uses the citation variable $W_{-} C I T$, whereas specification B uses the citation dummy $D_{-} W_{-} C I T$. The estimates in Table 7.2 reveal that Wald tests for specification A reject $\boldsymbol{\beta}=0$ and $\boldsymbol{\alpha}=0$, with lower significance for direct sale. A Wald test also rejects $\boldsymbol{\beta}=\boldsymbol{\alpha}$ which suggest that direct acquisitions are preemptive in nature. The citation variable $W_{-} C I T$ is neither significant for direct sale nor direct entry, although $\beta_{k}>0$ and $\alpha_{k}>0$. The estimates suggest that $\beta_{G}=\alpha_{G}$ can be rejected, whereas $\beta_{k}=\alpha_{k}$ cannot. A problem is that we cannot distinguish patents which are failed and successful in the data. An imperfect way to do this is to use the citation dummy $D_{-} W_{-} C I T$, assuming that patents that receive zero citations are more likely to be patents for which $k=0$, whereas patents with forward citations are more likely to be successful, $k>0$. We see that specification B leads to sharper estimates. Wald tests again reject $\boldsymbol{\beta}=\boldsymbol{\alpha}$ so direct acquisitions are preemptive in nature. We can also see that both $\beta_{k}=0$ and $\alpha_{k}=0$ can be rejected, while a Wald test shows that $\beta_{k}=\alpha_{k}$ cannot be rejected. While entrepreneurs do receive a premium for sold inventions, this premium is not further increased by higher quality. This suggests that the prior $\theta$ is low enough to dampen incumbents willingness to pay. In short, there is evidence of asymmetric information in direct sales.

Some additional evidence of information problems comes from the variable $P V C$ which measures the involvement by venture capitalists. It is now positive and marginally significant in specification A. In addition, there is some evidence that lower fixed costs of entry leads the entrepreneur not to commercialize the invention. Such an outcome can be rationalized from Figure 7.1(iv), where an entrepreneur with a failed invention will not commercialize when entry

${ }^{34}$ This assumption implies that $\frac{d \pi_{h}(l, s, \theta)}{d k}>0 \geq \frac{d \pi_{N}(l, s, \theta)}{d k}$ holds. In the Appendix, it is also shown that $\frac{d \pi_{h}(l, f, \theta)}{d k}>0 \geq \frac{d \pi_{N}(l, f, \theta)}{d k}$ if $\theta \in(0,1]$ in the LC-model, 
costs are medium high for a large region of perceived invention qualities.

\subsection{Incumbents have the information advantage}

Finally, it is useful to discuss the opposite case where incumbents have an information advantage over the entrepreneur, assuming that the entrepreneur does not know the true quality of the invention. It then follows that if the invention fails, entry is not profitable and incumbents do not provide any bids. If the invention is a success, incumbents will have a positive value of acquiring the invention. Then, if the incumbents place positive bids below the reservation price of a successful invention, the entrepreneurs will infer that the invention is successful and reject these bids. Consequently, we are back in the base model and our main analysis is valid.

\section{Concluding remarks}

Previous literature has shown that entrepreneurs play an important role in challenging existing oligopolistic markets through de-novo entry into the product market. Yet we identify another important role of the entrepreneur as a challenger of existing oligopolies through the aggressive development of inventions for sale. This development incentive is particularly strong when the invention has such high quality that incumbent buyers try to preempt each other from acquiring the inventions (preemptive acquisitions). The role of an aggressive invention supplier may be even more important than the role of de-novo entrant: preemptive acquisitions give entrepreneurs the incentive to increase their efforts in high-quality research projects so that the expected welfare can increase despite the risk of increased market power.

The welfare benefits of "creative destruction and productive preemption" then crucially depends on if there is bidding competition over entrepreneurial firms, i.e. if acquisitions are preemptive (where incumbents bid their full valuation) rather than entry deterring (where incumbents only pay the entrepreneur her entry value). In our empirical analysis, we do find evidence of preemptive acquisitions using detailed patent data on the commercialization process. The decisive evidence of this fact is that the estimates show that the reward function of sale increases more than the reward function of entry, when the quality of the patent increases.

These results suggest that industry policies supporting the growth of small innovative firms through subsidies and tax exemptions may be counterproductive, despite increasing the amount of entrepreneurial R\&D. The reason is that these policies also in effect, reduce entrepreneurs' incentives to discover high-quality inventions. Policies improving the M\&A market would be preferred such as, for example, making the tax system neutral between keeping and selling a firm or improving the legal system to reduce the transaction cost for ensuring bidding competition for target firms. In contrast, the existing EU-policies to a large extent exclusively focus on stimulating the growth of small firms, but lack policies stimulating the ownership transfers to large established firms.

We also show that the result of high quality inventions being sold under bidding competition remains in many extensions of the theoretical base model, allowing for asymmetric information, for a different scale of entry, allowing for asymmetric incumbents, synergies between the invention and incumbents' assets, and multi-firm licensing. 
"When would our theoretical result that a higher quality of inventions is conducive to commercialization by sale not hold? First, if oligopolistic effects are small, our results will vanish since the externalities on non-acquirers will then be small. However, in practise, many markets where patented innovations are used are oligopolistic. For instance, in Sweden most of the markets in the industry have concentration ratios consistent with oligopolistic competition (see Heyman, Norbäck and Persson (2013).

A second situation is when innovations cannot be transferred between the innovator and the incumbents without great losses in efficiency. When such transfer costs are increasing in quality (because of higher quality products or better technologies being more complex) higher innovation quality is instead conducive to innovation for entry. A special case would be if a potential acquisition by the incumbent only serves the purpose of close down. While being relevant in some cases, we believe that most sold patents are used efficiently. Indeed, there is ample evidence that many (leading) firms such as Microsoft, Google and Ericson, acquire inventions and patents incorporating them highly efficiently into their businesses.

Third, entrepreneurs might not sell their best innovations if cooperation between all firms (the entrepreneurial firm and all incumbents) is allowed and can be managed efficiently. To see this, suppose firms maximize the joint profit in the market. Write the difference in aggregate profits under sale $\Pi(i)$ and entry $\Pi(e)$ in terms of the valuations in our first-price auction $v_{e}$, $v_{i e}$ and $v_{i i}$, to get

$$
\Pi(i)-\Pi(e)=v_{i e}-v_{e}+(n-1) \underbrace{\left[v_{i e}-v_{i i}\right]}_{\pi_{N}(i)-\pi_{N}(e)}
$$

Note that the first two terms, $v_{i e}-v_{e}$, determine if commercialization by sale or entry occurs in our first-price auction, i.e. a sale occurs iff $v_{i e}>v_{e}$. It follows that it will not be worthwhile to buy low quality (low $k$ ) innovations, since after paying the reservation price of the entrepreneur $v_{e}$, the profit as acquirer will not suffice to exhaust the profit the firm would have made without an acquisition. This holds even if the acquisition leads to a concentration of the market, i.e. $v_{i e}<v_{e}$. This is a well-known result in the oligopoly literature on mergers (Salant, Switzer and Reynolds (1983)) and stems from the fact that rivals can free ride on an acquisition by aggressively increasing their sales.

Under joint maximization, we also need to take the term $(n-1)\left(v_{i e}-v_{i i}\right)$ into account. This term captures the difference in the aggregate profits of non-aquirers under sale and entry and it will be positive for low quality $k$. Thus, if the non-acquiring incumbents could transfer money to the acquirer such transfers might make acquisitions at low quality profitable. However, the gain from concentrating the market for a non-acquirer, $v_{i e}-v_{i i}=\pi_{N}(i)-\pi_{N}(e)$, declines when innovation quality increases (since rivals face a sharper possessor of the innovation), and may even become negative. Consequently, joint surplus maximization may therefore imply a negative correlation between innovation quality and commercialization by sale. In most jurisdictions, it will, however, be illegal under the competition law to transfer money between firms that are not directly trading with each other. Thus joint surplus maximization seems to not be a valid approach for the issue addressed in this paper.

We have treated the human capital of the entrepreneur as a constant in our analysis. However, the quality of the human capital will likely affect the entry and sale pattern, since it will 
affect the value of the entrepreneurial venture. Indeed, Lofstrom, Bates and Parker (2014) find that advanced educational credentials of potential entrants predict entry into high-barrier fields and that college graduates positively select into industries where expected earnings are high. On the other hand, the quality of the human capital will also be affected by the entry sale pattern. Parker (2013) finds that serial entrepreneurs' performance in one venture enhances their performance in subsequent ventures they engage in. However, these positive effects tend to decline with the length of time between ventures. Consequently, sales of ventures might enable serial entrepreneurs to better exploit learning opportunities. Thus, endogenizing the human capital level in the analysis seems as fruitful avenue of future research.

\section{References}

[1] Acs, Z.J. and Audretsch D.B., 2005, "Entrepreneurship, Innovation and Technological Change", Foundations and Trends in Entrepreneurship, Vol. 1(4), pp. 149-195.

[2] Aghion, P. and Howitt, P., 1992, "A Model of Growth through Creative Destruction", Econometrica, Vol. 60(2), pp. 323-351.

[3] Akerlof, G.A., 1970, "The Market for 'Lemons': Quality Uncertainty and the Market Mechanism", Quarterly Journal of Economics, Vol. 84(3), pp. 488-500.

[4] Anton, J.J. and Yao, D.A., 1994, "Expropriation and Invention: Appropriable Rents in the Absence of Property Rights", American Economic Review, Vol. 84(1), pp. 190-209.

[5] Arrow, K.J., 1962, "Economic Welfare and the Allocation of Resources for Innovation", in Nelson, R.R. (ed.), The Rate and Direction of Inventive Activity: Economic and Social Factors, NBER Special Conference Series Vol. 13, Princeton, NJ: Princeton University Press.

[6] Baumol, W.J., 2002, The Free-Market Innovation Machine: Analyzing the Growth Miracle of Capitalism, Princeton: Princeton University Press.

[7] Baumol W.J., 2004, "Entrepreneurial Enterprises, Large Established Firms and Other Components of the Free-Market Growth Machine", Small Business Economics, Vol. 23(1), pp. 9-21.

[8] Bianchi, M. and Henrekson M., 2005, "Is Neoclassical Economics Still Entrepreneurless?", Kyklos, Vol. 58(3), pp. 353-377.

[9] Bloningen, B.A. and Taylor, C.T., 2000, "R\&D Intensity and Acquisitions in HighTechnology Industries: Evidence from the US Electronic and Electrical Equipment Industries", Journal of Industrial Economics, Vol. 48(1), pp. 47-70.

[10] Bond, E.W., 1982, "A Direct Test of the "Lemons" Model: The Market for Used Pickup Trucks", American Economic Review, Vol. 72(4), pp. 836-840.

[11] Breschi, S., Lissoni, F. and Malerba, F., 2004, "The Empirical Assessment of Firms' Technological Coherence: Data and Methodology", in Cantwell, J., Gambardella, A. and 
Granstrand, O. (eds.), The Economics and Management of Technological Diversification, London: Routledge.

[12] Carlsson B., Braunerhjelm, P., McKelvey, M., Olofsson, C., Persson L. and Ylinenpää, H., 2013, "The Evolving Domain of Entrepreneurship Research", Small Business Economics. Vol 41(4), pp. 913-930.

[13] Coase, R., 1960, "The problem of social cost", Journal of Law and Economics, Vol. 3, pp. $1-44$.

[14] Chen, Y., 2000, "Strategic Bidding by Potential Competitors: Will Monopoly Persist?", Journal of Industrial Economics, Vol. 48(2), pp. 161-75.

[15] Commission of the European Communities, 2008, Think Small First. A "Small Business Act" for Europe. Communication COM (2008) 394. Brussels. http://ec.europa.eu/enterprise/policies/sme/small-business-act/index_en.htm

[16] Gale, D., and Hellwig, M., 1985, "Incentive-Compatible Debt Contracts: The One-Period Problem", The Review of Economic Studies, Vol. 52(4), pp. 647-63.

[17] Gans, J.S., Hsu, D.H. and Stern, S., 2002, "When does Start-Up Innovation Spur the Gale of Creative Destruction?", RAND Journal of Economics, Vol. 33(4), pp. 571-586.

[18] Gans, J.S. and Stern, S., 2000, "Incumbency and R\&D Incentives: Licensing the Gale of Creative Destruction", Journal of Economics and Management Strategy, Vol. 9(4), pp. $485-511$.

[19] Genesove, D., 1993, "Adverse Selection in the Wholesale Used Car Market", Journal of Political Economy, Vol. 101(4), pp. 644-665.

[20] Gilbert, R. and Newbery, D.M.G., 1982, "Preemptive Patenting and the Persistence of Monopoly", American Economic Review, Vol. 72(3), pp. 514-26.

[21] Gilbert, B.A., Audretsch, D.B. and McDougall, P.P., 2004, "The Emergence of Entrepreneurship Policy", Small Business Economics, Vol. 22 (3-4), pp. 313-323.

[22] Gilligan, T.W., 2004, "Lemons and Leases in the Used Business Aircraft Market", Journal of Political Economy, Vol. 112(5), pp. 1157-80.

[23] Granstrand, O. and Sjölander, S., 1990, "The Acquisition of Technology and Small Firms by Large Firms", Journal of Economic Behavior and Organization, Vol. 13(3), pp. 367-386.

[24] Griliches, Z., 1990, "Patent Statistics as Economic Indicators: A Survey", Journal of Economic Literature, Vol. 28(4), pp. 1661-1707.

[25] Grossman, S.J. and Hart O.D., 1986, "The Costs and Benefits of Ownership: A Theory of Vertical and Lateral Integration", Journal of Political Economy, Vol. 94(4), pp. 691-719.

[26] Grossman, G.M. and Helpman, E., 1991, Innovation and Growth in the Global Economy, Cambridge, MA: MIT Press. 
[27] Hall, B.H., 1990, "The Impact of Corporate Restructuring on Industrial Research and Development", Brookings Papers on Economic Activity, Special issue Vol. 1, pp. 85-124.

[28] Hall, B.H., Jaffe, A.B. and Trajtenberg, M., 2005, "Market Value and Patent Citations", RAND Journal of Economics, Vol. 36(1), pp. 16-38.

[29] Harhoff, D., Narin, F., Scherer, F.M. and Vogel, K., 1999, "Citation Frequency and the Value of Patented Inventions", Review of Economics and Statistics, Vol. 81(3), pp. 511-515.

[30] Hart, O.D. and Moore, J., 1990, "Property Rights and the Nature of the Firm", Journal of Political Economy, Vol. 98(6), 1119-1158.

[31] Heyman, F., Norbäck, P.-J. and Persson, L., 2013, "Jobbdynamiken i svenskt näringsliv 1990 till 2009 - teori och empiri", IFN Policy Paper No. 60.

[32] Jehiel, P. and Moldovanu, B., 1995, "Cyclical Delay in Infinite Horizon Bargaining with Externalities", Review of Economic Studies, Vol. 62(4), pp. 619-639.

[33] Jehiel, P. and Moldovanu, B., 1999, "Resale Markets and the Assignment of Property Rights", Review of Economic Studies, Vol. 66(4), 971-991.

[34] Jehiel, P. and Moldovanu, B., 2006, "Allocative and Informational Externalities in Auctions and Related Mechanisms", in Blundell, R., Newey, W. and Persson, T. (eds.), The Proceedings of the 9th World Congress of the Econometric Society, New York: Cambridge University Press.

[35] Jehiel, P., Moldovanu, B. and Stacchetti, E., 1996, "How (Not) to Sell Nuclear Weapons", American Economic Review, Vol. 86(4), pp. 814-829.

[36] Jehiel, P., Moldovanu, B. and Stacchetti, E., 1999, "Multidimensional Mechanism Design for Auctions with Externalities" Journal of Economic Theory, Vol. 85(2), pp. 258-293.

[37] Kamien, M.I., 1992, "Patent Licensing", in Handbook of Game Theory with Economic Applications, Vol. 1, pp. 331-354, , New York: North-Holland.

[38] Katz, M.L. and Shapiro, C., 1986, "How to Licence Intangible Property", Quarterly Journal of Economics, Vol. 101(3), pp. 567-89.

[39] Lanjouw, J.O. and Schankerman, M., 1999, "The Quality of Ideas: Measuring Innovation with Multiple Indicators", NBER Working paper No. 7345, Cambridge, MA.

[40] Lerner, J. and Merges, R., 1998, "The Control of Strategic Alliances: An Empirical Analysis of the Biotechnology Industry", Journal of Industrial Economics, Vol. 46(2), pp. 125-156.

[41] Lofstrom, M., Bates, T. and Parker, S.C., 2014, "Why are Some People More Likely to Become Small-Businesses Owners than Others: Entrepreneurship Entry and IndustrySpecific Barriers", Journal of Business Venturing, Elsevier, Vol. 29(2), pages 232-251. 
[42] Morgan, R.P., Kruytbosch, C. and Kannankutty, N., 2001, "Patenting and Invention Activity of U.S. Scientists and Engineers in the Academic Sector: Comparisons with Industry", Journal of Technology Transfer, Vol. 26(1-2), pp. 173-183.

[43] Norbäck, P.-J. and Persson, L., 2009, "The Organization of the Innovation Industry: Entrepreneurs, Venture Capitalists and Oligopolists", Journal of European Economics Association, Vol. 7(6), pp. 1261-1290.

[44] Parker, S.C., 2013, "Do Serial Entrepreneurs Run Successively Better-Performing Businesses?", Journal of Business Venturing, Vol. 28(5), pp. 652-666.

[45] Salant, S.W., Switzer, S. and Reynolds, R.J., 1983, "Losses from Horizontal Merger: The Effects of an Exogenous Change in Industry Structure on Cournot-Nash Equilibrium", The Quarterly Journal of Economics, Vol. 98(2), pp. 185-199.

[46] Scherer, F.M. and Ross, D., 1990, Industrial Market Structure and Economic Performance. Boston: Houghton Mifflin.

[47] Schumpeter, J., 1942, Capitalism, Socialism and Democracy, London: Harper \& Brothers.

[48] Serrano, C., 2010, "The Dynamics of the Transfer and Renewal of Patents", RAND Journal of Economics, Vol. 41(4), pp. 686-708.

[49] Svensson, R., 2007, "Commercialization of Patents and External Financing during the R\&D-Phase", Research Policy, Vol. 36(7), pp. 1052-1069.

[50] Townsend, R.M., 1979, "Optimal Contracts and Competitive Markets with Costly State Verification", Journal of Economic Theory, Vol. 21(2), pp. 265-93.

[51] Trajtenberg, M., 1990, "A Penny for your Quotes: Patent Citations and the Value of Innovations", RAND Journal of Economics, Vol. 21(1), pp. 172-187.

\section{Appendix}

\subsection{Proof of Lemma 1}

First, note that $b_{i} \geq \max v_{i l}, l=\{\mathrm{e}, \mathrm{i}\}$ is a weakly dominated strategy, since no incumbent will post a bid equal to or above its maximum valuation of obtaining the invention, and firm $e$ will accept a bid iff $b_{i}>v_{e}$.

Inequality I1 Consider equilibrium candidate $\mathbf{b}^{*}=\left(b_{1}^{*}, b_{2}^{*}, \ldots, y e s\right)$. Let us assume incumbent $w \neq e$ is the incumbent that has posted the highest bid and obtains the assets, and that firm $s \neq d$ is the incumbent with the second highest bid.

Then, $b_{w}^{*} \geq v_{i i}$ is a weakly dominated strategy. $b_{w}^{*}<v_{i i}-\varepsilon$ is not an equilibrium, since firm $j \neq w, e$ then benefits from deviating to $b_{j}=b_{w}^{*}+\varepsilon$, since it will then obtain the assets and pay a price lower than its valuation of obtaining them. If $b_{w}^{*}=v_{i i}-\varepsilon$, and $b_{s}^{*} \in\left[v_{i i}-\varepsilon, v_{i i}-2 \varepsilon\right]$, then no 
incumbent has an incentive to deviate. By deviating to no, the entrepreneur's payoff decreases since it foregoes a selling price exceeding its valuation, $v_{e}$. Accordingly, the entrepreneur has no incentive to deviate and thus, $\mathbf{b}^{*}$ is a Nash equilibrium.

Let $\mathbf{b}=\left(b_{1},,, b_{n}, n o\right)$ be a Nash equilibrium. Let incumbent $h$ be the incumbent with the highest bid. The entrepreneur will then say no iff $b_{h} \leq v_{e}$. But incumbent $j \neq e$ will have the incentive to deviate to $b^{\prime}=v_{e}+\varepsilon$ in period 1 , since $v_{i e}>v_{e}$. This contradicts the assumption that $\mathbf{b}$ is a Nash equilibrium.

Inequality I2 Consider equilibrium candidate $\mathbf{b}^{*}=\left(b_{1}^{*}, b_{2}^{*}, \ldots, y\right)$. Then, $b_{w}^{*} \geq v_{i j}$ is a weakly dominated strategy. $b_{w}^{*}<v_{i j}-\varepsilon$ is not an equilibrium since firm $j \neq w, e$ then benefits from deviating to $b_{j}=b_{w}^{*}+\varepsilon$, since it will then obtain the assets and pay a price lower than its valuation of obtaining them. If $b_{w}^{*}=v_{i i}-\varepsilon$, and $b_{s}^{*} \in\left[v_{i i}-\varepsilon, v_{i i}-2 \varepsilon\right]$, then no incumbent has an incentive to deviate. By deviating to $n o$, the entrepreneur's payoff decreases since it foregoes a selling price exceeding its valuation, $v_{e}$. Accordingly, the entrepreneur has no incentive to deviate and thus, $\mathbf{b}^{*}$ is a Nash equilibrium.

Consider the equilibrium candidate $\mathbf{b}^{* *}=\left(b_{1}^{* *}, b_{2}^{* *}, \ldots, n o\right)$. Then, $b_{w}^{*} \geq v_{i e}$ is not an equilibrium since the entrepreneur would benefit by deviating to yes. If $b_{w}^{*} \leq v_{e}$, then no incumbent has an incentive to deviate. By deviating to yes, the entrepreneur's payoff decreases since it then sells its assets at a price below its valuation, $v_{e}$. The entrepreneur has no incentive to deviate and thus, $\mathbf{b}^{* *}$ is a Nash equilibrium.

Inequality I3 Consider equilibrium candidate $\mathbf{b}^{*}=\left(b_{1}^{*}, b_{2}^{*}, \ldots, y e s\right)$. Then, $b_{w}^{*} \geq v_{i i}$ is a weakly dominated strategy. $b_{w}^{*}<v_{i i}-\varepsilon$ is not an equilibrium since firm $j \neq w, e$ then benefits from deviating to $b_{j}=b_{w}^{*}+\varepsilon$, since it will then obtain the assets and pay a price lower than its valuation of obtaining them. If $b_{w}^{*}=v_{i i}-\varepsilon$, and $b_{s}^{*} \in\left[v_{i i}-\varepsilon, v_{i i}-2 \varepsilon\right]$, then no incumbent has an incentive to deviate. By deviating to $n o$, the entrepreneur's payoff decreases since it foregoes a selling price exceeding its valuation, $v_{e}$. Accordingly, the entrepreneur has no incentive to deviate and thus, $b^{*}$ is a Nash equilibrium.

Let $b=\left(b_{1}, \ldots, b_{n}, n o\right)$ be a Nash equilibrium. The entrepreneur will then say no iff $b_{h} \leq v_{e}$. But incumbent $j \neq e$ will then have the incentive to deviate to $b^{\prime}=v_{e}+\varepsilon$ in stage 1 , since $v_{i e}>v_{e}$. This contradicts the assumption that $\mathbf{b}$ is a Nash equilibrium.

Inequality I4 Consider equilibrium candidate $b^{*}=\left(b_{1}^{*}, b_{2}^{*}, \ldots\right.$, yes). Then, $b_{w}^{*}>v_{e}$ is not an equilibrium since firm $w$ would then benefit from deviating to $b_{w}=v_{e} . b_{w}^{*}<v_{e}$ is not an equilibrium, since the entrepreneur would then not accept any bid. If $b_{w}^{*}=v_{e}-\varepsilon$, then firm $w$ has no incentive to deviate. By deviating to $b_{j}^{\prime} \leq b_{w}^{*}$, firm $j$ 's, $j \neq w, e$, payoff does not change. By deviating to $b_{j}^{\prime}>b_{w}^{*}$, firm $j$ 's payoff decreases since it must pay a price above its willingness to pay $v_{i i}$. Accordingly, firm $j$ has no incentive to deviate. By deviating to $n o$, the entrepreneur's payoff decreases since it foregoes a selling price above its valuation $v_{e}$. Accordingly, the entrepreneur has no incentive to deviate and thus, $b^{*}$ is a Nash equilibrium.

Let $b=\left(b_{1},,, b_{n}\right.$, yes $)$ be a Nash equilibrium. If $b_{w} \geq v_{i i}$, then firm $w$ will have the incentive to deviate to $b^{\prime}=b_{w}-\varepsilon$. If $b_{w}<v_{i i}$, the entrepreneur will have the incentive to deviate to $n o$, which contradicts the assumption that $b$ is a Nash equilibrium. 
Let $b=\left(b_{1}, \ldots, b_{n}, n o\right)$ be a Nash equilibrium. The entrepreneur will then say no iff $b_{h} \leq v_{e}$. But incumbent $j \neq d$ will have the incentive to deviate to $b^{\prime}=v_{e}+\varepsilon$ in stage 1 since $v_{i e}>v_{e}$, which contradicts the assumption that $b$ is a Nash equilibrium.

Inequalities I5 or I6 Consider equilibrium candidate $b^{*}=\left(b_{1}^{*}, b_{2}^{*}, \ldots, n o\right)$, where $b_{j}^{*}<v_{e}$ $\forall j \in J$. It then directly follows that no firm has an incentive to deviate and thus, $b^{*}$ is a Nash equilibrium.

Then, note that the entrepreneur will accept a bid iff $b_{j} \geq v_{e}$. But $b_{j} \geq v_{e}$ is a weakly dominating bid in these intervals, since $v_{e}>\max \left\{v_{i i}, v_{i e}\right\}$. Thus, the assets will not be sold in these intervals.

\subsection{Results in the LC-model}

First, use Example 1 with $\gamma=1$. From Definition $3 k^{E D}$ is defined from $v_{i e}\left(k^{E D}, \cdot\right)=v_{e}\left(k^{E D}, \cdot\right)$ and $k^{P E}$ is defined from $v_{i i}\left(k^{P E}, \cdot\right)=v_{e}\left(k^{P E}, \cdot\right)$. Using Example 1, we have

$$
\begin{aligned}
k^{E D} & =\frac{n^{2}-2}{6 n+3 n^{2}+2} \Lambda<\Lambda, k^{P E}=\frac{n+1}{3 n+5} \Lambda<\Lambda, \\
k^{P E}-k^{E D} & =2(n+2) \frac{2 n+3}{(3 n+5)\left(6 n+3 n^{2}+2\right)}>0
\end{aligned}
$$

where $\pi_{N}(l)=0$ for $k=\Lambda=a-c$. Also, note that $v_{i e}-v_{e}=-\frac{n^{2}-2}{(n+2)^{2}(n+1)^{2}} \Lambda^{2}<0$ for $k=0$ and $F=0$, and that $v_{i e}-v_{i i}=(\Lambda-k)^{2} \frac{2 n+3}{(n+2)^{2}(n+1)^{2}}>0$.

Now define, $\tilde{k}^{E D}$ is defined from $v_{i e, k}^{\prime}\left(\tilde{k}^{E D}, \cdot\right)=v_{e . k}^{\prime}\left(\tilde{k}^{E D}, \cdot\right)$ and $\tilde{k}^{P E}$ is defined from $v_{i i, k}^{\prime}\left(\tilde{k}^{P E}, \cdot\right)=v_{e, k}^{\prime}\left(\tilde{k}^{P E}, \cdot\right)$. By calculation:

$$
\begin{aligned}
\tilde{k}^{E D} & =\frac{2 n+3}{6 n+3 n^{2}+2} n \Lambda, \quad \tilde{k}^{P E}=\frac{3+2 n}{3 n+5} \Lambda \\
\tilde{k}^{P E}-\tilde{k}^{E D} & =\Lambda(n+2) \frac{2 n+3}{(3 n+5)\left(6 n+3 n^{2}+2\right)}>0
\end{aligned}
$$

Moreover,

$$
\begin{aligned}
\tilde{k}^{P E}-k^{P E} & =\frac{n+2}{3 n+5} \Lambda>0 \\
\tilde{k}^{E D}-k^{E D} & =(n+2) \frac{n+1}{6 n+3 n^{2}+2} \Lambda>0 \\
\tilde{k}^{E D}-k^{P E} & =\Lambda(n+2) \frac{4 n+3 n^{2}-1}{(3 n+5)\left(6 n+3 n^{2}+2\right)}>0
\end{aligned}
$$

Thus, we have established that:

$$
\Lambda>\tilde{k}^{P E}>\tilde{k}^{E D}>k^{P E}>k^{E D}>0
$$

In Assumption A2, we thus have $\tilde{k}=\tilde{k}^{E D}$. 


\subsection{Deriving the Bayes-Nash equilibrium in the LC-model}

Let us solve the for the Bayes-Nash equilibrium in the product market interaction in stage 3 . Let $P(l, t)=a-Q(l, t)$ be the inverse demand, where $Q(l, t)=\sum_{j=1}^{N(l)} q_{j}(l, t)$. In the Bayes-Nash equilibrium firms maximize the following direct profits :

$$
\begin{aligned}
\pi_{h}(\cdot, l, s) & =[P(l, s)-(c-k)] q_{h}(l, s) \\
\pi_{h}(\cdot, l, f) & =[P(l, f)-c] q_{h}(l, f) \\
\bar{\pi}_{N}(l) & =\theta[P(l, s)-c] q_{N}(l)+(1-\theta)[P(l, f)-c] q_{N}(l)
\end{aligned}
$$

where again non-acquiring incumbents do not know the true quality of the invention.

The first-order conditions are:

$$
\begin{aligned}
\frac{\partial \pi_{h}(\cdot, l, s)}{\partial q_{h}(l, s)} & =[P(l, f)-c] q_{h}(l, f)-q_{h}(l, s)=0 \\
\frac{\partial \pi_{h}(\cdot, l, f)}{\partial q_{h}(l, f)} & =[P(l, f)-c]-q_{h}(l, f)=0 \\
\frac{\partial \bar{\pi}_{N}(l)}{\partial q_{N}(l)} & =\theta[P(l, s)-c]+(1-\theta)[P(l, f)-c]-q_{N}(l)=0
\end{aligned}
$$

The Bayes-Nash equilibrium can then be solved as:

$$
\begin{aligned}
q_{h}^{*}(l, s, \theta) & =\frac{\Lambda+k-(N(l)-1) q_{N}^{*}(l, \theta)}{2} \\
q_{h}^{*}(l, f, \theta) & =\frac{\Lambda-(N(l)-1) q_{N}^{*}(l, \theta)}{2} \\
q_{N}^{*}(l, \theta) & =\frac{\Lambda-\theta k}{N(l)+1}
\end{aligned}
$$

Note that (9.1) and (9.4) implies a reduced-form profit $\pi_{h}(l, s, \theta)=\left[q_{h}^{*}(l, s, \theta)\right]^{2}$ for $h=A, E$ and (9.2) and (9.5) implies a reduced-form profit $\pi_{h}(l, f, \theta)=\left[q_{h}^{*}(l, f, \theta)\right]^{2}$ for $h=A, E$.

From (9.7) and (9.8) it then follows that $\pi_{h}(l, s, \theta)>\pi_{h}(l, f, \theta)$ for $h=A, E$.

Let $P(l, t, \theta)=a-Q^{*}(l, t, \theta)$ and note that $P(l, s, \theta)-P(l, f, \theta)=-\frac{k}{2}$. Note that $\pi_{N}(l, s, \theta)=$ $[P(l, s, \theta)-c)] q_{N}^{*}(l, \theta)$ and that $\pi_{N}(l, f, \theta)=[P(l, f, \theta)-c] q_{N}^{*}(l, \theta)$. It follows that $\pi_{N}(l, f, \theta)-$ $\pi_{N}(l, f, \theta)=[P(l, f, \theta)-P(l, s, \theta)] q_{N}^{*}(l, \theta)=\frac{k}{2} q_{N}^{*}(l, \theta)>0$. Also for $h=A, E, \pi_{h}(l, f, \theta)-$ $\pi_{N}(l, f, \theta)=[P(l, f, \theta)-c]\left[q_{h}^{*}(l, f, \theta)-q_{N}^{*}(l, f, \theta)\right]>0$, since $q_{h}^{*}(l, f, \theta)-q_{N}^{*}(l, \theta)=\frac{\theta k}{2} \geq 0$. Hence, we have shown that

$$
\pi_{h}(l, s, \theta)>\pi_{h}(l, f, \theta)>\pi_{N}(l, f, \theta)>\pi_{N}(l, s, \theta) \text { for } h=A, E
$$

Note that (9.7) and (9.8) implies, $\frac{d \pi_{h}(l, t, \theta)}{d k}>0$ for $h=A, E$. Moreover, we have that

$$
\begin{aligned}
\frac{d P(l, s, \theta)}{d k} & =-\frac{1}{2}\left[1-\theta \frac{N(l)-1}{N(l)+1}\right]<0 \\
\frac{d P(l, f, \theta)}{d k} & =\frac{\theta}{2} \frac{N(l)-1}{N(l)+1}>0
\end{aligned}
$$

Then, $\frac{d \pi_{N}(l, s, \theta)}{d k}=\frac{d P(l, s, \theta)}{d k} q_{N}^{*}(l, \theta)+[P(l, s, \theta)-c] \frac{d q_{N}^{*}(l, \theta)}{d k}<0$, since $\frac{d q_{N}^{*}(l, \theta)}{d k}<0$ and $\frac{d P(l, s, \theta)}{d k}<0$. It also follows that $\frac{d \pi_{h}(l, t, \theta)}{d k}-\frac{d \pi_{N}(l, t, \theta)}{d k}=\frac{d P(l, f, \theta)}{d k}\left[q_{h}^{*}(l, f, \theta)-q_{N}^{*}(l, \theta)\right]+[P(l, s, \theta)-c]\left(\frac{d q_{h}^{*}(l, f, \theta)}{d k}-\frac{d q_{N}^{*}(l, \theta)}{d k}\right)>$ 
0 since $\frac{d P(l, f, \theta)}{d k}>0, q_{h}^{*}(l, f, \theta)>q_{N}^{*}(l, \theta)$ and $\frac{d q_{h}^{*}(l, f, \theta)}{d k}>\frac{d q_{N}^{*}(l, \theta)}{d k}$ from (9.11), (9.8) and (9.9).

\subsection{Proof of Proposition 6}

Note that if incumbents are certain that the invention is successful $(\theta=1)$, Assumption A2 implies:

$$
\bar{w}_{i l, k}^{\prime}(1)-w_{e, k}^{\prime}(s, 1)=v_{i l, k}^{\prime}(s, 1)-v_{e, k}^{\prime}(s, 1)+v_{i l, k}^{\prime}(s)-v_{e, k}^{\prime}(s)>0,
$$

since $v_{i l, k}^{\prime}(s, 1)-v_{e, k}^{\prime}(s, 1)=v_{i l, k}^{\prime}(s)-v_{e, k}^{\prime}(s)>0$.

If incumbents are certain that the invention is unsuccessful $(\theta=0)$, we have:

$$
\bar{w}_{i l, k}^{\prime}(0)-w_{e, k}^{\prime}(s, 0)=\left\{\begin{array}{l}
-\left[v_{e, k}^{\prime}(s, 0)+v_{e, k}^{\prime}(s)\right]<0 \text { for } k \in\left[0, \breve{k}_{0}^{P E}\right) \\
-\left[v_{e, k}^{\prime}(s, 0)+v_{i i, k}^{\prime}(s)\right]<0 \text { for } k \in\left[\breve{k}_{0}^{P E}, k^{\max }\right)
\end{array}\right.
$$

noting that $v_{e, k}^{\prime}(s)>0$ and $v_{i i, k}^{\prime}(s)>0$ while $\bar{w}_{i l, k}^{\prime}(0)=0$ and $v_{e, k}^{\prime}(s, 0)>0$ from Assumption A4. Since the prior $\theta \in[0,1]$ is continuous, there must exist a cut-off prior $\tilde{\theta}$ such that $\bar{w}_{i l, k}^{\prime}(\tilde{\theta})-$ $w_{e, k}^{\prime}(s, \tilde{\theta})=0$ for $k \in\left[\breve{k}_{0}^{P E}, k^{\max }\right)$. For any $\theta=\tilde{\theta}+\varepsilon$ we then have $\bar{w}_{i l, k}^{\prime}(\theta)-w_{e, k}^{\prime}(s, \theta)>0$ and for any $\theta=\tilde{\theta}-\varepsilon, \bar{w}_{i l, k}^{\prime}(\theta)-w_{e, k}^{\prime}(s, \theta)<0$. 
Table 5.1. Explanatory variables and basic statistics.

\begin{tabular}{|c|c|c|c|c|c|c|c|}
\hline \multirow{2}{*}{$\begin{array}{l}\text { Variable } \\
\text { name }\end{array}$} & \multirow[t]{2}{*}{ Variable description } & \multirow[t]{2}{*}{$\begin{array}{c}\text { Measure } \\
\text { of: }\end{array}$} & \multirow{2}{*}{$\begin{array}{l}\text { Expected sign } \\
\text { (preemptive } \\
\text { acquisition): }\end{array}$} & \multicolumn{2}{|c|}{$\begin{array}{l}\text { All patents } \\
(\mathrm{n}=624)\end{array}$} & \multicolumn{2}{|c|}{$\begin{array}{l}\text { Commercialized } \\
\text { patents }(\mathrm{n}=364)\end{array}$} \\
\hline & & & & Mean & Std.dev & Mean & Std.dev. \\
\hline$W_{-} C I T$ & $\begin{array}{l}\text { Number of forward citations } \\
\text { within technologies per five- } \\
\text { year period }\end{array}$ & $k$ & $\gamma_{W_{-} C I T}>0$ & 0.41 & 0.93 & 0.49 & 1.03 \\
\hline$D \_W \_C I T$ & $\begin{array}{l}\text { Dummy }=1 \text { if the patent has } \\
\text { received forward citations } \\
\text { within technologies, and } 0 \\
\text { otherwise }\end{array}$ & $k$ & $\gamma_{W_{-} C I T}>0$ & 0.36 & 0.48 & 0.41 & 0.49 \\
\hline SMALL & $\begin{array}{l}\text { Dummy which equals } 1 \text { for } \\
\text { small firms (11-200 employees), } \\
\text { and } 0 \text { otherwise }\end{array}$ & $G$ & $\gamma_{S M A L L}<0$ & 0.16 & 0.37 & 0.20 & 0.40 \\
\hline MICRO & $\begin{array}{l}\text { Dummy which equals } 1 \text { for } \\
\text { micro firms ( } 2-10 \text { employees), } \\
\text { and } 0 \text { otherwise }\end{array}$ & $G$ & $\gamma_{M I C R O}<0$ & 0.20 & 0.40 & 0.24 & 0.43 \\
\hline$P V C$ & $\begin{array}{l}\text { Percentage of R\&D-phase } \\
\text { financed by private venture } \\
\text { capitalist }\end{array}$ & $\Gamma$ & $\gamma_{P V C}>0$ & 3.17 & 13.9 & 3.44 & 14.4 \\
\hline B_CIT & $\begin{array}{l}\text { Number of forward citations } \\
\text { between technologies per five- } \\
\text { year period }\end{array}$ & & & 0.05 & 0.21 & 0.07 & 0.24 \\
\hline$D \_B \_C I T$ & $\begin{array}{l}\text { Dummy = } 1 \text { if the patent has } \\
\text { received forward citations } \\
\text { between technologies, and } 0 \\
\text { otherwise }\end{array}$ & & & 0.08 & 0.28 & 0.10 & 0.30 \\
\hline$A P P L Y$ & Year patent was filed & & & 1995 & 1.7 & 1995 & 1.7 \\
\hline
\end{tabular}

Table 5.2. Commercialization mode and forward patent citations within technologies, number of patents and citations.

\begin{tabular}{|c|c|c|c|c|}
\hline $\bar{W}_{-} C I T$ & $\begin{array}{c}\text { No } \\
\text { commercialization }\end{array}$ & Entry & Sale & All \\
\hline \multirow[t]{2}{*}{$W_{-} C I T=0$} & 188 & 164 & 49 & 401 \\
\hline & $(72 \%)$ & $(60 \%)$ & $(54 \%)$ & $(64 \%)$ \\
\hline$W_{-} C I T=1$ & 32 & 46 & 16 & 94 \\
\hline$W_{-} C I T=2$ & 15 & 24 & 8 & 47 \\
\hline$W_{-} C I T=3$ & 8 & 11 & 6 & 25 \\
\hline$W_{-} C I T>3$ & 17 & 28 & 12 & 57 \\
\hline Total No. of patents & 260 & 273 & 91 & 624 \\
\hline $\begin{array}{l}\text { Total No. of } \\
\text { citations }\end{array}$ & 196 & 291 & 145 & 632 \\
\hline $\begin{array}{l}\text { Average No. of } \\
\text { citations per patent }\end{array}$ & 0.75 & 1.07 & 1.59 & 1.01 \\
\hline
\end{tabular}


Table 5.3 Commercialization mode across firm sizes, number of patents and percent.

\begin{tabular}{lcccc}
\hline \hline $\begin{array}{l}\text { Kind of firm where invention } \\
\text { was created }\end{array}$ & $\begin{array}{c}\text { Total number } \\
\text { of patents }\end{array}$ & $\begin{array}{c}\text { Percent latest } \\
\text { commercialized in 2003 }\end{array}$ & $\begin{array}{c}\text { Percent } \\
\text { Entry }\end{array}$ & $\begin{array}{c}\text { Percent } \\
\text { Sale }\end{array}$ \\
\hline \hline Small firms (11-200 employees) & 102 & $70 \%$ & $63 \%$ & $7 \%$ \\
Micro companies (2-10 employees) & 122 & $72 \%$ & $57 \%$ & $15 \%$ \\
\cline { 2 - 6 } \begin{tabular}{l} 
Individuals (1-4 inventors) \\
\cline { 2 - 6 } Total
\end{tabular} & 624 & $51 \%$ & $35 \%$ & $16 \%$ \\
\hline
\end{tabular}

Table 5.4. Results of the probit model

\begin{tabular}{|c|c|c|c|}
\hline \multirow{3}{*}{$\begin{array}{l}\text { Explanatory } \\
\text { variables }\end{array}$} & \multicolumn{3}{|c|}{ Dependent variable $=S A L E$} \\
\hline & \multicolumn{3}{|c|}{ Statistical model: Binomial probit model } \\
\hline & Specification A & Specification B & Specification C \\
\hline \multirow[t]{2}{*}{$W_{-} C I T$} & $0.144 * *$ & $0.161 * *$ & $0.161 * *$ \\
\hline & $(0.069)$ & $(0.073)$ & $(0.075)$ \\
\hline \multirow[t]{2}{*}{$S M A L L$} & $-0.946 * * *$ & $-0.938 * * *$ & $-0.954 * * *$ \\
\hline & $(0.247)$ & $(0.247)$ & $(0.246)$ \\
\hline \multirow[t]{2}{*}{ MICRO } & $-0.342 *$ & -0.315 & $-0.318 *$ \\
\hline & $(0.190)$ & $(0.192)$ & $(0.191)$ \\
\hline \multirow{2}{*}{$P V C$} & $6.1 \mathrm{E}-3$ & $5.8 \mathrm{E}-3$ & $6.0 \mathrm{E}-3$ \\
\hline & $(5.2 \mathrm{E}-3)$ & $(5.1 \mathrm{E}-3)$ & $(5.1 \mathrm{E}-3)$ \\
\hline \multirow[t]{2}{*}{$B \_C I T$} & & -0.429 & -0.428 \\
\hline & & $(0.38)$ & $(0.38)$ \\
\hline \multirow[t]{2}{*}{$A P P L Y$} & & & -0.031 \\
\hline & & & $(0.05)$ \\
\hline Technology FE & Yes & Yes & Yes \\
\hline Region FE & Yes & Yes & Yes \\
\hline Log Likelihood & -185.2 & -184.7 & -184.4 \\
\hline Wald, $\chi^{2}$ & $42.8 * *$ & $43.5 * *$ & $44.2 * *$ \\
\hline Wald, $\chi^{2}$ (Core var.) & $20.5 * * *$ & $20.8 * * *$ & $21.8 * * *$ \\
\hline
\end{tabular}


Table 5.5. Results of the probit model with citation dummies

\begin{tabular}{|c|c|c|c|}
\hline \multirow{3}{*}{$\begin{array}{l}\text { Explanatory } \\
\text { Variables }\end{array}$} & \multicolumn{3}{|c|}{ "Dependent variable $=S A L E$} \\
\hline & \multicolumn{3}{|c|}{ Statistical model: Binomial probit model } \\
\hline & Specification A & Specification B & Specification $\mathrm{C}$ \\
\hline \multirow[t]{2}{*}{$D_{-} W_{-} C I T$} & $0.280 *$ & $0302 *$ & $0.303 *$ \\
\hline & $(0.166)$ & $(0.170)$ & $(0.171)$ \\
\hline \multirow[t]{2}{*}{$S M A L L$} & $-0.967 * * *$ & $-0.959 * * *$ & $-0.972 * * *$ \\
\hline & $(0.247)$ & $(0.247)$ & $(0.246)$ \\
\hline \multirow[t]{2}{*}{ MICRO } & $-0.365 *$ & $-0.351 *$ & $-0.354 *$ \\
\hline & $(0.192)$ & $(0.194)$ & $(0.193)$ \\
\hline \multirow[t]{2}{*}{$P V C$} & $5.6 \mathrm{E}-3$ & $5.3 \mathrm{E}-3$ & $5.4 \mathrm{E}-3$ \\
\hline & $(5.1 \mathrm{E}-3)$ & $5.2 \mathrm{E}-3)$ & $(5.2 \mathrm{E}-3)$ \\
\hline \multirow[t]{2}{*}{$D \_B \_C I T$} & & -0.193 & -0.198 \\
\hline & & $(0.259)$ & $(0.25)$ \\
\hline \multirow[t]{2}{*}{$A P P L Y$} & & & -0.033 \\
\hline & & & $(0.045)$ \\
\hline Technology FE & Yes & Yes & Yes \\
\hline Region FE & Yes & Yes & Yes \\
\hline Log Likelihood & -185.2 & -184.7 & -184.4 \\
\hline Wald, $\chi^{2}$ & $40.9 * *$ & $41.9 * *$ & $45.1 * *$ \\
\hline Wald, $\chi^{2}$ (Core var.) & $19.4 * * *$ & $19.4 * * *$ & $21.3 * * *$ \\
\hline \multicolumn{4}{|c|}{$\begin{array}{l}\text { Note: The number of observations is } 364 \text {. SALE equals } 1 \text { for } 91 \text { observations. ***, ** and * indicate } \\
\text { significance at the } 1,5 \text { and } 10 \text { percent level. Standard errors clustered on the inventor are given in } \\
\text { parentheses. Parameter estimates for constants, technology and region dummies are not shown, but } \\
\text { available from the authors upon request. The Wald } \chi^{2} \text { tests the hypothesis } \gamma=0 \text { in }(5.4) \text {. The Wald } \chi^{2} \text { test in } \\
\text { the last row repeats this for the core variables for } D_{-} \text {W_CIT, SMALL, MICRO and PVC. }\end{array}$} \\
\hline
\end{tabular}


Table 6.1. Results of the multinomial logit model

\begin{tabular}{|c|c|c|c|c|c|c|}
\hline \multirow{3}{*}{$\begin{array}{l}\text { Explanatory } \\
\text { variables }\end{array}$} & \multicolumn{6}{|c|}{ Multinomial logit model with "No commercialization" as the base alternative } \\
\hline & \multicolumn{3}{|c|}{$\begin{array}{c}\text { Specification A } \\
\text { (Quality measured with W_CIT) }\end{array}$} & \multicolumn{3}{|c|}{$\begin{array}{c}\text { Specification B } \\
\text { (Quality measured with D_W_CIT- } \\
\text { dummy) }\end{array}$} \\
\hline & SALE & ENTRY & $\begin{array}{l}\text { Wald } \chi^{2} \\
\text { (diff) }\end{array}$ & $S A L E$ & ENTRY & $\begin{array}{l}\text { Wald } \chi^{2} \\
\text { (diff) }\end{array}$ \\
\hline$W_{-} C I T$ & $\begin{array}{l}0.454 * \\
(0.241)\end{array}$ & $\begin{array}{c}0.268 \\
(0.216)\end{array}$ & $3.32 *$ & $\begin{array}{c}1.340 * * * \\
(0.323)\end{array}$ & $\begin{array}{l}0.859 * * * \\
(0.256)\end{array}$ & $2.78^{*}$ \\
\hline$S M A L L$ & $\begin{array}{l}-0.458 \\
(0.526)\end{array}$ & $\begin{array}{l}1.174 * * * \\
(0.361)\end{array}$ & $12.84 * * *$ & $\begin{array}{l}-0.595 \\
(0.530)\end{array}$ & $\begin{array}{l}1.075 * * * \\
(0.364)\end{array}$ & $13.08 * * *$ \\
\hline$M I C R O$ & $\begin{array}{c}0.856 * * \\
(0.397)\end{array}$ & $\begin{array}{l}1.376 * * * \\
(0.337)\end{array}$ & 2.50 & $\begin{array}{c}0.678 \\
(0.400)\end{array}$ & $\begin{array}{l}1.274 * * * \\
(0.335)\end{array}$ & $3.19 *$ \\
\hline$P V C$ & $\begin{array}{l}1.1 \mathrm{E}-2 \\
(8.2 \mathrm{E}-3)\end{array}$ & $\begin{array}{l}4.1 \mathrm{E}-3 \\
(8.6 \mathrm{E}-3)\end{array}$ & 1.66 & $\begin{array}{l}8.9 \mathrm{E}-3 \\
(8.2 \mathrm{E}-3)\end{array}$ & $\begin{array}{l}-7.5 \mathrm{E}-3 \\
(8.6 \mathrm{E}-3)\end{array}$ & 1.36 \\
\hline Technology FE & \multicolumn{2}{|c|}{ Yes } & \multicolumn{4}{|c|}{ Yes } \\
\hline Regional FE & \multicolumn{2}{|c|}{ Yes } & \multicolumn{4}{|c|}{ Yes } \\
\hline Log likelihood & \multicolumn{2}{|c|}{483.0} & \multicolumn{4}{|c|}{-476.9} \\
\hline I. Wald $\chi^{2}$ & \multicolumn{2}{|c|}{$90.2 * * *$} & \multicolumn{4}{|c|}{$99.4 * * *$} \\
\hline II. Wald $\chi^{2}$ & $37.2 * *$ & $49.9 * * *$ & $39.7 * *$ & $55.0 * * *$ & $55.5 * * *$ & $38.2 * *$ \\
\hline III, Wald $\chi^{2}$ (core) & $13.2 * *$ & $28.5 * * *$ & $19.0 * * *$ & $23.9 * * *$ & $29.2 * * *$ & $17.8^{* * *}$ \\
\hline
\end{tabular}

Note : The number of observations equals 527, of which ENTRY=1 for 273 observations and $S A L E=1$ for 91 observations. 163 observations are classified as "No commercialization", where the patent has expired with the inventor receiving no income. Standard errors clustered on inventor are given in parentheses. ***, ** and * indicate significance at the 1,5 and 10 percent level. Parameter estimates for technology and region dummies are not shown, but are available from the authors upon request.

Wald test I tests the full specification. Wald test II tests $\boldsymbol{\beta}=\mathbf{0}$ and $\boldsymbol{\alpha}=\mathbf{0}$ in (5.8), respectively, under the assumption of $\psi=0$. Wald test III repeats this for the core variables W_CIT, SMALL, MICRO and PVC all being zero. The Wald $\chi^{2}$ (diff) given in columns four and seven test if individual parameter estimates differ between equations. Columns four and six for Wald tests II and III test $\boldsymbol{\beta}=\boldsymbol{\alpha}$ for the full specification and then repeat this for the core variables for $W_{-} C I T, S M A L L, M I C R O$ and $P V C$. 
Table 7.1. Results of the probit model with late sale

\begin{tabular}{|c|c|c|c|}
\hline \multirow{3}{*}{$\begin{array}{l}\text { Explanatory } \\
\text { variables }\end{array}$} & \multicolumn{3}{|c|}{ Dependent variable $=L A T E S A L E$} \\
\hline & \multicolumn{3}{|c|}{ Statistical model: Binomial probit model } \\
\hline & Specification A & Specification B & Specification C \\
\hline \multirow[t]{2}{*}{$W_{-} C I T$} & $0.229 * *$ & $0.249 * *$ & $0.248 * *$ \\
\hline & $(0.108)$ & $(0.110)$ & (0.109) \\
\hline \multirow[t]{2}{*}{$S M A L L$} & -0.197 & -0.196 & -0.176 \\
\hline & $(0.288)$ & $(0.289)$ & $(0.281)$ \\
\hline \multirow[t]{2}{*}{ MICRO } & 0.151 & 0.189 & 0.189 \\
\hline & $(0.262)$ & $(0.265)$ & $(0.264)$ \\
\hline \multirow[t]{2}{*}{$P V C$} & $-4.5 \mathrm{E}-3$ & $-4.6 \mathrm{E}-3$ & $5.2 \mathrm{E}-3$ \\
\hline & (8.5 E-3) & (8.5 E-3) & (8.6 E-3) \\
\hline \multirow[t]{2}{*}{ B_CIT } & & -0.436 & -0.444 \\
\hline & & $(0.472)$ & $(0.481)$ \\
\hline \multirow{2}{*}{$A P P L Y$} & & & 0.027 \\
\hline & & & $(0.068)$ \\
\hline Technology FE & Yes & Yes & Yes \\
\hline Region FE & Yes & Yes & Yes \\
\hline Log Likelihood & -84.8 & -84.5 & -84.4 \\
\hline Wald $\chi^{2} \mathrm{I}$ & $26.5 * *$ & $29.4 * *$ & $29.8 *$ \\
\hline Wald $\chi^{2}$ II & 5.81 & 6.54 & 6.53 \\
\hline Wald $\chi^{2}$ III & 1.52 & 2.51 & 2.48 \\
\hline \multicolumn{4}{|c|}{$\begin{array}{l}\text { Note: The number of observations is } 303 . \text { LATESALE equals } 1 \text { for } 30 \text { observations. ***, ** and } * \text { indicate } \\
\text { significance at the } 1,5 \text { and } 10 \text { percent level. Standard errors clustered on the inventor are given in } \\
\text { parentheses. Parameter estimates for constants, technology and region dummies are not shown, but } \\
\text { available from the authors upon request. The Wald } \chi^{2} \text { I test tests the hypothesis } \gamma=0 \text { in (5.4). The Wald } \chi^{2} \text { II } \\
\text { test repeats this for the core variables } W_{-} C I T, S M A L L, M I C R O \text { and } P V C \text { and Wald } \chi^{2} \text { III test for SMALL, } \\
\text { MICRO and PVC. }\end{array}$} \\
\hline
\end{tabular}


Table 7.2. Results of the multinomial logit model with direct sale

\begin{tabular}{|c|c|c|c|c|c|c|}
\hline \multirow{3}{*}{$\begin{array}{l}\text { Explanatory } \\
\text { variables }\end{array}$} & \multicolumn{6}{|c|}{ Multinomial logit model with "No commercialization" as the base alternative } \\
\hline & \multicolumn{3}{|c|}{ Specification A } & \multicolumn{3}{|c|}{ Specification B } \\
\hline & $\begin{array}{c}\text { DIRECT } \\
\text { SALE }\end{array}$ & $\begin{array}{c}\text { DIRECT } \\
\text { ENTRY }\end{array}$ & $\begin{array}{c}\text { Wald } \chi^{2} \\
\text { (diff) }\end{array}$ & $\begin{array}{c}\text { DIRECT } \\
\text { SALE }\end{array}$ & $\begin{array}{c}\text { DIRECT } \\
\text { ENTRY }\end{array}$ & $\begin{array}{l}\text { Wald } \chi^{2} \\
\text { (diff) }\end{array}$ \\
\hline$W_{-} C I T$ & $\begin{array}{c}0.418 \\
(0.260)\end{array}$ & $\begin{array}{c}0.275 \\
(0.228)\end{array}$ & 1.94 & & & \\
\hline$D \_W \_C I T$ & & & & $\begin{array}{c}1.16 * * * \\
(0.373)\end{array}$ & $\begin{array}{c}0.862 * * * \\
(0.236)\end{array}$ & 0.74 \\
\hline$S M A L L$ & $\begin{array}{l}-2.01 * \\
(1.08)\end{array}$ & $\begin{array}{c}1.24 * * * \\
(0.36)\end{array}$ & $9.64 * * *$ & $\begin{array}{c}-2.12 * * \\
(1.06)\end{array}$ & $\begin{array}{c}1.16 * * * \\
(0.363)\end{array}$ & $10.02 * * *$ \\
\hline MICRO & $\begin{array}{c}0.415 \\
(0.470)\end{array}$ & $\begin{array}{c}1.36 * * * \\
(0.35)\end{array}$ & $5.31 * *$ & $\begin{array}{c}0.263 \\
(0.472)\end{array}$ & $\begin{array}{c}1.26 \text { *** } \\
(0.353)\end{array}$ & $5.83 * *$ \\
\hline$P V C$ & $\begin{array}{c}0.015 \\
(9.4 \mathrm{E}-3)\end{array}$ & $\begin{array}{l}-1.5 \mathrm{E}-4 \\
(8.9 \mathrm{E}-3)\end{array}$ & $2.97 *$ & $\begin{array}{c}0.013 \\
(9.5 \mathrm{E}-3)\end{array}$ & $\begin{array}{l}-2.5 \mathrm{E}-3 \\
(8.8 \mathrm{E}-3)\end{array}$ & 2.73 \\
\hline $\begin{array}{l}\text { Technology FE } \\
\text { Regional FE }\end{array}$ & & $\begin{array}{l}\text { Yes } \\
\text { Yes }\end{array}$ & & & $\begin{array}{l}\text { Yes } \\
\text { Yes }\end{array}$ & \\
\hline Log likelihood & & & & & & \\
\hline I. Wald $\chi^{2}$ & & & & 99 & k** & \\
\hline II. Wald $\chi^{2}$ & $25.7 *$ & $44.7 * * *$ & $36.5 * * *$ & $38.9 * * *$ & $53.3 * * *$ & $38.1 * * *$ \\
\hline III, Wald $\chi^{2}$ (core) & $9.9 * *$ & $28.1 * * *$ & $18.4 * * *$ & $17.6 * * *$ & $36.3 * * *$ & $18.6 * * *$ \\
\hline
\end{tabular}

Note : The number of observations equals 527, of which $M O D E=1$ (Direct Entry) for 303 observations and $M O D E=2$ (Direct sale) for 61 observations. 163 observations are classified as "No commercialization" $(M O D E=0)$, where the patent has expired with the inventor receiving no income. Standard errors clustered on the inventor are given in parentheses. $* * *, * *$ and * indicate significance at the 1,5 and 10 percent level. Parameter estimates for technology and region dummies are not shown, but available from the authors upon request.

Wald test I tests the full specification. Wald test II tests $\boldsymbol{\beta}=\mathbf{0}$ and $\boldsymbol{\alpha}=\mathbf{0}$ in (5.8), respectively, under the assumption of $\psi=0$. Wald test III repeats this for the core variables $W_{-} C I T, S M A L L, M I C R O$ and PVC all being zero. The Wald $\chi^{2}$ (diff) given in columns four and seven test if individual parameter estimates differ between equations. Columns four and six for Wald tests II and III test $\boldsymbol{\beta}=\boldsymbol{\alpha}$ for the full specification and then repeat this for the core variables for $W_{-} C I T, S M A L L, M I C R O$ and $P V C$. 


\section{Appendix}

Table A1. Results of the logit model.

\begin{tabular}{lccc}
\hline \hline \multirow{2}{*}{ Explanatory } & \multicolumn{3}{c}{ Dependent variable $=$ SALE } \\
\cline { 2 - 4 } & \multicolumn{3}{c}{ Statistical model: Binomial logit model } \\
\cline { 2 - 4 }$W_{-} C I T$ & Specification A & Specification B & Specification C \\
SMALL & $0.232^{* *}$ & $0.265 * *$ & $0.264 * *$ \\
& $(0.118)$ & $(0.127)$ & $(0.129)$ \\
MICRO & $-1.62 * * *$ & $-1.61 * * *$ & $-1.62 * * *$ \\
& $(0.466)$ & $(0.466)$ & $(0.463)$ \\
PVC & $-0.548^{*}$ & $-0.494 *$ & $-0.498 *$ \\
& $(0.331)$ & $(0.337)$ & $(0.333)$ \\
\hline$B_{-} C I T$ & 0.010 & $9.9 \mathrm{E}-3$ & 0.010 \\
& $(8.7 \mathrm{E}-3)$ & $(8.7 \mathrm{E}-3)$ & $(8.6 \mathrm{E}-3)$ \\
APPLY & & -0.773 & -0.771 \\
& & $(0.723)$ & $(0.713)$ \\
\hline Technology FE & & & -0.046 \\
Region FE & Yes & Yes & $(0.085)$ \\
\hline Log Likelihood & Yes & Yes & Yes \\
Wald, $\chi^{2}$ & -185.9 & -185.3 & -185.1 \\
Wald, $\chi^{2}$ (Core var.) & $38.1 * *$ & $38.5 * *$ & $40.0 * *$ \\
\hline
\end{tabular}

Note: The number of observations is 364. SALE equals 1 for 91 observations. ***, ** and * indicate significance at the 1,5 and 10 percent level. Standard errors clustered on the inventor are given in parentheses. Parameter estimates for constants, technology and region dummies are not shown, but available from the authors upon request. The Wald $\chi^{2}$ tests the hypothesis $\gamma=0$ in (5.4). The Wald $\chi^{2}$ test in the last row repeats this for the core variables for W_CIT, SMALL, MICRO and PVC.

Table A2. Results of OLS estimations.

\begin{tabular}{|c|c|c|c|}
\hline \multirow{3}{*}{$\begin{array}{l}\text { Explanatory } \\
\text { variables }\end{array}$} & \multicolumn{3}{|c|}{ Dependent variable $=S A L E$} \\
\hline & \multicolumn{3}{|c|}{ Statistical model: Ordinary Least Squares } \\
\hline & Specification A & Specification B & Specification $\mathrm{C}$ \\
\hline \multirow[t]{2}{*}{ W_CIT } & $0.043 * *$ & $0.048 * *$ & $0.047 * *$ \\
\hline & $(0.020)$ & $(0.214)$ & $(0.021)$ \\
\hline \multirow[t]{2}{*}{ SMALL } & $-0.242 * * *$ & $-0.238 * * *$ & $-0.239 * * *$ \\
\hline & $(0.058)$ & $(0.058)$ & $(0.058)$ \\
\hline \multirow[t]{2}{*}{ MICRO } & $-0.101 *$ & $-0.095 *$ & $-0.095 *$ \\
\hline & $(0.058)$ & $(0.058)$ & (0058) \\
\hline \multirow[t]{2}{*}{$P V C$} & $2.3 \mathrm{E}-3$ & $2.2 \mathrm{E}-3$ & $2.3 \mathrm{E}-3$ \\
\hline & $(1.8 \mathrm{E}-3)$ & $(1.8 \mathrm{E}-3)$ & $(1.8 \mathrm{E}-3)$ \\
\hline \multirow[t]{2}{*}{ B_CIT } & & -0.093 & -0.093 \\
\hline & & $(0.072)$ & $(0.073)$ \\
\hline \multirow[t]{2}{*}{$A P P L Y$} & & & $-6.6 \mathrm{E}-3$ \\
\hline & & & $(0.015)$ \\
\hline \multirow{2}{*}{$\begin{array}{l}\text { Technology FE } \\
\text { Region FE }\end{array}$} & Yes & Yes & Yes \\
\hline & Yes & Yes & Yes \\
\hline $\mathrm{R}^{2}$ & 0.10 & 0.10 & 0.10 \\
\hline \multirow{2}{*}{$\begin{array}{l}\text { F-test } \\
\text { F-test (Core var.) }\end{array}$} & $2.11 * * *$ & $2.08 * * *$ & $2.09 * * *$ \\
\hline & $6.10 * * *$ & $6.22 * * *$ & $6.29 * * *$ \\
\hline \multicolumn{4}{|c|}{$\begin{array}{l}\text { Note: The number of observations is } 364 \text {. SALE equals } 1 \text { for } 91 \text { observations. } * * * * * \text { and } * \text { indicat } \\
\text { significance at the } 1,5 \text { and } 10 \text { percent level. Standard errors clustered on the inventor are given i } \\
\text { parentheses. Parameter estimates for constants, technology and region dummies are not shown, bu } \\
\text { available from the authors upon request. The F-test tests the hypothesis } \gamma=0 \text { in }(5.4) \text {. The F-test in the las } \\
\text { row repeats this for the core variables for } W \_C I T, S M A L L, M I C R O \text { and } P V C \text {. }\end{array}$} \\
\hline
\end{tabular}


Table A3. Results of probit model with extra covariates.

\begin{tabular}{|c|c|c|c|}
\hline \multirow{3}{*}{$\begin{array}{l}\text { Explanatory } \\
\text { variables }\end{array}$} & \multicolumn{3}{|c|}{ Dependent variable $=S A L E$} \\
\hline & \multicolumn{3}{|c|}{ Statistical model: Binomial probit model } \\
\hline & Specification A & Specification B & Specification $\mathrm{C}$ \\
\hline$W_{-} C I T$ & $0.158 * *$ & $0.149 * *$ & $0.133 *$ \\
\hline & $(0.075)$ & $(0.075)$ & $(0.071)$ \\
\hline SMALL & $-1.01 * * *$ & $-0.842 * * *$ & $-0.883 * * *$ \\
\hline & $(0.246)$ & $(0.258)$ & $(0.265)$ \\
\hline MICRO & $-0.361 *$ & -0.202 & $-0.215 *$ \\
\hline & $(0.193)$ & $(0.207)$ & $(0.208)$ \\
\hline$P V C$ & $5.1 \mathrm{E}-3$ & 7.6 E-3 & $7.5 \mathrm{E}-3$ \\
\hline & $(5.3 \mathrm{E}-3)$ & $5.1 \mathrm{E}-3)$ & $(5.2 \mathrm{E}-3)$ \\
\hline B_CIT & -0.470 & -0.416 & -0.417 \\
\hline & $(0.375)$ & $(0.380)$ & $(0.389)$ \\
\hline$A P P L Y$ & -0.020 & 0.022 & -0.024 \\
\hline & $(0.048)$ & $(0.048)$ & $(0.048)$ \\
\hline UNIV & -0.819 & -0.623 & -0.734 \\
\hline & $(0.632)$ & $(0.663)$ & $(0.681)$ \\
\hline SEX & $-1.63 * *$ & $-1.69 * *$ & $-1.78 * *$ \\
\hline & $(0.641)$ & $(0.666)$ & $(0.72)$ \\
\hline$P C T$ & & 0.012 & $0.013 * * *$ \\
\hline & & $(4.9 \mathrm{E}-3)$ & $4.9 \mathrm{E}-3$ \\
\hline KOMPL & & & 0.300 \\
\hline & & & $(0.191)$ \\
\hline Technology FE & Yes & Yes & Yes \\
\hline Region FE & Yes & Yes & Yes \\
\hline Log Likelihood & -180.5 & -177.2 & -176.0 \\
\hline Wald, $\chi^{2}$ & $52.2 * * *$ & $54.8 * * *$ & $56.1 * * *$ \\
\hline Wald, $\chi^{2}$ (Core var.) & $23.1 * * *$ & $17.7 * * *$ & $17.5 * * *$ \\
\hline
\end{tabular}

Note: The number of observations is 364. SALE equals 1 for 91 observations. ***, ** and * indicate significance at the 1,5 and 10 percent level. Standard errors clustered on the inventor are given in parentheses. Parameter estimates for constants, technology and region dummies are not shown, but available from the authors upon request. The Wald $\chi^{2}$ tests the hypothesis $\gamma=0$ in (5.4). The Wald $\chi^{2}$ test in the last row repeats this for the core variables for $W_{-} C I T, S M A L L, M I C R O$ and $P V C$. 
Table A4. Results of the probit model. Large sample.

\begin{tabular}{|c|c|c|c|}
\hline \multirow{3}{*}{$\begin{array}{l}\text { Explanatory } \\
\text { variables }\end{array}$} & \multicolumn{3}{|c|}{ Dependent variable $=S A L E$} \\
\hline & \multicolumn{3}{|c|}{ Statistical model: Binomial probit model } \\
\hline & Specification A & Specification B & Specification $\mathrm{C}$ \\
\hline \multirow[t]{2}{*}{$W_{-} C I T$} & $0.140 * *$ & $0.164 * *$ & $0.164 * *$ \\
\hline & $(0.067)$ & $(0.073)$ & $(0.074)$ \\
\hline \multirow[t]{2}{*}{$S M A L L$} & $-0.976 * * *$ & $-0.968 * * *$ & $-0.978 * * *$ \\
\hline & $(0.197)$ & $(0.198)$ & $(0.199)$ \\
\hline \multirow[t]{2}{*}{ MICRO } & $-0.396 * *$ & $-0.366 * *$ & $-0.370 * *$ \\
\hline & $(0.180)$ & $(0.181)$ & $(0.181)$ \\
\hline \multirow[t]{2}{*}{$P V C$} & $1.9 \mathrm{E}-3$ & $1.4 \mathrm{E}-3$ & $1.6 \mathrm{E}-3$ \\
\hline & $(4.6 \mathrm{E}-3)$ & $4.7 \mathrm{E}-3)$ & $(4.6 \mathrm{E}-3)$ \\
\hline \multirow[t]{2}{*}{ B_CIT } & & -0.496 & -0.501 \\
\hline & & $(0.371)$ & $(0.369)$ \\
\hline \multirow[t]{2}{*}{$A P P L Y$} & & & -0.036 \\
\hline & & & $(0.045)$ \\
\hline Technology FE & Yes & Yes & Yes \\
\hline Region FE & Yes & Yes & Yes \\
\hline Log Likelihood & -210.4 & -209.6 & -209.3 \\
\hline Wald, $\chi^{2}$ & $50.0 * * *$ & $51.6 * * *$ & $51.9 * * *$ \\
\hline Wald, $\chi^{2}$ (Core var.) & $29.6 * * *$ & $30.0 * * *$ & $30.4 * * *$ \\
\hline \multicolumn{4}{|c|}{$\begin{array}{l}\text { Note: The number of observations is } 449 \text {. SALE equals } 1 \text { for } 99 \text { observations. ***, ** and * indicate } \\
\text { significance at the } 1,5 \text { and } 10 \text { percent level. Standard errors clustered on the inventor are given in } \\
\text { parentheses. Parameter estimates for constants, technology and region dummies are not shown, but } \\
\text { available from the authors upon request. The Wald } \chi^{2} \text { I tests the hypothesis } \gamma=0 \text { in }(5.4) \text {. The Wald } \chi^{2} \text { test } \\
\text { II repeats this for the core variables } W \_C I T, S M A L L, M I C R O \text { and } P V C \text {. }\end{array}$} \\
\hline
\end{tabular}

